INSTITUTO DE PESQUISAS ENERGÉTICAS E NUCLEARES Autarquia associada à Universidade de São Paulo

ESTUDOS DE SINTERIZAÇÃO E DE ENVELHECIMENTO TÉRMICO DE CERÂMICAS DE ZIRCÔNIA - ÍTRIA POR ESPECTROSCOPIA DE IMPEDÂNCIA

DANIEL ZANETTI DE FLORIO

\begin{abstract}
DisSERTAÇÃo APRESENTAda COMO PARTE DOS REQUISITOS PARA A obTenÇão do GRAu de Mestre em CiênCias na Área de TeCnologia NUCLEAR.
\end{abstract}

ORIENTADOR:

DR. Reginaldo Muccillo

SÃo PAULO 
Para meus pais,

Wanderley e Dirce $e$ minhas irmãs, Sandra e Laura. 
Durmo quando sonho o que não há; vou despertar quando sonho o que pode haver.

Bernardo Soares 


\section{AGRADECIMENTOS}

Gostaria de agradecer ao Dr. Reginaldo Muccillo pela orientação, apoio e confiança constantes durante esses anos.

A Dra. Eliana N. S. Muccillo pelas sugestões e sempre simpáticas e enriquecedoras discussões.

Ao Dr. Michel Kleitz, Grenoble, França, que gentilmente cedeu os pós de zircônia ítria fabricados pela Nissan.

A Fredner Leitão pelo processamento dos pós de zircônia - ítria coprecipitada.

A todos os colegas da MM principalmente Yone V. França, Donis Perini, Daniela M. Ávila e Rosa M. R. Pasotti.

A Luis A. Genova pela discussão sobre a moagem dos pós de zircônia.

A Selma L. Silva, do Laboratório de Materiais do CTM, Aramar, pelas medidas de difração de raios X e a Newton H. Saito, do IPT, pelos cortes nos tubos de alumina. 
A Manoel F. Cardoso por ter me "dado o toque" da iniciação científica no IPEN com o Dr. Reginaldo.

Agradecer nominalmente a todos os amigos do IFUSP e de outras unidades da USP seria muito extenso e eu, provavelmente, esqueceria de alguns nomes. No entanto, não poderia deixar de agradecer especialmente aos meus grandes amigos Fabio C. Fonseca, Maximiliano L. Munford e André S. Ferlauto.

A toda "galera da night" em especial aos integrantes da banda Fábrica Fagus.

A Luigi Stavale pelas fotos dos equipamentos.

Agradeço muito especialmente a Verônica Mello, de todo coração, não encontro palavras... Vê, você é maravilhosa! Sem você eu não teria saído do lugar, literalmente!!

Aos meus pais e irmãs pelo apoio em todos os momentos.

Ao CNPq pelo apoio financeiro e ao IPEN fundamental na realização deste projeto. 


\title{
ESTUDOS DE SINTERIZAÇÃO E DE ENVELHECIMENTO TÉRMICO DE CERÂMICAS DE ZIRCÔNIA - ÍTRIA POR ESPECTROSCOPIA DE IMPEDÂNCIA
}

\author{
Daniel Zanetti de Florio
}

\begin{abstract}
RESUMO
Eletrólitos sólidos cerâmicos de $\mathrm{ZrO}_{2}: 8 \%$ mol $\mathrm{Y}_{2} \mathrm{O}_{3}$ foram preparados com pós de três origens: pó comercial fabricado pela Nissan (Japão), pó obtido por coprecipitação dos hidróxidos no IPEN e pó obtido por mistura de óxidos (utilizando-se $\mathrm{ZrO}_{2}$ produzido na Usina de Zircônio do IPEN e $\mathrm{Y}_{2} \mathrm{O}_{3}$ (USA) de pureza superior a 99,9\%). Esses materiais de partida foram analisados pelas seguintes técnicas: fluorescência de raios $\mathrm{X}$ para a determinação dos teores de ítrio, difração de raios X para a determinação das fases, sedimentação para a determinação da distribuição do tamanho de partículas, adsorsão gasosa (BET) para a determinação da área de superfície específica e microscopia eletrônica de transmissão para a determinação do tamanho médio de partícula. Amostras compactadas foram analisadas por dilatometria para avaliar os estágios de sinterização. As amostras sinterizadas foram caracterizadas por difração de raios $\mathrm{X}$ para análise de fases e microscopia eletrônica de varredura para análise da morfologia dos grãos. Análises por espectroscopia de impedância foram feitas para acompanhar o envelhecimento térmico dos eletrólitos sólidos de zircônia-ítria a $600{ }^{\circ} \mathrm{C}$, temperatura de trabalho do sensor permanente de oxigênio, e para estudar a sua cinética de sinterização. Os principais resultados mostram que o envelhecimento térmico a $600{ }^{\circ} \mathrm{C}$ diminui a resposta (fem) do sensor nas primeiras $100 \mathrm{~h}$ até um valor estável. Além disso, os estudos de sinterização por espectroscopia de impedância permitiram encontrar correlações entre parâmetros elétricos, a cinética de sinterização e os mecanismos de crescimento de grão.
\end{abstract}




\title{
SINTERING AND THERMAL AGEING STUDIES OF ZIRCONIA - YTTRIA CERAMICS BY IMPEDANCE SPECTROSCOPY
}

\author{
Daniel Zanetti de Florio
}

\begin{abstract}
$\mathrm{ZrO}_{2}: 8 \mathrm{~mol} \% \mathrm{Y}_{2} \mathrm{O}_{3}$ solid electrolyte ceramic pellets have been prepared with powders of three different origins: a Nissan (Japan) commercial powder, a powder obtained by the coprecipitation technique at IPEN, and the mixing of powder oxides $\left(\mathrm{ZrO}_{2}\right.$ produced at a Pilot Plant at IPEN and 99.9\% pure $\mathrm{Y}_{2} \mathrm{O}_{3}$ of USA origin). These starting powders have been analysed by the following techniques: X-ray fluorescence for yttrium content, X-ray diffraction for structural phase content, sedimentation for particle size distribution, gas adsorption (BET) for surface area determination, and transmission electron microscopy for average particle size determination. Pressed ceramic pellets have been analysed by dilatometry to evaluate the sintering stages. Sintered pellets have been characterized by Xray diffraction for phase analysis and scanning electron microscopy for grain morphology analysis. Impedance spectroscopy analysis have been carried out to follow thermal ageing of zirconia-yttria solid electrolyte at $600{ }^{\circ} \mathrm{C}$, the working temperature of permanent oxygen sensor, and to study sintering kinetics. The main results show that ageing at $600{ }^{\circ} \mathrm{C}$ decreases the emf sensor response in the first $100 \mathrm{~h}$ to a steady value. Moreover, sintering studies by impedance spectroscopy allowed for finding correlations between electrical parameters, sintering kinetics and grain growth mechanisms.
\end{abstract}




\section{SUMÁRIO}

PÁGINA

1 INTRODUÇÃO 1

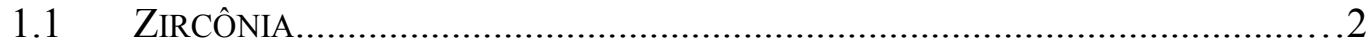

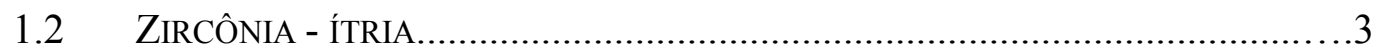

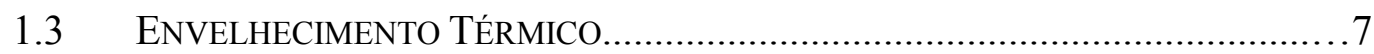

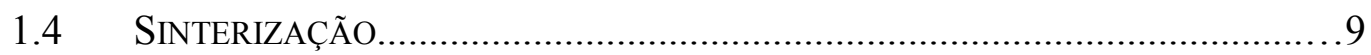

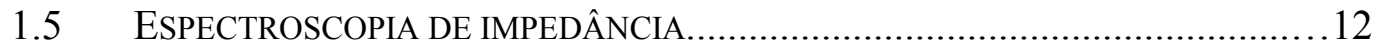

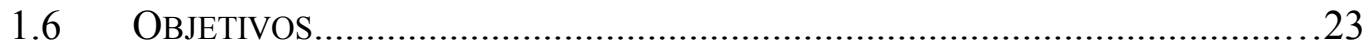

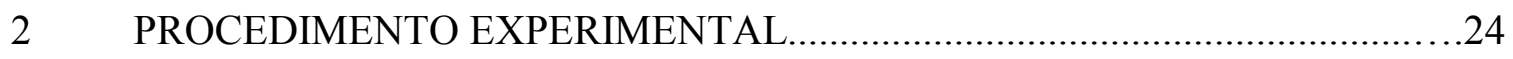

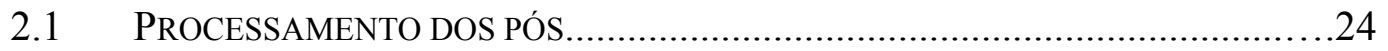

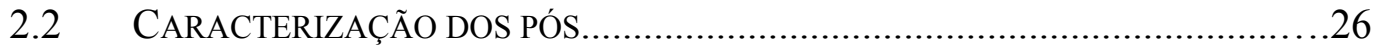

2.3 PREPARAÇÃO DOS ELETRÓLITOS SÓLIDOS.................................................28

2.4 CARACTERIZAÇÃO DOS ELETRÓLITOS SÓLIDOS........................................29

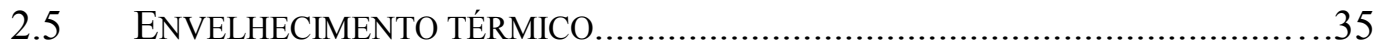

2.6 ESPECTROSCOPIA DE IMPEDÂNCIA E SINTERIZAÇÃO.....................................36

3 RESULTADOS E DISCUSSÃO

3.1 MOAGEM DO PÓ DE ZIRCÔNIA - IPEN.....................................................40

3.2 CARACTERIZAÇÃO DOS PÓS....................................................................41

3.3 CARACTERIZAÇÃO DOS ELETRÓLITOS SÓLIDOS..........................................51

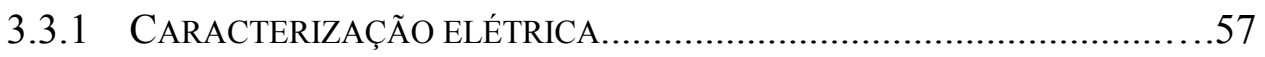

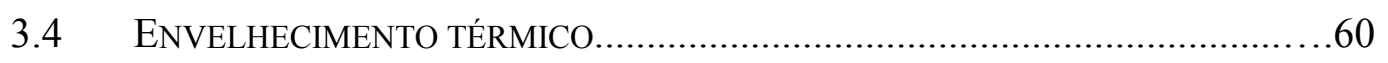

3.5 ESPECTROSCOPIA DE IMPEDÂNCIA E SINTERIZAÇÃO..................................69

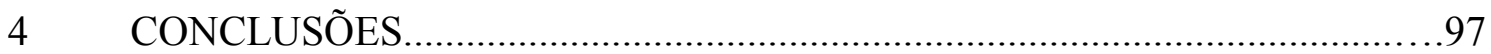

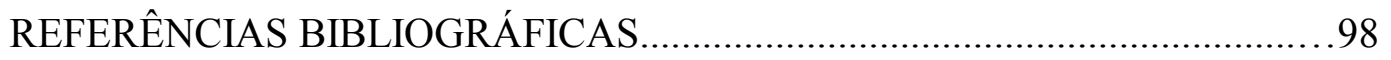




\section{LISTA DE TABELAS}

TABela

Título
Página

42

43

44

44 


\section{LISTA DE FIGURAS}

FIGURA

LEGENDA

PÁGINA

1.2.1 Diagrama de fases do sistema $\mathrm{ZrO}_{2}: \mathrm{Y}_{2} \mathrm{O}_{3}$. 5

1.3.1 Esquema de um sensor comercial. $\quad 8$

1.5.1 Célula simétrica constituída por um eletrólito sólido cilíndrico, recoberto em suas faces paralelas por um metal (eletrodos).

1.5.2 Representação no plano complexo do vetor impedância.

1.5.3 Circuito elétrico contendo uma resistência $\mathrm{r}$ em série com um $\mathrm{RC}$ em paralelo.

1.5.4 Diagrama de impedância, ou gráfico de Cole-Cole, do circuito mostrado na figura 1.5.3.

1.5.5 Circuito equivalente a um dielétrico.

1.5.6 Diagrama de impedância do circuito mostrado na figura 1.5.5.

1.5.7 Diagrama de impedância esperado para uma amostras de $\mathrm{ZrO}_{2}: 8 \%$ $\mathrm{mol} \mathrm{Y}_{2} \mathrm{O}_{3}$.

2.1.1 Sequência experimental para o processamento do pó de $\mathrm{ZrO}_{2}+8 \%$ mol $\mathrm{Y}_{2} \mathrm{O}_{3}$ por mistura de óxidos.

2.3.1 Sequência experimental para a preparação das amostras de $\mathrm{ZrO}_{2}: 8 \%$ $\mathrm{mol} \mathrm{Y}_{2} \mathrm{O}_{3}$.

2.4.1 Câmara de medidas elétricas, feita em Inconel 600, para até três amostras.

2.4.2 Detalhe do porta amostras da câmara de medidas elétricas.

2.4.3 Sistema de medidas de espectroscopia de impedância: controlador HP362, monitor - impressora - teclado, analisador de impedância HP4192A LF, traçador gráfico - multímetro digital FLUKE 8050A (de cima para baixo).

2.5.1 Perfis de temperatura e roteiro para a obtenção das medidas de espectroscopia de impedância durante o envelhecimento térmico das amostras de $\mathrm{ZrO}_{2}: 8 \% \mathrm{~mol}_{2} \mathrm{O}_{3}$. 
FIGURA

LEGENDA

PÁgina

2.6.1 Câmara utilizada nas medidas de espectroscopia de impedância durante a sinterização.

2.6.2 Perfis de temperatura e roteiro para a obtenção das medidas de espectroscopia de impedância durante a sinterização das amostras de $\mathrm{ZrO}_{2}: 8 \%$ mol $\mathrm{Y}_{2} \mathrm{O}_{3}$ em função da temperatura de sinterização.

2.6.3 Perfis de temperatura e roteiro para a obtenção das medidas de espectroscopia de impedância durante a sinterização das amostras de $\mathrm{ZrO}_{2}: 8 \%$ mol $\mathrm{Y}_{2} \mathrm{O}_{3}$ em função do tempo de sinterização na temperatura de $1350{ }^{\circ} \mathrm{C}$.

3.1.1 Distribuição do tamanho de partículas, ou de aglomerados, por sedimentação com raios $\mathrm{X}$ do pó de $\mathrm{ZrO}_{2}-\mathrm{IPEN}$, antes e depois da moagem.

3.2.1 Condutividade do grão das amostras de $\mathrm{ZrO}_{2}: \mathrm{Y}_{2} \mathrm{O}_{3}(8 \% \mathrm{~mol}$ nominal $)$ em função do teor de $\mathrm{Y}_{2} \mathrm{O}_{3}$.

3.2.2 Difratograma de raios $\mathrm{X}$ dos pós comercial e coprecipitado de $\mathrm{ZrO}_{2}: 8 \%$ mol $\mathrm{Y}_{2} \mathrm{O}_{3}$ mostrando a estrutura cúbica da zircônia.

3.2.3 Difratograma de raios $\mathrm{X}$ dos pós comercial e coprecipitado de $\mathrm{ZrO}_{2}: 8 \%$ mol $\mathrm{Y}_{2} \mathrm{O}_{3}$ mostrando a estrutura cúbica da zircônia (detalhe da figura 3.2.2).

3.2.4 Difratograma de raios $\mathrm{X}$ dos pós comercial e coprecipitado de $\mathrm{ZrO}_{2}: 8 \%$ mol $\mathrm{Y}_{2} \mathrm{O}_{3}$ mostrando a estrutura cúbica da zircônia (detalhe da figura 3.2.2).

3.2.5 Distribuição do tamanho de partículas, ou de aglomerados, por sedimentação (raios X) dos pós utilizados na preparação das amostras.

3.2.6 Distribuição do tamanho de partículas, ou de aglomerados, por sedimentação (LASER) dos pós utilizados na preparação das amostras.

3.2.7 Micrografia obtida por microscopia eletrônica de transmissão do pó de $\mathrm{ZrO}_{2}: 8 \%$ mol $\mathrm{Y}_{2} \mathrm{O}_{3}$ comercial utilizado na preparação das amostras. 
3.2.8 Micrografia obtida por microscopia eletrônica de transmissão do pó $\mathrm{ZrO}_{2}: 8 \%$ mol $\mathrm{Y}_{2} \mathrm{O}_{3}$ obtido por coprecipitação do hidróxidos utilizado na preparação das amostras.

3.2.9 Micrografia obtida por microscopia eletrônica de transmissão do pó $\mathrm{ZrO}_{2}+8 \%$ mol $\mathrm{Y}_{2} \mathrm{O}_{3}$ obtido por mistura de óxidos utilizado na preparação das amostras.

3.3.1 Retração linear por dilatometria das amostras de $\mathrm{ZrO}_{2}: 8 \%$ mol $\mathrm{Y}_{2} \mathrm{O}_{3}$ comercial e coprecipitada.

3.3.2 Valores de densidade geométrica $(\Delta)$ e hidrostática $(\Delta)$, em relação a densidade teórica da amostra preparada com o pó comercial, da amostra de $\mathrm{ZrO}_{2}: 8 \%$ mol $\mathrm{Y}_{2} \mathrm{O}_{3}$ preparada com o pó obtido por mistura de óxidos em função da temperatura de sinterização.

3.3.3 Difratograma de raios $\mathrm{X}$ das amostras de $\mathrm{ZrO}_{2}: 8 \%$ mol $\mathrm{Y}_{2} \mathrm{O}_{3}$, de várias origens, mostrando a estabilização da fase cúbica da zircônia em todas as amostras.

3.3.4 Difratograma de raios $\mathrm{X}$ das amostras de $\mathrm{ZrO}_{2}: 8 \%$ mol $\mathrm{Y}_{2} \mathrm{O}_{3}$, de várias origens, mostrando a estabilização da fase cúbica da zircônia em todas as amostras.

3.3.5 Micrografia da superfície de fratura da amostra de $\mathrm{ZrO}_{2}: 8 \%$ mol $\mathrm{Y}_{2} \mathrm{O}_{3}$ comercial.

3.3.6 Micrografia da superfície de fratura da amostra de $\mathrm{ZrO}_{2}: 8 \%$ mol $\mathrm{Y}_{2} \mathrm{O}_{3}$ coprecipitada.

3.3.7 Micrografia da superfície de fratura da amostra de $\mathrm{ZrO}_{2}: 8 \%$ mol $\mathrm{Y}_{2} \mathrm{O}_{3}$ obtida por mistura de óxidos.

3.3.1.1 Efeito dos eletrodos de platina $(x)$ e prata $(+)$ nos diagramas de impedância.

3.3.1.2 Gráfico de Arrhenius para a condutividade total das amostras de $\mathrm{ZrO}_{2}: 8 \%$ mol $\mathrm{Y}_{2} \mathrm{O}_{3}$ comercial (ロ), coprecipitada (๑) e obtida por mistura de óxidos (A). 
3.3.1.3 Gráfico de Arrhenius para a condutividade do grão das amostras de $\mathrm{ZrO}_{2}: 8 \%$ mol $\mathrm{Y}_{2} \mathrm{O}_{3}$ comercial ( $\left.\mathbf{(}\right)$, coprecipitada (•) e obtida por mistura de óxidos $(\boldsymbol{\Delta})$.

3.3.1.4 Gráfico de Arrhenius para a condutividade do contorno de grão das amostras de $\mathrm{ZrO}_{2}: 8 \%$ mol $\mathrm{Y}_{2} \mathrm{O}_{3}$ comercial (๘), coprecipitada (•) e obtida por mistura de óxidos (ム).

3.4.1 Variação da condutividade da amostra de $\mathrm{ZrO}_{2}: 8 \%$ mol $\mathrm{Y}_{2} \mathrm{O}_{3}$ obtida por mistura de óxidos com o tempo na temperatura de $600{ }^{\circ} \mathrm{C}$.

3.4.2 Diagrama de impedância da amostra de $\mathrm{ZrO}_{2}: 8 \%$ mol $\mathrm{Y}_{2} \mathrm{O}_{3}$ antes do início $(\mathrm{t}=0)$ do envelhecimento térmico a $600{ }^{\circ} \mathrm{C}$ (a contribuição dos eletrodos foi subtraída).

3.4.3 Diagrama de impedância da amostra de $\mathrm{ZrO}_{2}: 8 \%$ mol $\mathrm{Y}_{2} \mathrm{O}_{3}$ após $75 \mathrm{~h}$ de envelhecimento térmico a $600{ }^{\circ} \mathrm{C}$ (a contribuição dos eletrodos foi subtraída).

3.4.4 Diagrama de impedância da amostra de $\mathrm{ZrO}_{2}: 8 \%$ mol $\mathrm{Y}_{2} \mathrm{O}_{3}$ após 170 $\mathrm{h}$ de envelhecimento térmico a $600{ }^{\circ} \mathrm{C}$ (a contribuição dos eletrodos foi subtraída).

3.4.5 Variação da condutividade total da amostra de $\mathrm{ZrO}_{2}: 8 \%$ mol $\mathrm{Y}_{2} \mathrm{O}_{3}$ obtida por mistura de óxidos com o tempo na temperatura de $600{ }^{\circ} \mathrm{C}$.

3.4.6 Variação da condutividade do grão da amostra de $\mathrm{ZrO}_{2}: 8 \%$ mol $\mathrm{Y}_{2} \mathrm{O}_{3}$ obtida por mistura de óxidos com o tempo na temperatura de $600{ }^{\circ} \mathrm{C}$.

3.4.7 Variação da condutividade do contorno de grão da amostra de $\mathrm{ZrO}_{2}: 8 \%$ mol $\mathrm{Y}_{2} \mathrm{O}_{3}$ obtida por mistura de óxidos com o tempo na temperatura de $600{ }^{\circ} \mathrm{C}$.

3.4.8 Variação da condutividade total da amostra, normalizada para o seu valor inicial $(\mathrm{t}=0)$, com a raiz quadrada do tempo de envelhecimento

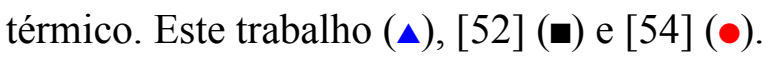


FIGURA

LEGENDA

PÁGina

3.4.9 Variação do logaritmo da condutividade atribuída ao grão da amostra de $\mathrm{ZrO}_{2}: 8 \%$ mol $\mathrm{Y}_{2} \mathrm{O}_{3}$ com o tempo de envelhecimento térmico a 600 ${ }^{\circ} \mathrm{C}$.

3.4.10 Difratograma de raios $\mathrm{X}$ da amostra de $\mathrm{ZrO}_{2}: 8 \%$ mol $\mathrm{Y}_{2} \mathrm{O}_{3}$ obtida por mistura de óxidos antes e depois de $2000 \mathrm{~h}$ de envelhecimento térmico a $600{ }^{\circ} \mathrm{C}$.

3.4.11 Micrografia, obtida em microscópio eletrônico de varredura, da superfície de fratura da amostra de $\mathrm{ZrO}_{2}: 8 \%$ mol $\mathrm{Y}_{2} \mathrm{O}_{3}$ obtida por mistura de óxidos após envelhecimento térmico a $600{ }^{\circ} \mathrm{C}$ por $2000 \mathrm{~h}$.

3.5.1 Diagrama de impedância, obtido a aproximadamente $400{ }^{\circ} \mathrm{C}$, da amostra de $\mathrm{ZrO}_{2}: 8 \%$ mol $\mathrm{Y}_{2} \mathrm{O}_{3}$, comercial, tratada termicamente a 800 ${ }^{\circ} \mathrm{C}$.

3.5.2 Diagrama de impedância, obtido a aproximadamente $400{ }^{\circ} \mathrm{C}$, da amostra de $\mathrm{ZrO}_{2}: 8 \%$ mol $\mathrm{Y}_{2} \mathrm{O}_{3}$, comercial, tratada termicamente a 900 ${ }^{\circ} \mathrm{C}$.

3.5.3 Diagrama de impedância, obtido a aproximadamente $400{ }^{\circ} \mathrm{C}$, da amostra de $\mathrm{ZrO}_{2}: 8 \%$ mol $\mathrm{Y}_{2} \mathrm{O}_{3}$, comercial, tratada termicamente a $1000{ }^{\circ} \mathrm{C}$.

3.5.4 Diagrama de impedância, obtido a aproximadamente $400{ }^{\circ} \mathrm{C}$, da amostra de $\mathrm{ZrO}_{2}: 8 \%$ mol $\mathrm{Y}_{2} \mathrm{O}_{3}$, comercial, tratada termicamente a $1100{ }^{\circ} \mathrm{C}$.

3.5.5 Diagrama de impedância, obtido a aproximadamente $400{ }^{\circ} \mathrm{C}$, da amostra de $\mathrm{ZrO}_{2}: 8 \%$ mol $\mathrm{Y}_{2} \mathrm{O}_{3}$, comercial, tratada termicamente a $1200{ }^{\circ} \mathrm{C}$.

3.5.6 Diagrama de impedância, obtido a aproximadamente $400{ }^{\circ} \mathrm{C}$, da amostra de $\mathrm{ZrO}_{2}: 8 \%$ mol $\mathrm{Y}_{2} \mathrm{O}_{3}$, comercial, tratada termicamente a $1300{ }^{\circ} \mathrm{C}$. 
FIGURA

LEGENDA

PÁGINA

3.5.7 Diagrama de impedância, obtido a aproximadamente $400{ }^{\circ} \mathrm{C}$, da amostra de $\mathrm{ZrO}_{2}: 8 \%$ mol $\mathrm{Y}_{2} \mathrm{O}_{3}$, comercial, tratada termicamente a $1350{ }^{\circ} \mathrm{C}$.

3.5.8 Sobreposição dos diagramas de impedância apresentados nas figuras 3.5.1 a 3.5.7. As temperaturas de tratamento térmico foram: $800{ }^{\circ} \mathrm{C}$ ), $900{ }^{\circ} \mathrm{C}(\bullet), 1000{ }^{\circ} \mathrm{C}(\Delta), 1100^{\circ} \mathrm{C}(\nabla), 1200{ }^{\circ} \mathrm{C}(\diamond), 1300{ }^{\circ} \mathrm{C}(+)$, $1350{ }^{\circ} \mathrm{C}(\times)$.

3.5.9 Diagrama de impedância, obtido a aproximadamente $400{ }^{\circ} \mathrm{C}$, da amostra de $\mathrm{ZrO}_{2}: 8 \%$ mol $\mathrm{Y}_{2} \mathrm{O}_{3}$, coprecipitada, tratada termicamente a $800^{\circ} \mathrm{C}$.

3.5.10 Diagrama de impedância, obtido a aproximadamente $400{ }^{\circ} \mathrm{C}$, da amostra de $\mathrm{ZrO}_{2}: 8 \%$ mol $\mathrm{Y}_{2} \mathrm{O}_{3}$, coprecipitada, tratada termicamente a $900{ }^{\circ} \mathrm{C}$.

3.5.11 Diagrama de impedância, obtido a aproximadamente $400{ }^{\circ} \mathrm{C}$, da amostra de $\mathrm{ZrO}_{2}: 8 \%$ mol $\mathrm{Y}_{2} \mathrm{O}_{3}$, coprecipitada, tratada termicamente a $1000{ }^{\circ} \mathrm{C}$.

3.5.12 Diagrama de impedância, obtido a aproximadamente $400{ }^{\circ} \mathrm{C}$, da amostra de $\mathrm{ZrO}_{2}: 8 \%$ mol $\mathrm{Y}_{2} \mathrm{O}_{3}$, coprecipitada, tratada termicamente a $1100{ }^{\circ} \mathrm{C}$.

3.5.13 Diagrama de impedância, obtido a aproximadamente $400{ }^{\circ} \mathrm{C}$, da amostra de $\mathrm{ZrO}_{2}: 8 \%$ mol $\mathrm{Y}_{2} \mathrm{O}_{3}$, coprecipitada, tratada termicamente a $1200{ }^{\circ} \mathrm{C}$.

3.5.14 Diagrama de impedância, obtido a aproximadamente $400{ }^{\circ} \mathrm{C}$, da amostra de $\mathrm{ZrO}_{2}: 8 \%$ mol $\mathrm{Y}_{2} \mathrm{O}_{3}$, coprecipitada, tratada termicamente a $1300{ }^{\circ} \mathrm{C}$.

3.5.15 Diagrama de impedância, obtido a aproximadamente $400{ }^{\circ} \mathrm{C}$, da amostra de $\mathrm{ZrO}_{2}: 8 \%$ mol $\mathrm{Y}_{2} \mathrm{O}_{3}$, coprecipitada, tratada termicamente a $1350{ }^{\circ} \mathrm{C}$. 
3.5.16 Sobreposição dos diagramas de impedância apresentados nas figuras 3.5.9 a 3.5.15. As temperaturas de tratamento térmico foram: $800^{\circ} \mathrm{C}$ ( च), $900{ }^{\circ} \mathrm{C}(\bullet), 1000{ }^{\circ} \mathrm{C}(\Delta), 1100^{\circ} \mathrm{C}(\nabla), 1200{ }^{\circ} \mathrm{C}(\diamond), 1300{ }^{\circ} \mathrm{C}(+)$, $1350{ }^{\circ} \mathrm{C}(\times)$.

3.5.17 Derivada da função apresentada na figura 3.3.1 para as amostras de $\mathrm{ZrO}_{2}: 8 \%$ mol $\mathrm{Y}_{2} \mathrm{O}_{3}$, comercial e coprecipitada.

3.5.18 Variação da condutância total e da retração linear da amostra de $\mathrm{ZrO}_{2}: 8 \%$ mol $\mathrm{Y}_{2} \mathrm{O}_{3}$, comercial, com a temperatura de sinterização.

3.5.19 Variação da condutância total e da retração linear da amostra de $\mathrm{ZrO}_{2}: 8 \%$ mol $\mathrm{Y}_{2} \mathrm{O}_{3}$, coprecipitada, com a temperatura de sinterização.

3.5.20 Variação da resistência com a densidade das amostras de $\mathrm{ZrO}_{2}: 8 \%$ mol $\mathrm{Y}_{2} \mathrm{O}_{3}$, comercial (ø) e coprecipitada (๑); os números indicam a temperatura de sinterização, como segue: $1 \rightarrow \mathrm{T}_{\text {sinterização }}=800{ }^{\circ} \mathrm{C}, 2 \rightarrow$ $\mathrm{T}_{\text {sinterização }}=900{ }^{\circ} \mathrm{C}, 3 \rightarrow \mathrm{T}_{\text {sinterização }}=1000{ }^{\circ} \mathrm{C}, 4 \rightarrow \mathrm{T}_{\text {sinterização }}=1100{ }^{\circ} \mathrm{C}$, $5 \rightarrow \mathrm{T}_{\text {sinterização }}=1200{ }^{\circ} \mathrm{C}, 6 \rightarrow \mathrm{T}_{\text {sinterização }}=1300{ }^{\circ} \mathrm{C}$ e $7 \rightarrow \mathrm{T}_{\text {sinterização }}=$ $1350{ }^{\circ} \mathrm{C}$.

3.5.21 Diagrama de impedância, obtido a aproximadamente $400{ }^{\circ} \mathrm{C}$, da amostra de $\mathrm{ZrO}_{2}: 8 \%$ mol $\mathrm{Y}_{2} \mathrm{O}_{3}$, comercial, sinterizada a $1350{ }^{\circ} \mathrm{C}$ por $0,2 \mathrm{~h}$.

3.5.22 Diagrama de impedância, obtido a aproximadamente $400{ }^{\circ} \mathrm{C}$, da amostra de $\mathrm{ZrO}_{2}: 8 \%$ mol $\mathrm{Y}_{2} \mathrm{O}_{3}$, comercial, sinterizada a $1350{ }^{\circ} \mathrm{C}$ por $0,6 \mathrm{~h}$.

3.5.23 Diagrama de impedância, obtido a aproximadamente $400{ }^{\circ} \mathrm{C}$, da amostra de $\mathrm{ZrO}_{2}: 8 \%$ mol $\mathrm{Y}_{2} \mathrm{O}_{3}$, comercial, sinterizada a $1350{ }^{\circ} \mathrm{C}$ por $1,2 \mathrm{~h}$.

3.5.24 Diagrama de impedância, obtido a aproximadamente $400{ }^{\circ} \mathrm{C}$, da amostra de $\mathrm{ZrO}_{2}: 8 \%$ mol $\mathrm{Y}_{2} \mathrm{O}_{3}$, comercial, sinterizada a $1350{ }^{\circ} \mathrm{C}$ por $1,7 \mathrm{~h}$. 
3.5.25 Diagrama de impedância, obtido a aproximadamente $400{ }^{\circ} \mathrm{C}$, da amostra de $\mathrm{ZrO}_{2}: 8 \%$ mol $\mathrm{Y}_{2} \mathrm{O}_{3}$, comercial, sinterizada a $1350{ }^{\circ} \mathrm{C}$ por $2,2 \mathrm{~h}$.

3.5.26 Diagrama de impedância, obtido a aproximadamente $400{ }^{\circ} \mathrm{C}$, da amostra de $\mathrm{ZrO}_{2}: 8 \%$ mol $\mathrm{Y}_{2} \mathrm{O}_{3}$, comercial, sinterizada a $1350{ }^{\circ} \mathrm{C}$ por $2,7 \mathrm{~h}$.

3.5.27 Diagrama de impedância, obtido a aproximadamente $400{ }^{\circ} \mathrm{C}$, da amostra de $\mathrm{ZrO}_{2}: 8 \%$ mol $\mathrm{Y}_{2} \mathrm{O}_{3}$, comercial, sinterizada a $1350{ }^{\circ} \mathrm{C}$ por $3,2 \mathrm{~h}$.

3.5.28 Diagrama de impedância, obtido a aproximadamente $400{ }^{\circ} \mathrm{C}$, da amostra de $\mathrm{ZrO}_{2}: 8 \%$ mol $\mathrm{Y}_{2} \mathrm{O}_{3}$, comercial, sinterizada a $1350{ }^{\circ} \mathrm{C}$ por $3,7 \mathrm{~h}$.

3.5.29 Sobreposição dos diagramas de impedância apresentados nas figuras 3.5.21 a 3.5.28. Os intervalos de tempo de sinterização a $1350{ }^{\circ} \mathrm{C}$

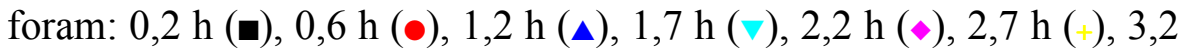
$\mathrm{h}(\times) 3,7 \mathrm{~h}(*)$.

3.5.30 Diagrama de impedância, obtido a aproximadamente $400{ }^{\circ} \mathrm{C}$, da amostra de $\mathrm{ZrO}_{2}: 8 \%$ mol $\mathrm{Y}_{2} \mathrm{O}_{3}$, coprecipitada, sinterizada a $1350{ }^{\circ} \mathrm{C}$ por $0,2 \mathrm{~h}$.

3.5.31 Diagrama de impedância, obtido a aproximadamente $400{ }^{\circ} \mathrm{C}$, da amostra de $\mathrm{ZrO}_{2}: 8 \%$ mol $\mathrm{Y}_{2} \mathrm{O}_{3}$, coprecipitada, sinterizada a $1350{ }^{\circ} \mathrm{C}$ por $0,6 \mathrm{~h}$.

3.5.32 Diagrama de impedância, obtido a aproximadamente $400{ }^{\circ} \mathrm{C}$, da amostra de $\mathrm{ZrO}_{2}: 8 \%$ mol $\mathrm{Y}_{2} \mathrm{O}_{3}$, coprecipitada, sinterizada a $1350{ }^{\circ} \mathrm{C}$ por $1,2 \mathrm{~h}$.

3.5.33 Diagrama de impedância, obtido a aproximadamente $400{ }^{\circ} \mathrm{C}$, da amostra de $\mathrm{ZrO}_{2}: 8 \%$ mol $\mathrm{Y}_{2} \mathrm{O}_{3}$, coprecipitada, sinterizada a $1350{ }^{\circ} \mathrm{C}$ por $1,7 \mathrm{~h}$. 
3.5.34 Diagrama de impedância, obtido a aproximadamente $400{ }^{\circ} \mathrm{C}$, da amostra de $\mathrm{ZrO}_{2}: 8 \%$ mol $\mathrm{Y}_{2} \mathrm{O}_{3}$, coprecipitada, sinterizada a $1350{ }^{\circ} \mathrm{C}$ por $2,2 \mathrm{~h}$.

3.5.35 Diagrama de impedância, obtido a aproximadamente $400{ }^{\circ} \mathrm{C}$, da amostra de $\mathrm{ZrO}_{2}: 8 \%$ mol $\mathrm{Y}_{2} \mathrm{O}_{3}$, coprecipitada, sinterizada a $1350{ }^{\circ} \mathrm{C}$ por $2,7 \mathrm{~h}$.

3.5.36 Diagrama de impedância, obtido a aproximadamente $400{ }^{\circ} \mathrm{C}$, da amostra de $\mathrm{ZrO}_{2}: 8 \%$ mol $\mathrm{Y}_{2} \mathrm{O}_{3}$, coprecipitada, sinterizada a $1350{ }^{\circ} \mathrm{C}$ por $3,2 \mathrm{~h}$.

3.5.37 Sobreposição dos diagramas de impedância apresentados nas figuras 3.5.30 a 3.5.36. Os intervalos de tempo de sinterização a $1350{ }^{\circ} \mathrm{C}$ foram: 0,2 h (•), 0,6 h (•), 1,2 h (^), 1,7 h ( $), 2,2 \mathrm{~h}(\diamond), 2,7 \mathrm{~h}(+), 3,2$ $\mathrm{h}(\times)$.

3.5.38 Variação da resistência dos grãos das amostras de $\mathrm{ZrO}_{2}: 8 \%$ mol $\mathrm{Y}_{2} \mathrm{O}_{3}$, comercial (ロ) e coprecipitada (๑), com o tempo de sinterização na temperatura de $1350{ }^{\circ} \mathrm{C}$.

3.4.39 Variação da resistência dos contornos de grão da amostra de $\mathrm{ZrO}_{2}: 8 \%$ mol $\mathrm{Y}_{2} \mathrm{O}_{3}$, comercial, com o tempo de sinterização na temperatura de $1350{ }^{\circ} \mathrm{C}$.

3.5.40 Variação da resistência dos contornos de grão da amostra de $\mathrm{ZrO}_{2}: 8 \%$ mol $\mathrm{Y}_{2} \mathrm{O}_{3}$, coprecipitada, com o tempo de sinterização na temperatura de $1350{ }^{\circ} \mathrm{C}$.

3.5.41 Variação do parâmetro $\alpha_{\mathrm{R}}$ com o tempo de sinterização a $1350{ }^{\circ} \mathrm{C}$, (匹) comercial e (๑) coprecipitada.

3.5.42 Dependência do produto $\alpha_{R} \cdot \alpha_{f}$ (porosidade) com o tempo de sinterização isotérmica para a amostra de $\mathrm{ZrO}_{2}: 8 \%$ mol $\mathrm{Y}_{2} \mathrm{O}_{3}$ comercial.

3.4.43 Dependência do produto $\alpha_{R} \cdot \alpha_{f}$ (porosidade) com o tempo de sinterização isotérmica para a amostra de $\mathrm{ZrO}_{2}: 8 \%$ mol $\quad \mathrm{Y}_{2} \mathrm{O}_{3}$ coprecipitada. 
O dióxido de zircônio, ou zircônia, é um material cerâmico excepcional devido principalmente ao grande número de possíveis aplicações. Desde a metade do século a zircônia $\left(\mathrm{ZrO}_{2}\right)$ tem atraído a atenção de um grande número de pesquisadores e, atualmente, o conhecimento desse material é substancial, assim como suas aplicações que vão desde em ferramentas de corte até em sensores de oxigênio. As duas principais fontes de zircônia no mundo são a badeleíta, descoberta no Brasil por Hussak em 1892 e o zircão $\left(\mathrm{ZrSiO}_{4}\right)$, que é encontrado na Índia, Austrália e Estados Unidos da América [1].

No final da década de 80 o consumo mundial de zircônia foi estimado em 25000 toneladas, sendo que 50\% desse consumo era destinado a aplicações em refratários. Algumas aplicações da zircônia, como em capacitores e em piezoelétricos, crescem rapidamente, enquanto que em outras, como em células de combustível, por exemplo, esse crescimento é lento pelo alto custo envolvido na produção desses dispositivos [2].

O IPEN tem de uma usina de produção de zircônia com dois níveis de pureza: graus cerâmico e nuclear. Por isso é importante que se tenha um conhecimento desta cerâmica, tanto no que diz respeito às suas aplicações tecnológicas, quanto em seus aspectos mais básicos [3]. 


\subsection{ZIRCÔNIA}

A zircônia, à pressão ambiente, apresenta três formas: monoclínica, tetragonal e cúbica. Em altas pressões e temperaturas ou após resfriamento rápido até temperaturas próximas ou inferiores à do nitrogênio líquido observa-se a estrutura ortorrômbica [4].

Abaixo são mostradas as temperaturas das transformações de fase na zircônia.

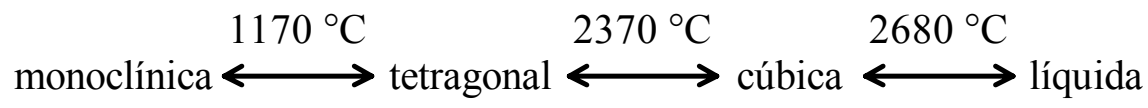

Em seu estado natural a zircônia se apresenta com simetria monoclínica, que é estável até temperaturas de aproximadamente $1170^{\circ} \mathrm{C}$. Entre $1170{ }^{\circ} \mathrm{C}$ e $2370{ }^{\circ} \mathrm{C}$ a zircônia exibe a estrutura tetragonal. Acima de $2370{ }^{\circ} \mathrm{C}$, e até a fusão $\left(2680 \pm 15^{\circ} \mathrm{C}\right)$, a zircônia se encontra na fase cúbica tipo fluorita.

Ruff e Ebert, em um estudo clássico de 1929, utilizando difração de raios X, foram os primeiros a estabelecer a simetria monoclínica para a zircônia; eles também utilizaram difração de raios $\mathrm{X}$ em altas temperaturas para estudar a transformação monoclínicatetragonal. Smith e Cline, em um artigo publicado em 1962, foram os primeiros a detectar a fase cúbica da zircônia utilizando difração de raios X em altas temperaturas.

A transformação reversível monoclínica-tetragonal vem sendo intensamente estudada nas últimas quatro décadas pelas mais variadas técnicas (difração de raios X e de elétrons, microscopia óptica e eletrônica, resistividade elétrica, etc.), principalmente por causa do interesse em compreender a grande mudança de volume associada a essa transformação. Durante o resfriamento de uma cerâmica de zircônia, a qual foi submetida à temperatura de transformação monoclínica-tetragonal, um aumento de até $\sim 5 \%$ em seu 
volume pode ocorrer, provocando a ruptura dessa cerâmica; devido a isso, o uso de cerâmicas de zircônia pura como elementos estruturais é inviabilizado em altas temperaturas. A expansão térmica da zircônia monoclínica é fortemente anisotrópica, ocorrendo uma mudança abrupta nos parâmetros de rede durante a transformação. Existe um movimento cooperativo de um grande número de átomos, por distâncias inferiores ao parâmetro de rede, e por um mecanismo de cisalhamento, com uma velocidade que se aproxima à do som em sólidos. A transformação monoclínica-tetragonal é atérmica, ou seja, a quantidade de fase transformada muda variando a temperatura mas não muda variando o tempo em temperatura fixa; porém, já foi observado que cerâmicas de zircônia que possuem tamanhos de cristalito inferiores $\mathrm{a} \sim 100 \mathrm{~nm}$ apresentam um comportamento isotérmico na sua cinética de transformação monoclínica-tetragonal [1].

Estudos em monocristais de zircônia, utilizando dilatometria, mostraram que a transformação monoclínica-tetragonal apresenta uma histerese térmica considerável. A transformação monoclínica-tetragonal inicia-se em $1179{ }^{\circ} \mathrm{C}$, completando-se em $1190{ }^{\circ} \mathrm{C}$ e, para a transformação inversa (tetragonal-monoclínica) essas temperaturas são, respectivamente, de $1048^{\circ} \mathrm{C}$ e $950{ }^{\circ} \mathrm{C}[5]$.

A transformação tetragonal-cúbica ainda foi muito pouco estudada; a alta temperatura dessa transformação $\left(2680^{\circ} \mathrm{C}\right)$ dificulta a realização de experimentos, por isso essa transformação foi mais estudada em soluções sólidas do que na zircônia pura [1].

\subsection{ZIRCÔNIA - ÍTRIA}

Os primeiros estudos envolvendo a adição de óxidos de terras raras e óxidos contendo cátions aliovalentes, como por exemplo $\mathrm{Ca}^{+2}, \mathrm{Mg}^{+2} \mathrm{e}^{+3}$, à zircônia revelaram 
que as temperaturas de transição das fases monoclínica-tetragonal e tetragonal-cúbica são substancialmente reduzidas, devido a essa adição. Esse fenômeno de estabilização na zircônia ainda não foi completamente esclarecido.

A estabilização da zircônia pode ser total ou parcial. A zircônia parcialmente estabilizada geralmente consiste em uma mistura das estruturas cúbica e monoclínica ou tetragonal. $\mathrm{O}$ interesse nas zircônias parcialmente estabilizadas é grande devido ao seu comportamento mecânico. Pode-se fazer uso da transformação tetragonal-monoclínica para aumentar a resistência mecânica e a tenacidade à fratura dessa cerâmica. $\mathrm{O}$ comportamento elétrico também depende da simetria da rede cristalina, já tendo sido determinado que $\sigma_{\mathrm{c}}>\sigma_{\mathrm{t}}>\sigma_{\mathrm{m}}(\sigma$ : condutividade elétrica; c: cúbica; t: tetragonal; m: monoclínica) [1].

As soluções sólidas com estabilização total da fase cúbica na zircônia são condutoras de íons oxigênio em uma ampla faixa de temperatura e pressão parcial de oxigênio. Na figura 1.2.1 é mostrado o diagrama de fases mais citado para o sistema $\mathrm{ZrO}_{2}: \mathrm{Y}_{2} \mathrm{O}_{3}$; esse sistema é particularmente interessante por apresentar, relativamente, um grande campo de solução sólida cúbica [6]. 


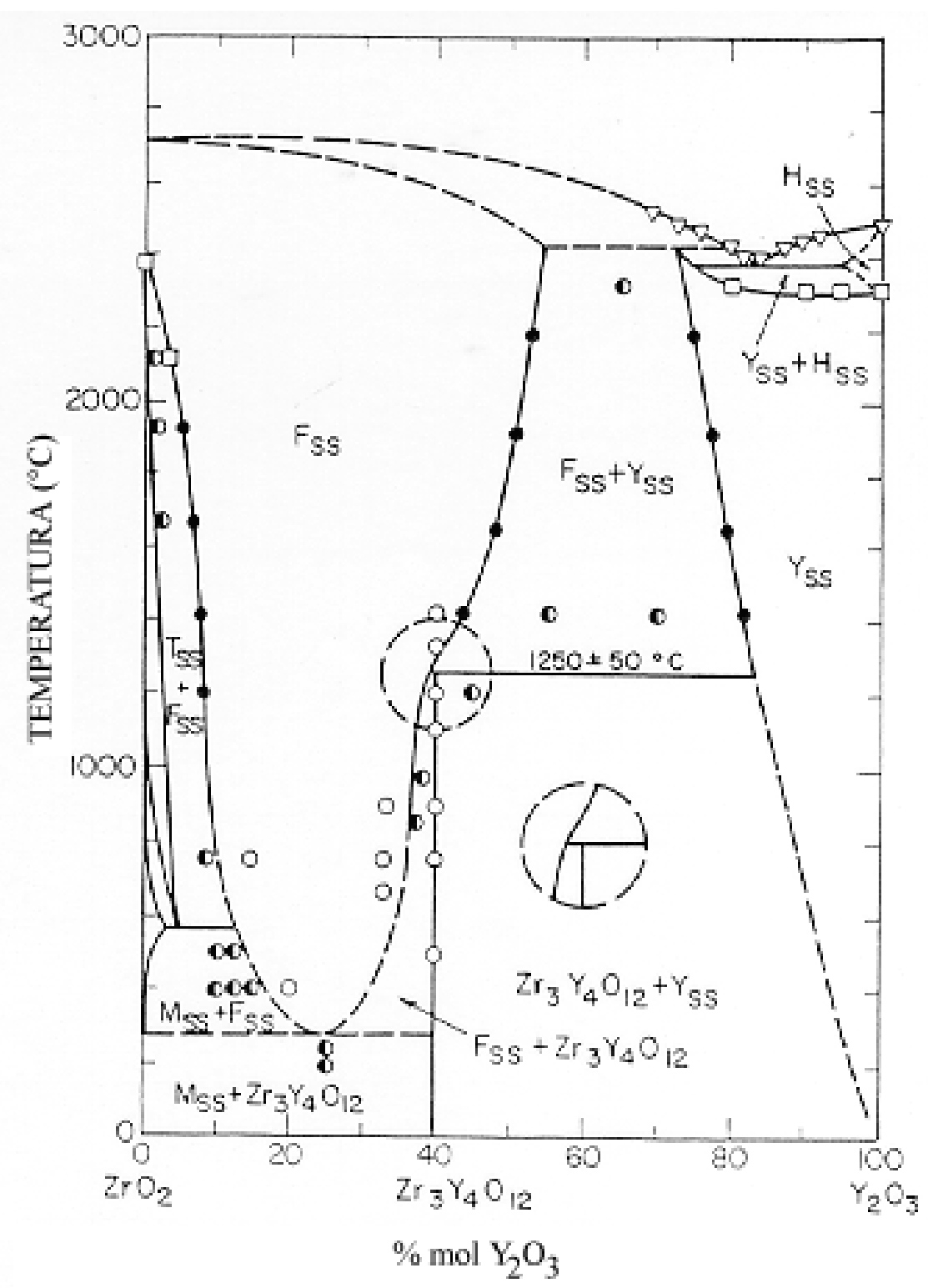

Figura 1.2.1: Diagrama de fases do sistema $\mathrm{ZrO}_{2}: \mathrm{Y}_{2} \mathrm{O}_{3}$.

Devido a alta condutividade iônica, que chega mesmo a ser próxima da condutividade de eletrólitos líquidos, a zircônia completamente estabilizada faz parte de uma relativamente nova categoria de materiais, os condutores sólidos de íons rápidos. Os eletrólitos sólidos são materiais cristalinos ou amorfos cujas estruturas permitem o transporte de íons. 
A condutividade iônica das zircônias estabilizadas apresenta um comportamento do tipo Arrhenius em uma determinada faixa de temperatura com uma energia de ativação térmica de aproximadamente $1 \mathrm{eV}$. A condução é puramente eletrolítica, com o número de transporte $\left(\mathrm{t}_{\mathrm{i}}\right)$ dos íons oxigênio praticamente igual a 1 e o número de transporte dos elétrons $\left(\mathrm{t}_{\mathrm{e}}\right)<1 \%$. A variação da condutividade elétrica em uma dada temperatura exibe um máximo na menor concentração de dopante necessária para a estabilização da fase cúbica [1].

As zircônias estabilizadas são utilizadas em uma grande variedade de dispositivos, mas uma de suas aplicações mais importantes é em sensores de oxigênio, para a otimização da relação ar-combustível em caldeiras ou em motores de combustão, e na detecção de teores de oxigênio em gases. Um exemplo é no controle da atmosfera de sinterização de óxidos combustíveis nucleares, um requisito importante para se obter combustíveis à base de óxido de urânio na estequiometria correta.

Os sensores de oxigênio se baseiam na relação entre a força eletromotriz (E) gerada pela diferença na pressão parcial de oxigênio $\left(\mathrm{p}_{\mathrm{O}_{2}}\right)$ em dois lados da célula que compõem o sensor. Conhecendo-se a pressão parcial de referência e medindo-se a força eletromotriz determina-se a pressão parcial de oxigênio desconhecida, segundo a equação 1.2.1.

$$
\begin{aligned}
& \mathrm{E}=\frac{\mathrm{R} \cdot \mathrm{T}}{4 \cdot \mathrm{F}} \cdot \int_{\mathrm{p}_{\mathrm{O}_{2}^{\prime}}^{\prime \prime}}^{\mathrm{O}_{2}^{\prime \prime}} \mathrm{d}\left(\ln \mathrm{p}_{\mathrm{O}_{2}}\right) \\
& \mathrm{E}=\frac{\mathrm{R} \cdot \mathrm{T}}{4 \cdot \mathrm{F}} \cdot \ln \left(\frac{\mathrm{p}_{\mathrm{O}_{2}}^{\prime \prime}}{\mathrm{p}_{\mathrm{O}_{2}}^{\prime}}\right)
\end{aligned}
$$

onde $\mathrm{R}=8,314 \mathrm{~J} / \mathrm{mol} \cdot \mathrm{K}$, T é a temperatura absoluta, $\mathrm{F}=9,649 \cdot 10^{4} \mathrm{C} / \mathrm{mol}$, e p ${ }_{\mathrm{O}_{2}}$ e p ${ }^{\prime}{ }_{\mathrm{O}_{2}}$ são as pressões parciais nos lados da célula do sensor. 
Os eletrólitos sólidos de $\mathrm{ZrO}_{2}: \mathrm{Y}_{2} \mathrm{O}_{3}$ formam uma solução sólida substitucional, por atração eletrostática de espécies de cargas opostas envolvendo a produção de uma vacância de $\mathrm{O}^{-2}$ para cada dois íons de $\mathrm{Y}^{+3}$ que entram na solução. São essas vacâncias que permitem o transporte iônico nesses materiais.

\subsection{ENVELHECIMENTO TÉRMICO}

Em Y-TZPs (Zircônia Tetragonal Policristalina, estabilizada com $\mathrm{Y}_{2} \mathrm{O}_{3}$ ) a transformação de fase tetragonal para monoclínica, devida ao envelhecimento térmico, é bastante conhecida [7-12]. Já para os policristais de $\mathrm{ZrO}_{2}: 8 \% \mathrm{~mol} \mathrm{Y}_{2} \mathrm{O}_{3}$ a ocorrência de transformações de fase, durante o envelhecimento térmico, continua controversa.

Estudos mostraram que a fase cúbica dos sistemas à base de zircônia não são completamente estáveis na temperatura ambiente. A lenta desestabilização e a formação de fases intermediárias, como por exemplo $\mathrm{Zr}_{3} \mathrm{Y}_{4} \mathrm{O}_{12}$, no caso da $\mathrm{ZrO}_{2}: \mathrm{Y}_{2} \mathrm{O}_{3}$, é devida aos baixos coeficientes de difusão dos cátions em relação ao coeficiente de difusão do oxigênio. Como conseqüência, a fase cúbica pode se manter metaestável por longos períodos de tempo em temperaturas abaixo da temperatura de decomposição [1].

Segundo Stubican e Hellmann [6], a transformação de fase eutetóide $\mathrm{ZrO}_{2}$ cúbica $(\mathrm{ss}) \rightarrow \mathrm{ZrO}_{2}$ monoclínica (ss) $+\mathrm{Zr}_{3} \mathrm{Y}_{4} \mathrm{O}_{12}$ ocorre em temperaturas abaixo de $750{ }^{\circ} \mathrm{C}$; no entanto, os resultados obtidos a partir de transformações ocorridas em temperaturas abaixo dos $700^{\circ} \mathrm{C}$ só podem ser considerados como tentativas. 
Estudos, utilizando microscopia eletrônica de transmissão, feitos por Lange e colaboradores [in 11], em amostras de $\mathrm{ZrO}_{2}: 6,6 \%$ mol $\mathrm{Y}_{2} \mathrm{O}_{3}$, consistindo inicialmente de grãos cúbicos grandes apresentaram, após envelhecimento térmico, a formação de pequenos "clusters" ricos em ítrio e estes eram freqüentemente adjacentes à fase monoclínica transformada a partir da fase cúbica. Baukal, estudando o envelhecimento térmico do sistema $\mathrm{ZrO}_{2}: \mathrm{Y}_{2} \mathrm{O}_{3}$, propôs que a diminuição da condutividade elétrica desse material se deve a uma transformação ordem-desordem no grão, no qual são precipitados microdomínios de $\mathrm{Zr}_{3} \mathrm{Y}_{4} \mathrm{O}_{12}$ e, algumas vezes, ocorrendo a transformação de fase cúbica para monoclínica [in 13]. Resultados análogos são encontrados para o sistema $\mathrm{ZrO}_{2}: \mathrm{CaO}$ [in 13 e 14,15$]$.

Eletrólitos sólidos de $\mathrm{ZrO}_{2}: 8 \%$ mol $\mathrm{Y}_{2} \mathrm{O}_{3}$ são usados em sensores permanentes de teores de oxigênio em gases. Esses sensores são operados na temperatura de $600{ }^{\circ} \mathrm{C}$ (faixa eletrolítica). A figura 1.3.1 mostra um esquema de um sensor comercial, consistindo basicamente da cerâmica de $\mathrm{ZrO}_{2}: \mathrm{Y}_{2} \mathrm{O}_{3}$, um forno para mantê-la a $600{ }^{\circ} \mathrm{C}$, entrada e saída dos gases de teste, e terminais para aferição da força eletromotriz do sensor. A estabilidade da solução sólida, na temperatura de trabalho, dá o grau de estabilidade do sensor.

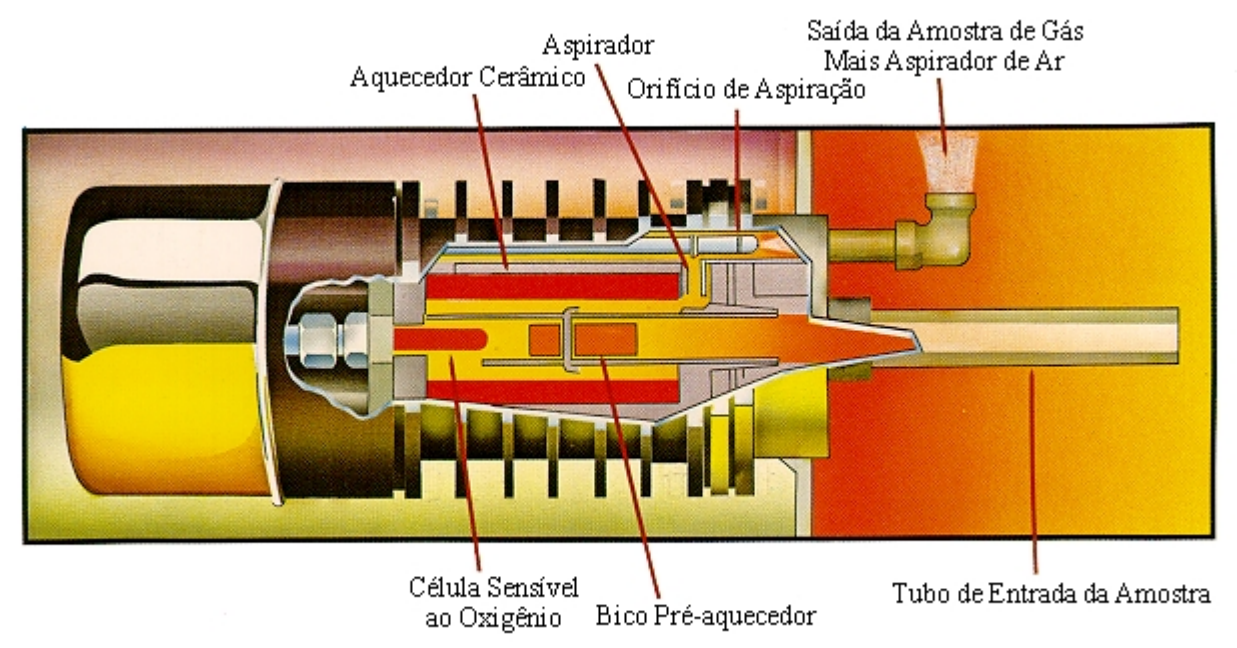

Figura 1.3.1: Esquema de um sensor comercial. 


\subsection{SINTERIZAÇÃo}

Pode-se descrever a sinterização como um processo complexo no qual, pós cristalinos ou não, compactados, são tratados termicamente, em uma temperatura abaixo de sua temperatura de fusão, envolvendo uma mudança na microestrutura desse material, por meio de um ou mais mecanismos de transporte, que podem ser concorrentes ou consecutivos, para se obter um único sólido coerente [16-19].

As reações que ocorrem na sinterização no estado sólido são termicamente ativadas e algumas dessas reações ocorrem espontaneamente quando uma temperatura particular é atingida; outras reações ocorrem lentamente em um amplo intervalo de temperatura e somente entre as partículas em contato. Nesse caso, não só a temperatura, mas também o tamanho de partícula e a área de contato entre elas são muito importantes.

Em geral as reações no estado sólido envolvem três processos subsequentes: o transporte de substâncias potencialmente reativas (íons) para as superfícies de contato dos componentes em reação, a própria reação entre os componentes em contato e o transporte dos produtos das reações para fora dos lugares onde ocorre a reação, ou seja, as reações dependem da taxa de transporte dos reagentes e produtos das reações. Por esse motivo, em geral, a difusão é o único processo que determina as reações e suas velocidades.

Assumindo que durante as reações químicas no estado sólido os íons se difundem pelo cristal, seu movimento está conectado com o movimento das vacâncias, que são substituídas pelos íons móveis. Os saltos dos íons de uma posição da rede para a próxima é dependente de uma certa quantidade de energia que é requerida para que a barreira de energia seja vencida, a energia de ativação. Quando a temperatura aumenta o número de 
íons (vacâncias) que podem vencer a barreira aumenta exponencialmente facilitando as reações no estado sólido. A temperatura é sem dúvida o principal parâmetro que controla o curso dessas reações, mas a altura da barreira de energia, ou seja, a magnitude da energia de ativação, é também afetada pela pureza, estequiometria e estrutura do material; valência dos íons que se difundem e suas dimensões, etc. O fluxo dos componentes reativos pode ser afetado, pela área de superfície específica, tamanho do cristal, homogeneidade do sistema, densidade, etc. [20].

Na produção de cerâmicas à base de zircônia o processo de sinterização mais importante é, sem dúvida, a sinterização no estado sólido [17, 21]. Este método é preferível na produção de cerâmicas com boas propriedades mecânicas, elétricas ou ópticas. Nesse processo de sinterização, todos os constituintes do pó compactado permanecem sólidos durante todo o processo de sinterização. A densificação máxima do material é atingida basicamente pela mudança na forma dos grãos constituintes.

O parâmetro mais importante da sinterização é a redução da energia livre de superfície do sistema, ou seja, a tendência do sistema de atingir o estado de menor energia livre. Esta é acompanhada por uma redução nas áreas das superfícies e interfaces dos pós compactados, sendo que essa redução se consegue pela combinação de dois processos. Basicamente o que ocorre é a conversão de muitas partículas pequenas em partículas maiores em menor número, ou seja, crescimento de grão e a substituição das interfaces gássólido, por interfaces sólido-sólido de menor energia, ou seja, densificação.

O estudo da sinterização é simplificado, assumindo que o processo ocorre em estágios. Dessa forma a sinterização é, geralmente, dividida em três estágios: inicial, intermediário e final. Não existe uma diferenciação clara entre os três estágios de sinterização e alguns autores chegam a omitir o estágio intermediário. 
Vários modelos têm sido propostos e refinados com a finalidade de determinar o mecanismo, ou os mecanismos, responsáveis pela sinterização. Esses esforços têm atingido vários graus de sucesso [17].

Apesar do fato de que a grande diferença entre os coeficientes de difusão do zircônio e do oxigênio sugerem a difusão na rede como mecanismo de sinterização nos materiais à base de zircônia, alguns autores têm sugerido mecanismos diferentes deste, como por exemplo, difusão por contorno de grão [21]. A zircônia tem recebido relativamente muito pouca atenção em termos de estudos de sua cinética de sinterização; raramente se encontram trabalhos onde os modelos de sinterização são aplicados aos materiais à base de zircônia ou modelos são propostos para a sinterização desses materiais, sendo a ênfase dada no estudo da otimização dos processos de sinterização.

O crescimento de grão ocorre em todos os estágios de sinterização. O modelo mais simples de crescimento de grão leva em consideração o movimento dos contornos de grão, que é inversamente proporcional ao tamanho médio de grão. Dessa forma a segregação de impurezas nos contornos de grão pode reduzir a energia livre do sistema e consequentemente diminuir a taxa de crescimento do grão [22, 23].

Apesar de muitos materiais, produzidos por sinterização, serem desenvolvidos com finalidades de utilização em dispositivos elétricos, pouco se sabe sobre as mudanças de suas propriedades elétricas durante a sinterização, e além disso, medidas elétricas são muito pouco utilizadas para se estudar os processos de sinterização destes mesmos materiais [24].

Como sugerido por Hausner e Dedrick [24], medidas elétricas são excelentes indicadores das mudanças ocorridas durante a sinterização de materiais, chegando mesmo a apresentar um grau de precisão maior do que as técnicas convencionais. 


\subsection{ESPECTROSCOPIA DE IMPEDÂNCIA}

Desde o trabalho pioneiro de Bauerle [25], a espectroscopia de impedância tem se tornado uma ferramenta muito comum na pesquisa e desenvolvimento de materiais, pois os resultados dessa técnica podem freqüentemente ser relacionados a variáveis complicadas de materiais, tais como, microestrutura, influência da composição na condutividade de sólidos, propriedades dielétricas, etc. [26].

As medidas de espectroscopia de impedância possibilitam a separação das diferentes contribuições individuais dos constituintes do material quando estes têm diferentes respostas em um determinado domínio de freqüências [27].

Uma diferença de potencial que muda de sinal ciclicamente com o tempo é uma tensão alternada:

$$
\mathrm{v}(\mathrm{t})=\mathrm{v}_{\mathrm{m}} \cdot \cos (\omega \cdot \mathrm{t})
$$

onde $\mathrm{v}_{\mathrm{m}}$ é o valor máximo dessa tensão alternada, também chamado de valor de pico e $\omega$ é a freqüência angular, que está relacionada com a freqüência f por:

$$
\omega=2 \cdot \pi \cdot \mathrm{f}
$$

Podemos representar essa tensão alternada, como a parte real de uma grandeza complexa: 


$$
\hat{v}(t)=v_{m} \cdot \cos (\omega \cdot t)+j \cdot v_{m} \cdot \operatorname{sen}(\omega \cdot t)
$$

onde $^{\wedge}$ representa uma grandeza complexa e j é a unidade imaginária $\left(\mathrm{j}=(-1)^{1 / 2}\right)$; aplicando a relação de Euler $\left(\mathrm{e}^{\mathrm{j}} \cdot \theta=\cos \theta+\mathrm{j} \cdot \operatorname{sen} \theta\right)$ na equação 1.5.3, vem:

$$
\hat{v}(t)=v_{m} \cdot e^{j \cdot \omega \cdot t}
$$

Analogamente uma corrente alternada, gerada por um elemento de circuito em resposta a uma tensão alternada, pode ser escrita como:

$$
\hat{i}(t)=i_{m} \cdot e^{j(\omega \cdot t+\varphi)}
$$

onde $\varphi$ é a diferença de fase entre tensão e corrente.

A relação entre tensão e corrente alternadas num elemento de circuito (ou em um circuito contendo vários elementos), por exemplo em uma célula simétrica como mostrado na figura 1.5.1, é expressa pela lei de Ohm na forma:

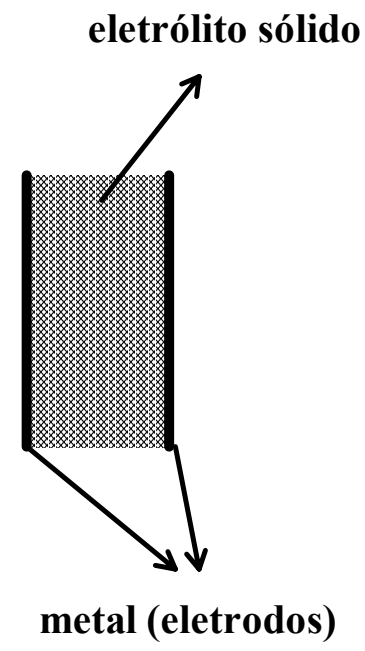

Figura 1.5.1: Célula simétrica constituída por um eletrólito sólido cilíndrico, recoberto em suas faces paralelas por um metal (eletrodos). 


$$
\hat{v}(t)=\hat{Z} \cdot \hat{i}(t) \Rightarrow \hat{Z}=\frac{\hat{v}(t)}{\hat{i}(t)}
$$

substituindo 1.5 .4 e 1.5 .5 em 1.5.6 e observando que para cada freqüência $\omega$ temos um valor de impedância, podemos escrever:

$$
\hat{Z}(\omega)=Z_{m} \cdot e^{j \cdot \phi}
$$

onde devemos ter, necessariamente, o módulo de $\hat{Z}, Z_{m}=v_{m} / i_{m}$; e $\phi=-\varphi$.

Aplicando a relação de Euler na equação 1.5.7, temos:

$$
\hat{Z}(\omega)=Z_{m} \cdot \cos \phi+j \cdot Z_{m} \cdot \operatorname{sen} \phi
$$

Podemos, então, representar a impedância como um vetor no plano complexo (figura 1.5.2), onde:

$$
\vec{Z}(\omega)=\underbrace{\operatorname{Re}[\hat{Z}(\omega)]}_{Z^{\prime}} \vec{i}+\underbrace{\operatorname{Im}[\hat{Z}(\omega)]}_{Z^{\prime \prime}} \vec{j}
$$

e dessa forma:

$$
Z^{\prime}=\operatorname{Re}[\hat{Z}(\omega)]=Z_{m} \cdot \cos \phi
$$

e:

$$
Z^{\prime \prime}=\operatorname{Im}[\hat{Z}(\omega)]=Z_{m} \cdot \operatorname{sen} \phi
$$




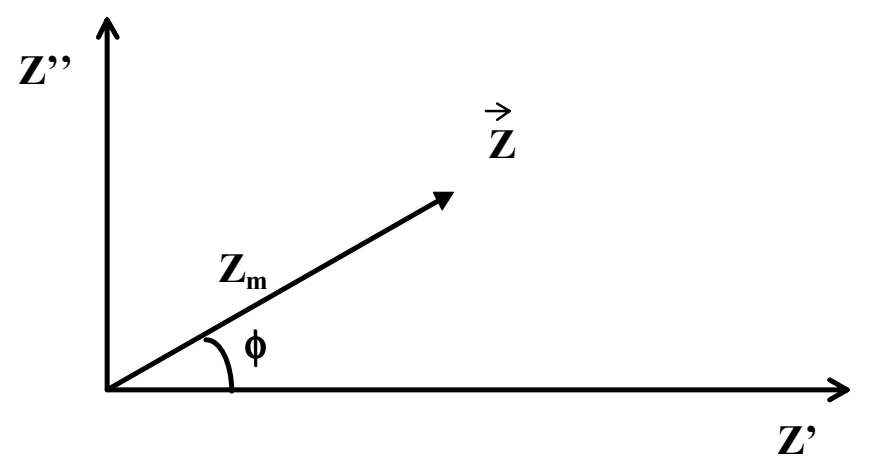

Figura 1.5.2: Representação no plano complexo do vetor impedância.

A parte real da impedância é chamada de parte resistiva do elemento de circuito, enquanto a parte imaginária é chamada de reatância desse mesmo elemento de circuito.

Ainda temos as seguintes relações:

$$
\hat{Z}(\omega)=Z^{\prime}+j \cdot Z^{\prime \prime} \text { (representação de Fresnel) }
$$

e:

$$
Z_{m}=|\hat{Z}(\omega)|=\sqrt{Z^{\prime 2}+Z^{\prime \prime 2}}
$$

e:

$$
\phi=\frac{Z^{\prime \prime}}{Z^{\prime}}
$$

Um circuito como mostrado na figura 1.5.3, tem sua impedância dada por: 


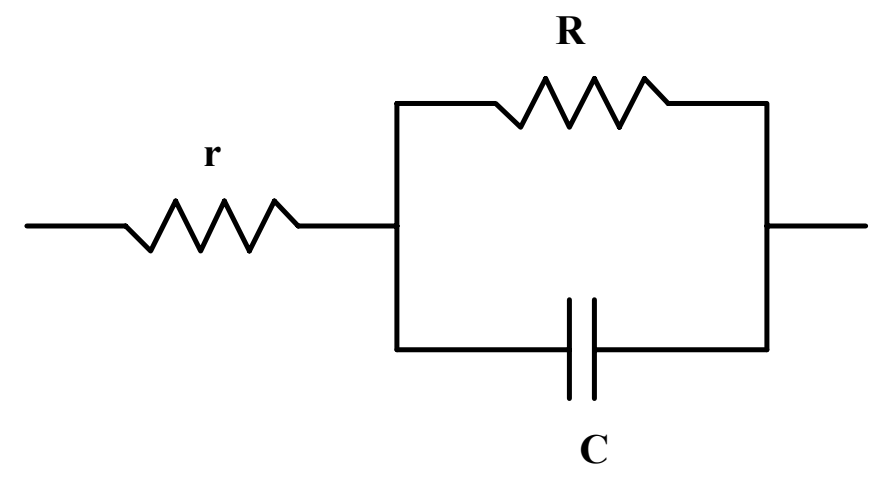

Figura 1.5.3: Circuito elétrico contendo uma resistência $r$ em série com um RC em paralelo.

$$
\mathrm{Z}=\mathrm{r}+\frac{\mathrm{R}}{1+\mathrm{j} \cdot \omega \cdot \mathrm{R} \cdot \mathrm{C}}
$$

Multiplicando o numerador e o denominador do segundo termo da equação 1.5.15 pelo complexo conjugado do denominador, podemos separar as partes real e imaginária da impedância Z:

$$
\begin{aligned}
& Z=r+\frac{R-j \cdot \omega \cdot R^{2} \cdot C}{1-\underbrace{j^{2} \cdot \omega^{2} \cdot R^{2} \cdot C^{2}}_{-1}} \\
& Z=\underbrace{r+\frac{R}{1+(\omega \cdot R \cdot C)^{2}}}_{\operatorname{Re}(Z)}-j \cdot \underbrace{\frac{\omega \cdot R^{2} \cdot C}{1+(\omega \cdot R \cdot C)^{2}}}_{\operatorname{Im}(Z)}
\end{aligned}
$$

Podemos expressar a parte imaginária da impedância $\mathrm{Z}$ em função da parte real, assim:

$$
-\operatorname{Im}(Z)=[\operatorname{Re}(Z)-r] \cdot \omega \cdot \mathrm{R} \cdot \mathrm{C}
$$

Fazendo $\omega \cdot \mathrm{R} \cdot \mathrm{C}=\mathrm{x}$, vem: 


$$
\begin{aligned}
& -\operatorname{Im}(Z)=[\operatorname{Re}(Z)-r] \cdot x \\
& \therefore x=-\frac{\operatorname{Im}(Z)}{\operatorname{Re}(Z)-r}
\end{aligned}
$$

substituindo 1.5 .18 na parte real de 1.5.16, temos:

$$
\begin{aligned}
& \operatorname{Re}(Z)=r+\frac{\mathrm{R}}{1+\left(\frac{-\operatorname{Im}(Z)}{\operatorname{Re}(Z)-r}\right)^{2}} \\
& \operatorname{Re}(Z)-r=\frac{\mathrm{R} \cdot[\operatorname{Re}(Z)-\mathrm{r}]^{2}}{[\operatorname{Re}(Z)-\mathrm{r}]^{2}+[-\operatorname{Im}(Z)]^{2}} \\
& {[\operatorname{Re}(Z)-r]^{2}-\mathrm{R} \cdot[\operatorname{Re}(Z)-r]+[-\operatorname{Im}(Z)]^{2}=0}
\end{aligned}
$$

e completando o quadrado, vem:

$[\operatorname{Re}(Z)-r]^{2}-\mathrm{R} \cdot[\operatorname{Re}(Z)-r]+\frac{\mathrm{R}^{2}}{4}+[-\operatorname{Im}(Z)]^{2}=\frac{\mathrm{R}^{2}}{4}$

então:

$$
\left\{[\operatorname{Re}(\mathrm{Z})-\mathrm{r}]-\frac{\mathrm{R}}{2}\right\}^{2}+[-\operatorname{Im}(\mathrm{Z})]^{2}=\left(\frac{\mathrm{R}}{2}\right)^{2}
$$

A expressão 1.5.21, é a equação de uma circunferência centrada em $(r+R / 2,0)$ e de raio $\mathrm{R} / 2$. Na figura 1.5.4 é mostrada a variação da impedância, em função da freqüência, no plano complexo, do circuito da figura 1.5.3. 


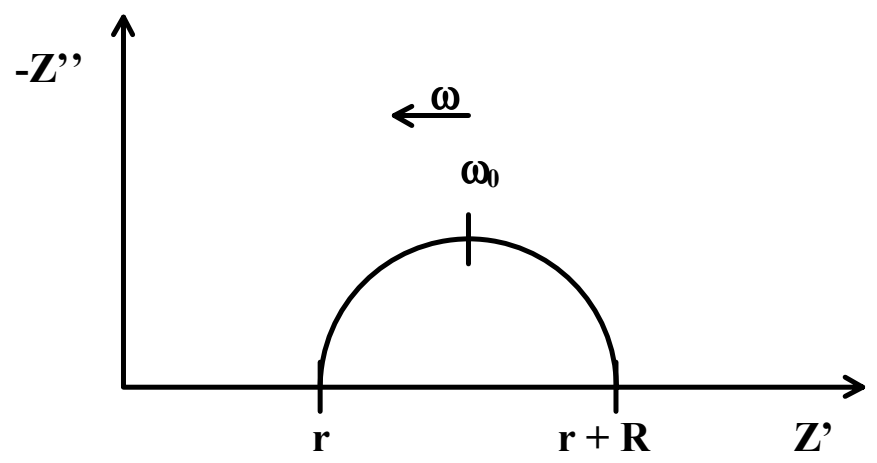

Figura 1.5.4: Diagrama de impedância, ou gráfico de Cole-Cole, do circuito mostrado na figura 1.5.3.

Um dielétrico, que pode ser representado pelo circuito mostrado na figura 1.5.5, tem seu diagrama de impedância mostrado na figura 1.5.6, desde de que as freqüências características sejam suficientemente distintas. A impedância desse circuito é:

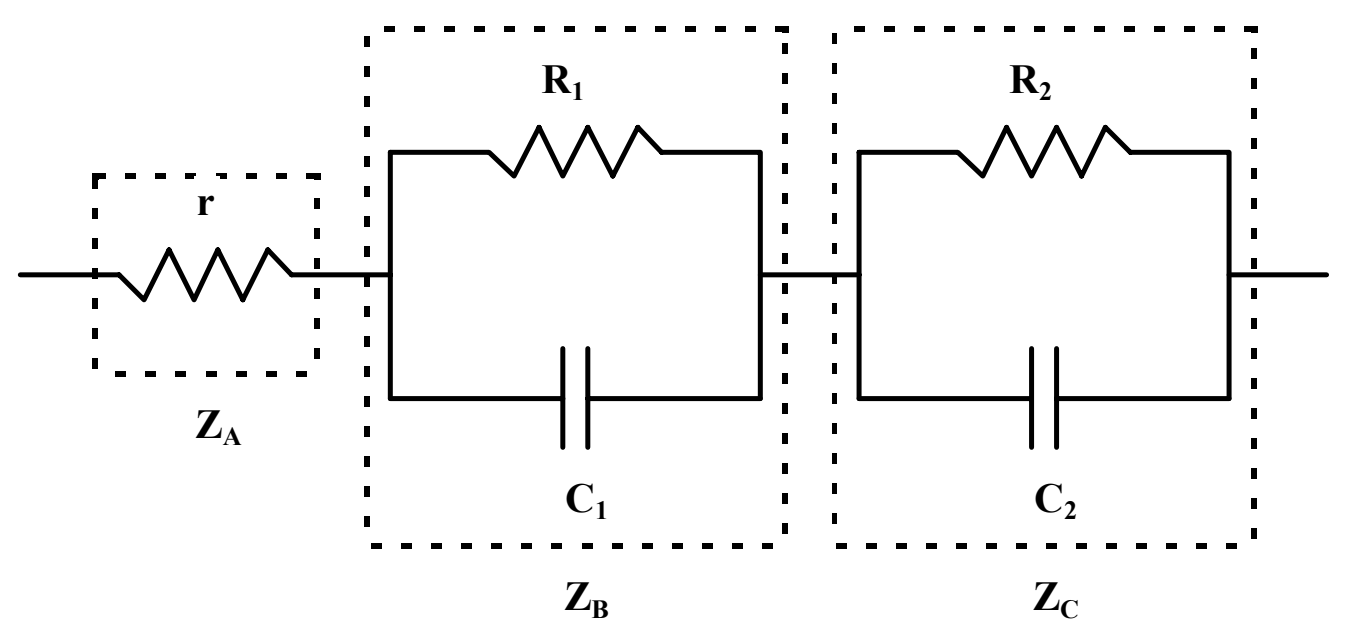

Figura 1.5.5: Circuito equivalente a um dielétrico. 


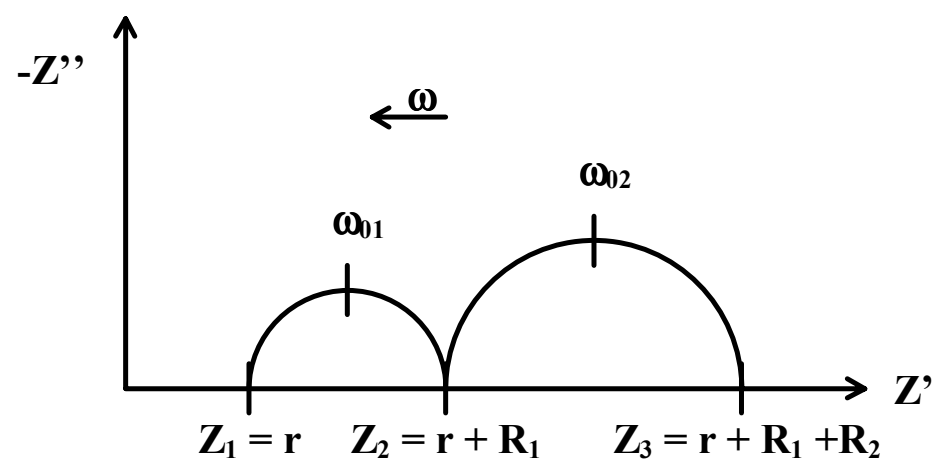

Figura 1.5.6: Diagrama de impedância do circuito mostrado na figura 1.5.5.

$$
\mathrm{Z}=\mathrm{Z}_{\mathrm{A}}+\mathrm{Z}_{\mathrm{B}}+\mathrm{Z}_{\mathrm{C}}
$$

onde:

$$
\begin{aligned}
& \mathrm{Z}_{\mathrm{A}}=\mathrm{r} \\
& \mathrm{Z}_{\mathrm{B}}=\frac{\mathrm{R}_{1}}{1+\mathrm{j} \cdot \omega \cdot \mathrm{R}_{1} \cdot \mathrm{C}_{1}} \\
& \mathrm{Z}_{\mathrm{C}}=\frac{\mathrm{R}_{2}}{1+\mathrm{j} \cdot \omega \cdot \mathrm{R}_{2} \cdot \mathrm{C}_{2}}
\end{aligned}
$$

lembrando que:

$$
\omega_{0} \cdot \mathrm{R} \cdot \mathrm{C}=1
$$

e da figura 1.5.6, temos que:

$$
\begin{aligned}
& \mathrm{r}=\mathrm{Z}_{1} \\
& \mathrm{R}_{1}=\mathrm{Z}_{2}-\mathrm{Z}_{1} \\
& \mathrm{R}_{2}=\mathrm{Z}_{3}-\mathrm{Z}_{2}
\end{aligned}
$$

então, podemos escrever a impedância do circuito da figura 1.5.5, como: 


$$
Z=Z_{1}+\frac{Z_{2}-Z_{1}}{1+j \cdot \frac{\omega}{\omega_{01}}}+\frac{Z_{3}-Z_{2}}{1+j \cdot \frac{\omega}{\omega_{02}}}
$$

onde:

$$
\omega_{01}=\frac{1}{\mathrm{R}_{1} \cdot \mathrm{C}_{1}}
$$

e:

$$
\omega_{02}=\frac{1}{\mathrm{R}_{2} \cdot \mathrm{C}_{2}}
$$

Experimentalmente se observa que os centros dos semicírculos não se encontram sobre o eixo real. Nesse caso a expressão 1.5.26 torna-se:

$$
Z=Z_{1}+\frac{Z_{2}-Z_{1}}{\left.1+\left(j \cdot \frac{\omega}{\omega_{01}}\right)^{\left(1-\vartheta_{1}\right.}\right)}+\frac{Z_{3}-Z_{2}}{1+\left(j \cdot \frac{\omega}{\omega_{02}}\right)^{\left.1-\vartheta_{2}\right)}}
$$

onde os ângulos de descentralização $\left(\theta_{1}\right.$ e $\left.\theta_{2}\right)$ são dados, respectivamente, por $[3,26]$ :

$$
\theta_{1}=\vartheta_{1} \cdot \frac{\pi}{2}
$$

e:

$$
\theta_{2}=\vartheta_{2} \cdot \frac{\pi}{2}
$$

Quando as freqüências características não são suficientemente distintas a sobreposição dos arcos de semicírculo nos diagramas de impedância se torna significativa. 
Nesse caso se faz necessário a resolução numérica desses diagramas. Essa resolução numérica também pode ser aplicada a diagramas contendo apenas um arco de semicírculo para a determinação mais precisa de seus parâmetros [28].

O diagrama de impedância de uma célula, contendo um eletrólito sólido de $\mathrm{ZrO}_{2}: 8 \%$ mol $\mathrm{Y}_{2} \mathrm{O}_{3}$, consiste em três arcos de semicírculos (figura 1.5.7).

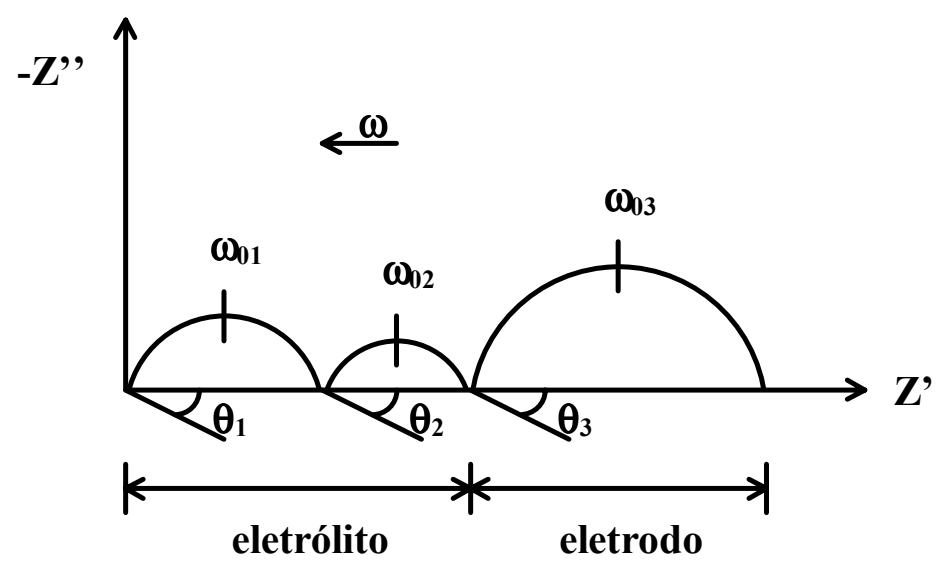

Figura 1.5.7: Diagrama de impedância esperado para uma amostras de $\mathrm{ZrO}_{2}: 8 \%$ $\mathrm{mol} \mathrm{Y}_{2} \mathrm{O}_{3}$.

O arco de semicírculo de freqüências menores está relacionado com reações que ocorrem na interface eletrólito-eletrodo, denominadas genericamente de polarização dos eletrodos. $\mathrm{O}$ arco de semicírculo de freqüências intermediárias está relacionado com os componentes microestruturais dos contornos de grão e o arco de semicírculo de freqüências maiores está relacionado com as características elétricas e dielétricas do interior dos grãos. É conveniente expressar o semicírculo de freqüências intermediárias como um bloqueio exercido pelos componentes dos contornos de grão ao processo de migração dos íons de $\mathrm{O}^{-}$ 2 . Pode-se calcular a fração dos portadores de carga bloqueados nos contornos de grão em relação ao número total de portadores pela equação:

$$
\alpha_{R}=\frac{R_{c g}}{R_{g}+R_{c g}}
$$


onde $\alpha_{R}$ é denominado fator de bloqueio em resistência, $R_{c g}$ é a resistência dos contornos de grão e $\mathrm{R}_{\mathrm{g}}$ é a resistência dos grãos.

Analogamente podem ser definidos os fatores capacitivo e de freqüência:

$$
\alpha_{C}=\frac{C_{c g}}{C_{g}}
$$

e:

$$
\alpha_{f}=\frac{f_{c g}^{0}}{f_{g}^{0}}
$$

O parâmetro $\alpha_{R}$ representa uma espécie de parâmetro característico de contato entre os grãos e dessa forma pode estar associado a densidade de contornos de grão ou a área de bloqueio destes [29, 30]. 


\subsection{OBJETIVOS}

Os principais objetivos desse trabalho são:

- Avaliar a estabilidade da solução sólida $\mathrm{ZrO}_{2}: 8 \%$ mol $\mathrm{Y}_{2} \mathrm{O}_{3}$, utilizada em sensores permanentes de oxigênio, na temperatura de trabalho do sensor $\left(600^{\circ} \mathrm{C}\right)$.

- Mostrar a possibilidade de se estudar os mecanismos e a cinética de sinterização de materiais por espectroscopia de impedância. 
Foram utilizados pós de óxido de zircônio de duas origens na preparação dos eletrólitos sólidos: Nissan (Japão) do tipo $\mathrm{ZrO}_{2}: 8 \%$ mol $\mathrm{Y}_{2} \mathrm{O}_{3}$ e o produzido na Usina de Zircônio do IPEN. O pó produzido no IPEN ( $\mathrm{ZrO}_{2}$-IPEN) foi estabilizado com $\mathrm{Y}_{2} \mathrm{O}_{3}$ (USA), de pureza superior a 99,9\% por duas técnicas: coprecipitação dos hidróxidos e mistura de óxidos.

\subsection{Processamento dos Pós}

Para a preparação do pó de $\mathrm{ZrO}_{2}: 8 \%$ mol $\mathrm{Y}_{2} \mathrm{O}_{3}$ por coprecipitação dos hidróxidos uma solução contendo os cátions de interesse foi preparada e, como os cátions em solução são aproximadamente do mesmo tamanho e quimicamente similares, foi obtida a coprecipitação [31]. A seguir esse produto foi colocado em navícula de alumina e calcinado em forno resistivo tubular Lindberg a $900{ }^{\circ} \mathrm{C} / 2 \mathrm{~h}$, ao ar, com taxa de aquecimento de $5{ }^{\circ} \mathrm{C} / \mathrm{min}$ e taxa de resfriamento de $10^{\circ} \mathrm{C} / \mathrm{min}$. Após a calcinação, o pó foi desaglomerado em almofariz de ágata por aproximadamente $15 \mathrm{~min}$.

Foi feita medida de distribuição de tamanho de partículas, por sedimentação, com raios X, utilizando-se sedígrafo Micromeritics Sedigraph 5100, em dispersão do pó de $\mathrm{ZrO}_{2}$-IPEN com água deionizada e defloculante pirofosfato de sódio, preparada em ultrasom por $6 \mathrm{~min}$. Devido ao relativamente alto valor encontrado para o tamanho médio de 
partículas ou de aglomerados, e sabendo que pós mais finos são desejáveis, por serem mais reativos [32, 33], quotas de aproximadamente $15 \mathrm{~g}$ do pó de $\mathrm{ZrO}_{2}$-IPEN foram desaglomeradas em meio líquido (álcool isopropílico), por moinho de bolas, durante $15 \mathrm{~h}$, utilizando-se como meio de moagem cilindros de TZP (Zircônia Tetragonal Policristalina, $\mathrm{ZrO}_{2}: 3 \%$ mol $\mathrm{Y}_{2} \mathrm{O}_{3}$ processada no IPEN). Medidas de distribuição de tamanho de partículas foram feitas para cada quota desaglomerada.

As quantidades de pós de $\mathrm{ZrO}_{2}$-IPEN e $\mathrm{Y}_{2} \mathrm{O}_{3}$ necessárias para a preparação do pó de $\mathrm{ZrO}_{2}: 8 \%$ mol $\mathrm{Y}_{2} \mathrm{O}_{3}$, por mistura de óxidos, foram calculadas. Em excesso, essas quantidades foram secas em estufa a $100{ }^{\circ} \mathrm{C}$. As quantidades calculadas foram, então, pesadas em balança analítica Mettler H315, e homogeneizadas, em meio líquido (álcool isopropílico) com cilindros de TZP, no misturador mecânico Turbula T2C, durante $5 \mathrm{~h}$. Na figura 2.1.1 é apresentado o fluxograma da seqüência experimental utilizada no processamento dos pós por mistura de óxidos.

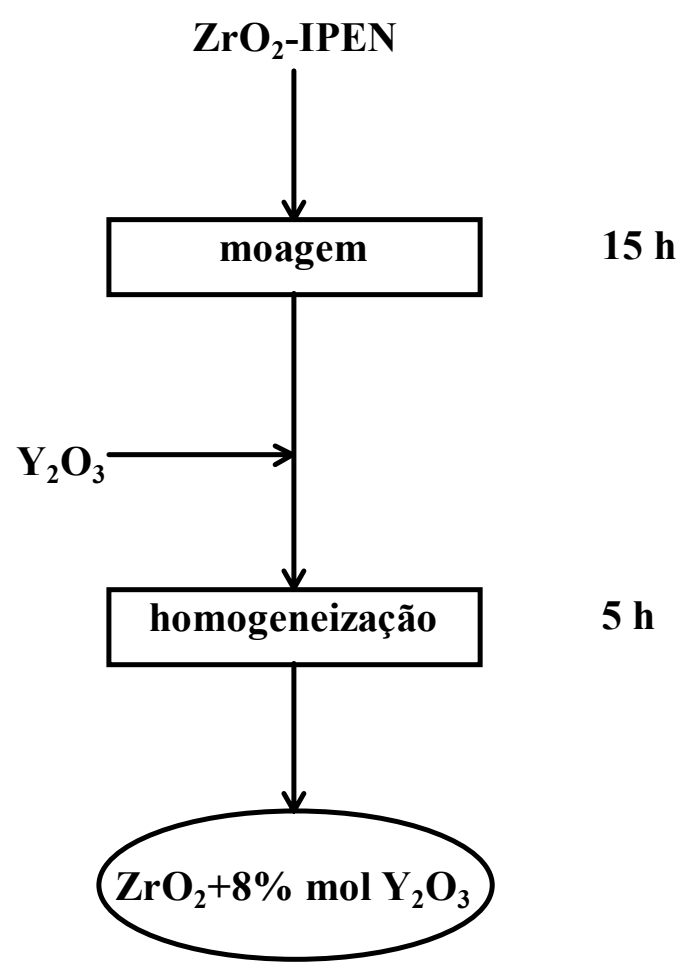

Figura 2.1.1: Seqüência experimental para o processamento do pó de $\mathrm{ZrO}_{2}+8 \%$ mol $\mathrm{Y}_{2} \mathrm{O}_{3}$ por mistura de óxidos. 


\subsection{CARACTERIZAÇÃo dos PÓS}

Foram feitas análises de espectrografia de emissão semiquantitativa, em todos os pós, para a determinação das quantidades de impurezas metálicas.

A concentração de $\mathrm{Y}_{2} \mathrm{O}_{3}$ nos pós foi calculada a partir da porcentagem de ítrio determinada pela técnica de espectrometria de fluorescência de raios X por dispersão do comprimento de onda. O equipamento utilizado foi um espectrômetro semi-automático seqüencial Rigaku Denki 3063P.

Foram feitas análises de difração de raios $\mathrm{X}$, dos pós de $\mathrm{ZrO}_{2}: 8 \%$ mol $\mathrm{Y}_{2} \mathrm{O}_{3}$, com adição de $\mathrm{Si}$, para calibração angular, na proporção de $\mathrm{ZrO}_{2}: \mathrm{Si}=2: 1$ em peso [34]. As faixas angulares das medidas de difração foram de $20^{\circ} \leq 2 \theta \leq 90^{\circ}, 27^{\circ} \leq 2 \theta \leq 38^{\circ}$ e $71^{\circ}$ $\leq 2 \theta \leq 76^{\circ}$, com passo de $0,06^{\circ} 2 \theta / 3 \mathrm{~s}$. As medidas de difração de raios X foram feitas em difratômetro Philips PW3710, utilizando-se radiação k $\alpha$ do $\mathrm{Cu}$.

Utilizando-se o programa AFI, para IBM PC, desenvolvido pelo Dr. A. P. J. Beis para o Institut National Polytéchnique de Grenoble, França, determinou-se o parâmetro de rede da estrutura cúbica dos pós a partir dos valores experimentais de $2 \theta$ e os respectivos $h$, k e 1 das raias de difração.

Medidas de distribuição de tamanho de partículas, por sedimentação, com raios X e LASER, utilizando-se os sedígrafos Micromeritics Sedigraph 5100 e CILAS 1064, respectivamente, foram feitas em dispersões dos pós de $\mathrm{ZrO}_{2}: 8 \%$ mol $\mathrm{Y}_{2} \mathrm{O}_{3}$ e $\mathrm{ZrO}_{2}+8 \%$ 
mol $\mathrm{Y}_{2} \mathrm{O}_{3}$, para se avaliar o tamanho médio de partículas ou de aglomerados. As dispersões foram preparadas, em ultra-som por $6 \mathrm{~min}$, com água deionizada e defloculante pirofosfato de sódio.

Foram feitas análises pelo método de BET (Brunauer, Emmet e Teller) para a determinação da área de superfície específica das partículas dos pós de $\mathrm{ZrO}_{2}: 8 \%$ mol $\mathrm{Y}_{2} \mathrm{O}_{3}$ e $\mathrm{ZrO}_{2}+8 \%$ mol $\mathrm{Y}_{2} \mathrm{O}_{3}$. Os pós foram analisados no equipamento Area-meter II Strohlein Instruments. Utilizando esses resultados e a equação 2.2.1 foi calculado o tamanho médio de partículas de cada pó.

$$
d=\frac{6}{\rho \cdot S}
$$

na qual d é o diâmetro médio da partícula $(\mathrm{m}), \rho$ é a densidade teórica do pó $\left(6,008 \cdot 10^{6}\right.$ $\left.\mathrm{g} / \mathrm{m}^{3}\right)[35]$ e $\mathrm{S}$ a área de superfície específica $\left(\mathrm{m}^{2} / \mathrm{g}\right)$.

Foram obtidas micrografias dos pós de $\mathrm{ZrO}_{2}: 8 \%$ mol $\mathrm{Y}_{2} \mathrm{O}_{3}$ e $\mathrm{ZrO}_{2}+8 \%$ mol $\mathrm{Y}_{2} \mathrm{O}_{3}$, utilizando-se microscópio eletrônico de transmissão Jeol JEM200C, para se avaliar a morfologia e tamanho médio de partículas. As micrografias foram obtidas de dispersões, em ultra-som por $7 \mathrm{~min}$, dos pós em água deionizada. No caso do pó preparado por mistura de óxidos $\left(\mathrm{ZrO}_{2}+8 \%\right.$ mol $\left.\mathrm{Y}_{2} \mathrm{O}_{3}\right)$ foi acrescentada à dispersão o defloculante pirofosfato de sódio. 


\subsection{PREPARAÇão dOS ELETRÓlitos SÓlidoS}

Os pós foram conformados em amostras cilíndricas, de diâmetro $10 \mathrm{~mm}$ e espessuras variando entre 3 e $12 \mathrm{~mm}$, por compactação uniaxial, em matriz de aço inoxidável, utilizando-se prensa Schulz, e compactação isostática, a frio, utilizando-se prensa National Forge, segundo o roteiro: pressão uniaxial de $30 \mathrm{MPa}$ para acomodação do pó na matriz, pressão uniaxial de $100 \mathrm{MPa}$, e pressão isostática de $200 \mathrm{MPa}$.

As amostras, com exceção daquelas usadas nas medidas de espectroscopia de impedância em função da temperatura/tempo de sinterização, foram sinterizadas, em forno resistivo Lindberg, a $1600{ }^{\circ} \mathrm{C} / 1 \mathrm{~h}$, ao ar, com taxa de aquecimento de $3{ }^{\circ} \mathrm{C} / \mathrm{min}$ e taxa de resfriamento de $10{ }^{\circ} \mathrm{C} / \mathrm{min}$. A navícula usada na sinterização foi fechada e revestida com pó de $\mathrm{ZrO}_{2}$, tomando-se o cuidado de posicionar a navícula de tal forma que o fluxo de calor fosse perpendicular à menor distância entre as extremidades e o centro das amostras. $\mathrm{Na}$ figura 2.3.1 é apresentado o fluxograma da seqüência experimental utilizada na preparação das amostras. 


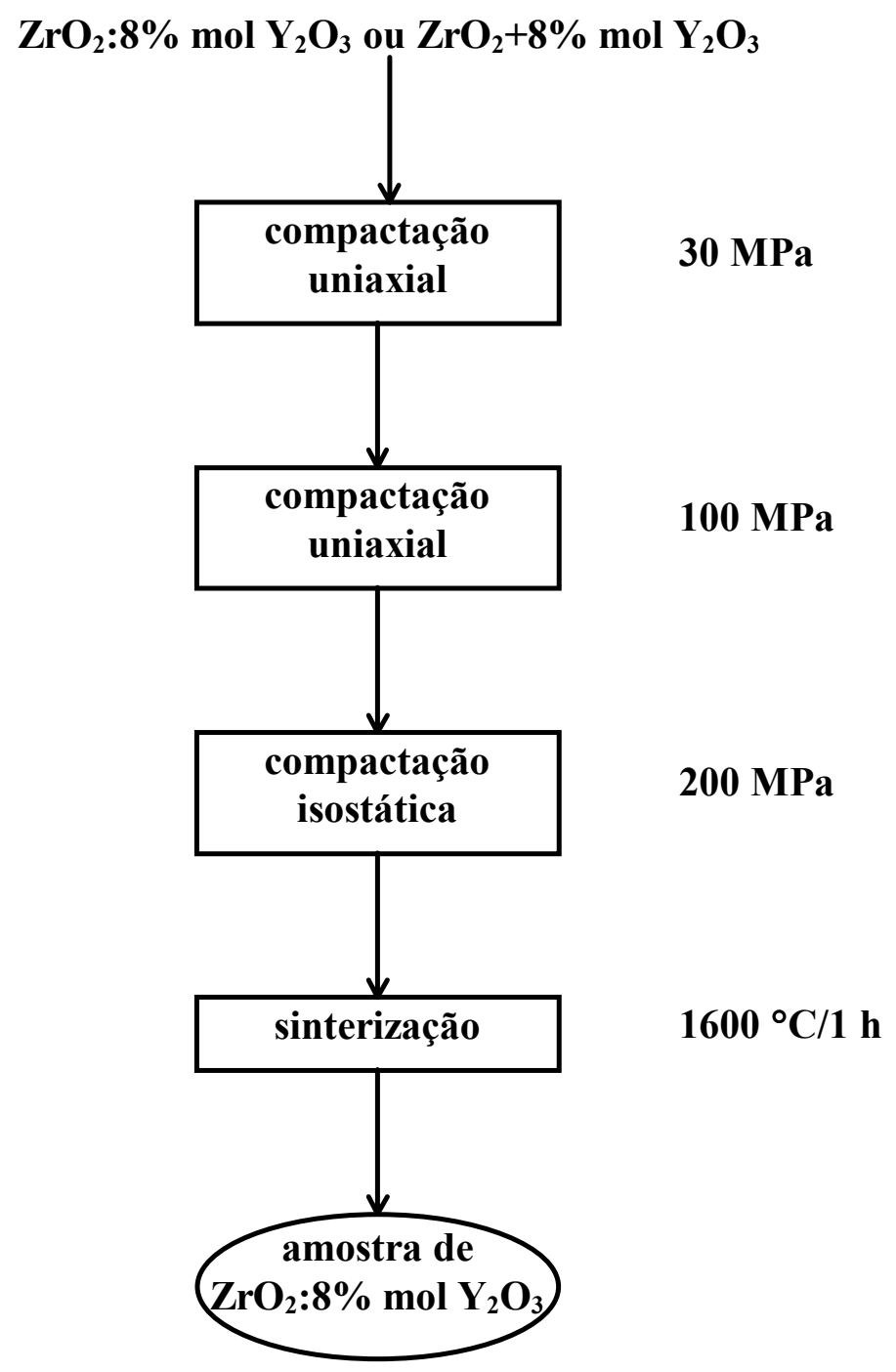

Figura 2.3.1: Seqüência experimental para a preparação das amostras de $\mathrm{ZrO}_{2}: 8 \%$ $\mathrm{mol} \mathrm{Y}_{2} \mathrm{O}_{3}$.

\subsection{CARACTERIZAÇÃo dOS ELETRÓLITOS SÓLIDOS}

Foram feitas medidas para se determinar a densidade a verde, e as densidades geométrica e hidrostática das amostras sinterizadas. 
Medidas de dilatometria foram feitas em amostras preparadas com os pós comercial e coprecipitado em dilatômetro Netzsch DIL402E/7, para se estimar as temperaturas a serem utilizadas nas medidas de espectroscopia de impedância durante a sinterização. No caso da amostra preparada com o pó comercial a medida foi feita até a temperatura de 1500 ${ }^{\circ} \mathrm{C}$ com taxa de aquecimento de $8{ }^{\circ} \mathrm{C} /$ min e taxa de resfriamento de $20{ }^{\circ} \mathrm{C} / \mathrm{min}$. Para a amostra preparada com o pó coprecipitado a medida foi feita até a temperatura de $1380{ }^{\circ} \mathrm{C}$ com taxa de aquecimento de $10{ }^{\circ} \mathrm{C} / \mathrm{min}$ e taxa de resfriamento de $20{ }^{\circ} \mathrm{C} / \mathrm{min}$.

Amostras preparadas com o pó obtido por mistura de óxidos foram sinterizadas, em forno resistivo Lindberg, com taxa de aquecimento de $3{ }^{\circ} \mathrm{C} / \mathrm{min}$ e taxa de resfriamento de $10{ }^{\circ} \mathrm{C} / \mathrm{min}$, variando-se a temperatura do patamar de sinterização. A faixa de temperatura foi de 1100 até $1500{ }^{\circ} \mathrm{C}$ durante $1 \mathrm{~h}$. Cada amostra foi colocada em navícula que foi fechada e revestida com pó de $\mathrm{ZrO}_{2}$, tomando-se o cuidado de posicionar a navícula de tal forma que o fluxo de calor fosse perpendicular à menor distância entre as extremidades e o centro das amostras. As densidades geométrica e hidrostática destas amostras foram determinadas.

Foram feitas análises de difração de raios $\mathrm{X}$, das amostras sinterizadas para se verificar a estabilização de fase. A faixa angular foi de $20^{\circ} \leq 2 \theta \leq 40^{\circ}$ e de $70^{\circ} \leq 2 \theta \leq 75$ ${ }^{\circ}$ com passo de $0,05^{\circ} 2 \theta / 5 \mathrm{~s}$. As análises foram feitas no difratômetro Philips PW3710 com radiação $\mathrm{k} \alpha$ do $\mathrm{Cu}$.

Superfícies de fratura das amostras foram recobertas com ouro depositado por "sputtering", utilizando-se equipamento Balzers Union SCD040, e observadas em microscópio eletrônico de varredura Philips XL30. Foram feitas micrografias dessas superfícies de fratura a fim de avaliar a microestrutura. 
Medidas de espectroscopia de impedância foram feitas em parte das amostras para a verificação de seu comportamento elétrico.

As faces paralelas da amostra preparada com o pó comercial foram polidas em carbeto de silício. Já as faces paralelas das amostras preparadas com os pós obtidos por coprecipitação dos hidróxidos e mistura de óxidos foram polidas em lixa 400. Nessas superfícies foram pintados eletrodos de platina (Demetron A308) ou prata (Degussa 200) coloidal que foram tratados termicamente a $800{ }^{\circ} \mathrm{C} / 15 \mathrm{~min}$ e $600{ }^{\circ} \mathrm{C} / 15 \mathrm{~min}$, respectivamente. Essas amostras foram montadas na câmara de medidas elétricas mostrada nas figuras 2.4.1 e 2.4.2.

As medidas de espectroscopia de impedância foram feitas na faixa de freqüência de $5 \mathrm{~Hz}$ a $13 \mathrm{MHz}$, em temperaturas entre 300 e $500{ }^{\circ} \mathrm{C}$ utilizando-se analisador de impedância HP4192A LF conectado a um controlador HP362 (figura 2.4.3) para coleta, armazenamento e processamento dos dados, executando um programa desenvolvido pelo Dr. M. Kleitz e pelo Dr. J. H. Kennedy para a Hydro Quebec Research Center, Canadá [28, 29]. A tensão aplicada na amostra foi $100 \mathrm{mV}$. Foram coletados 16 pontos experimentais para cada década de freqüência. A temperatura das amostras foi monitorada por um termopar tipo S conectado a um multímetro digital Fluke 8050A. 


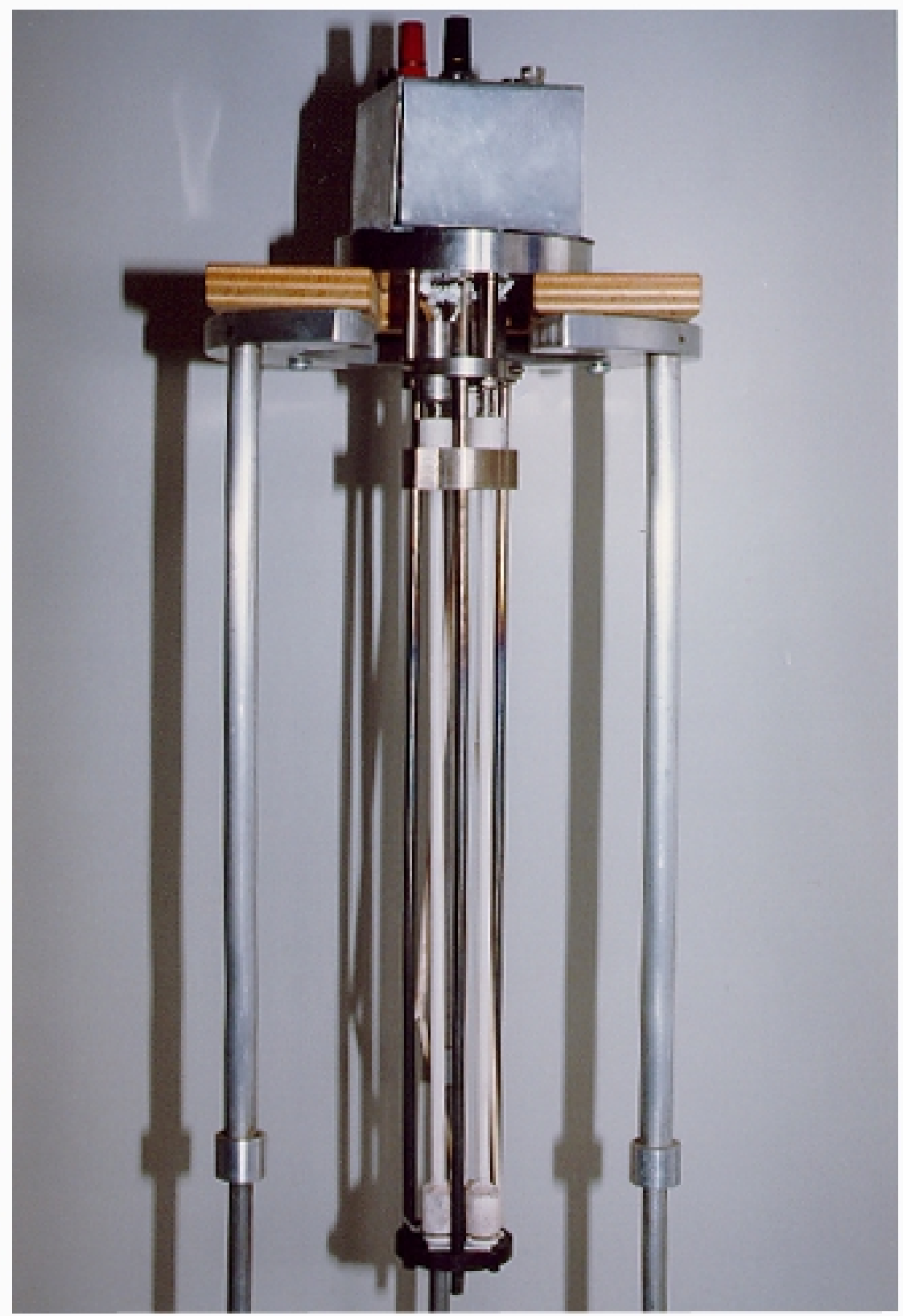

Figura 2.4.1: Câmara de medidas elétricas, feita em Inconel 600, para até três amostras. 


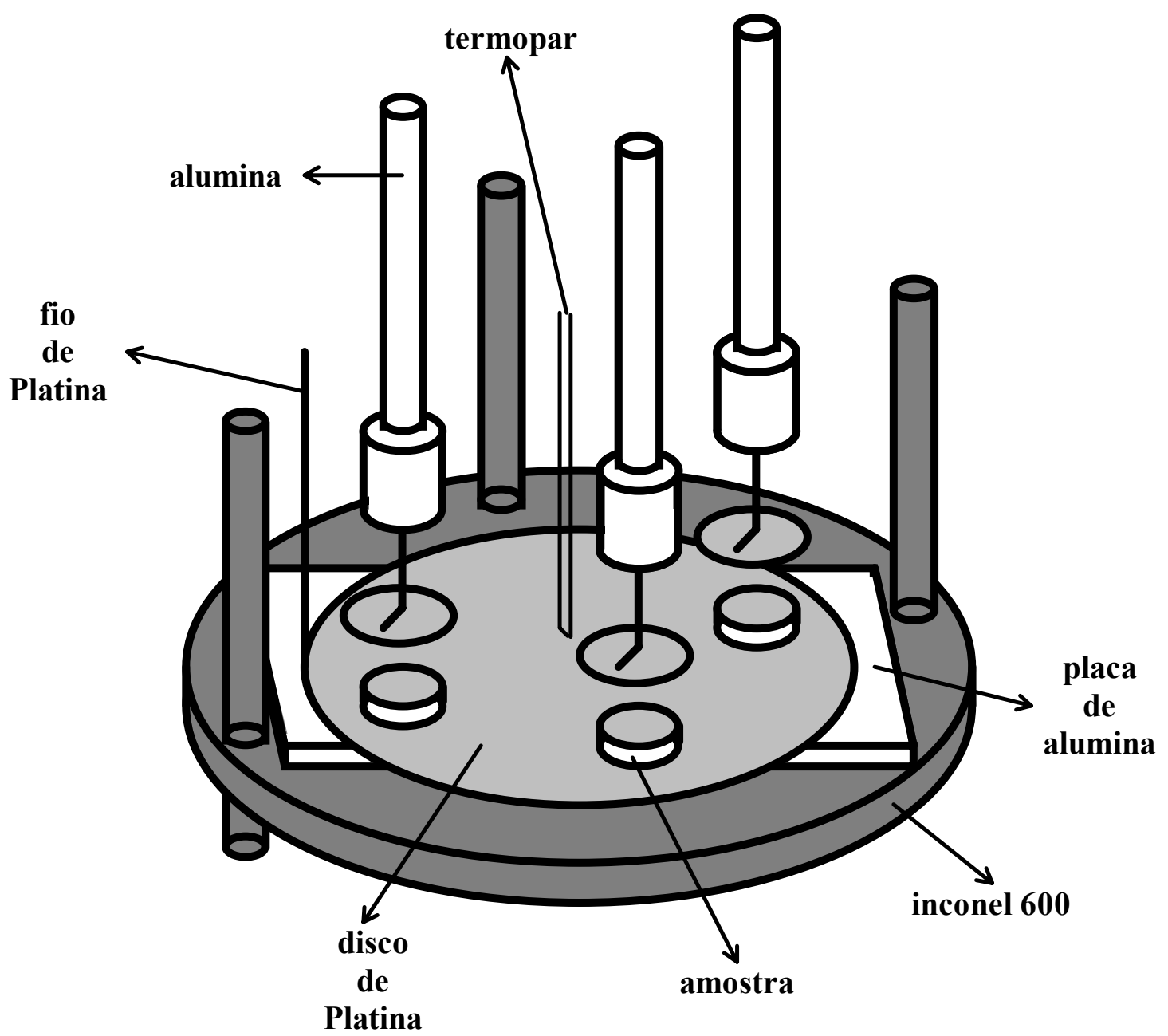

Figura 2.4.2: Detalhe do porta amostras da câmara de medidas elétricas. 


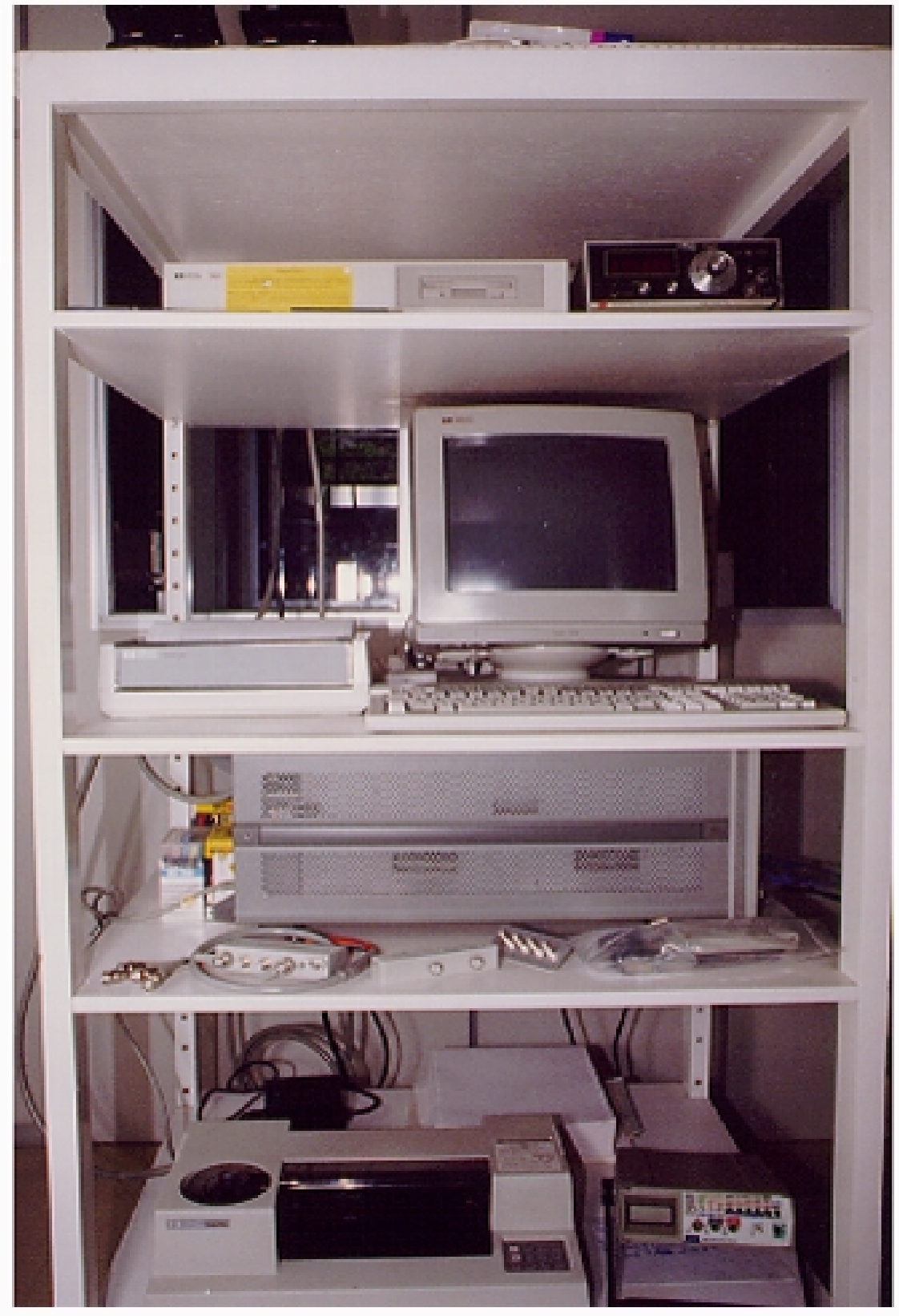

Figura 2.4.3: Sistema de medidas de espectroscopia de impedância: controlador HP362, monitor - impressora - teclado, analisador de impedância HP4192A LF, traçador gráfico - multímetro digital FLUKE 8050A (de cima para baixo). 


\subsection{ENVELHECIMENTO TÉRMICO}

Amostras de $\mathrm{ZrO}_{2}: 8 \%$ mol $\mathrm{Y}_{2} \mathrm{O}_{3}$ foram submetidas a envelhecimento térmico a 600 ${ }^{\circ} \mathrm{C}$ durante 2000 h. As amostras foram montadas em câmara de medidas elétricas, feita com tubos de alumina e fios de platina, e esse conjunto foi colocado em forno resistivo tubular vertical. Em intervalos de tempo convenientes, medidas de espectroscopia de impedância foram feitas nessas amostras em temperaturas de aproximadamente 400 e $600{ }^{\circ} \mathrm{C}$ como mostrado na figura 2.5.1. A temperatura das amostras foi monitorada com um termopar tipo K ligado a um multímetro digital Simpson 461.

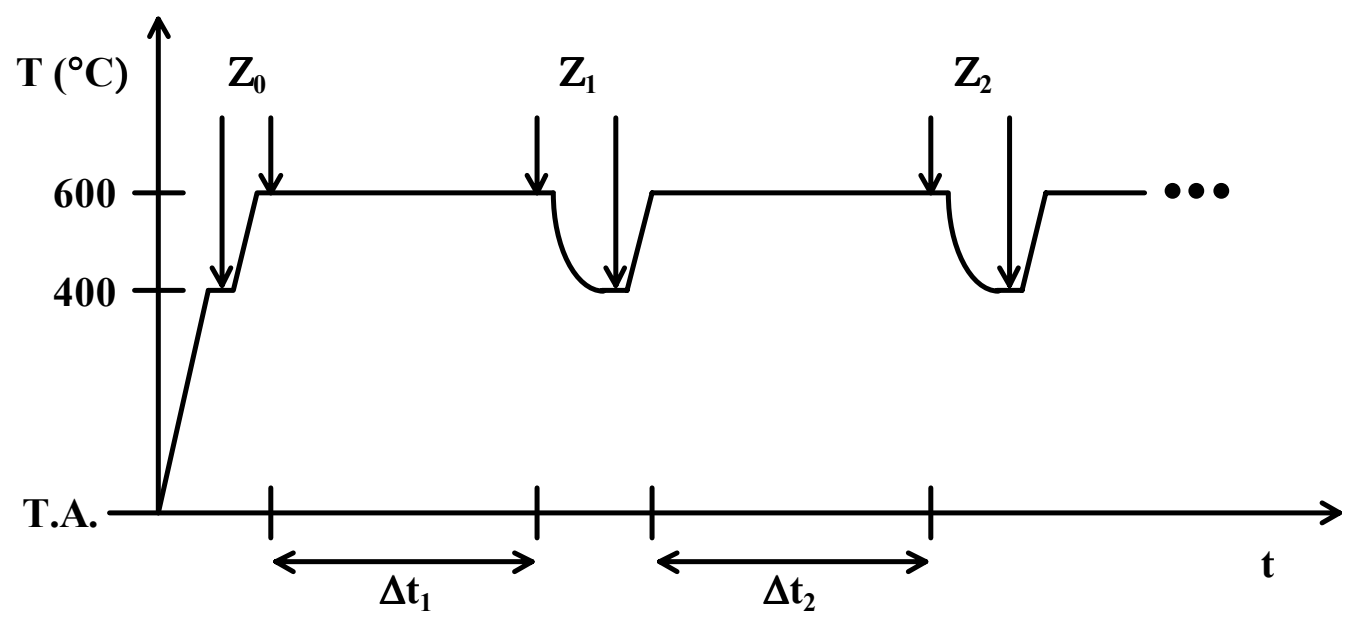

Figura 2.5.1: Perfis de temperatura e roteiro para a obtenção das medidas de espectroscopia de impedância durante o envelhecimento térmico das amostras de $\mathrm{ZrO}_{2}: 8 \%$ $\mathrm{mol}_{2} \mathrm{O}_{3}$.

Esse tratamento térmico e as medidas de espectroscopia de impedância foram repetidos por intervalos de tempo até $200 \mathrm{~h}$ em amostra preparada com o pó obtido por mistura de óxidos para comparação dos resultados. 
Ao término das $2000 \mathrm{~h}$ de envelhecimento térmico foram feitas medidas de difração de raios $\mathrm{X}$ e também foram obtidas micrografias das superfícies de fratura das amostras para se observar possíveis diferenças antes e depois do envelhecimento térmico.

Utilizando-se as relações 2.5.1 e 2.5.2 determinou-se a razão entre as intensidades das raias de difração das fases cúbica e monoclínica $\left(X_{m}\right)$ e calculou-se a fração volumétrica de fase monoclínica presente, quando esta foi detectável.

$$
X_{m}=\frac{I_{m}(\overline{1} 11)+I_{m}(111)}{I_{m}(\overline{1} 11)+I_{m}(111)+I_{c}(111)}
$$

e:

$$
\mathrm{v}_{\mathrm{m}}=\frac{\mathrm{P} \cdot \mathrm{X}_{\mathrm{m}}}{1+(\mathrm{P}-1) \mathrm{X}_{\mathrm{m}}}
$$

nas quais $\mathrm{I}_{\mathrm{m}, \mathrm{c}}(h k l)$ são as intensidades lidas diretamente do difratograma de raios $\mathrm{X}$ e $\mathrm{P}=$ $1,306[36-44]$.

\subsection{ESPECTROSCOPIA DE IMPEDÂNCIA E SINTERIZAÇÃO}

As medidas de espectroscopia de impedância em função da temperatura de sinterização foram feitas em amostras preparadas com os pós comercial e obtido por coprecipitação dos hidróxidos. Nas faces paralelas das amostras foram pintados eletrodos de platina (Demetron A308) coloidal, que foram tratados termicamente a $800{ }^{\circ} \mathrm{C}$, com taxa de aquecimento de $10{ }^{\circ} \mathrm{C} / \mathrm{min}$ e resfriamento ao ar, em forno resistivo tubular Lindberg. As 
amostras foram montadas em câmara horizontal de medidas elétricas como é mostrado na figura 2.6.1. Esse sistema foi introduzido em forno resistivo tubular Lindberg e os terminais da câmara (fios de platina) conectados ao analisador de impedância HP4192A LF.

As medidas de espectroscopia de impedância foram feitas entre $5 \mathrm{~Hz}$ e $13 \mathrm{MHz}$ na temperatura de aproximadamente $400{ }^{\circ} \mathrm{C}$. Foram feitas no mínimo 3 medidas para cada ciclo de sinterização. As medidas iniciais foram efetuadas com a coleta de 5 pontos experimentais para cada década de freqüência. A medida final de cada ciclo foi efetuada com 16 pontos experimentais para cada década de freqüência. A tensão aplicada na amostra foi $100 \mathrm{mV}$.

O ciclo de sinterização seguiu o roteiro: a câmara horizontal de medidas elétricas foi aquecida a $10{ }^{\circ} \mathrm{C} / \mathrm{min}$ até a temperatura de medida $\left(400{ }^{\circ} \mathrm{C}\right)$, a qual era mantida por 12 min, tempo suficiente para minimizar o gradiente térmico na amostra e executar as medidas de impedância; então, a câmara era novamente aquecida, com a mesma taxa, até uma temperatura entre 800 e $1350{ }^{\circ} \mathrm{C}$; a seguir, era resfriada, seguindo a inércia térmica do forno até a temperatura ambiente, quando o ciclo era reiniciado (figura 2.6.2). O mesmo procedimento foi adotado variando-se o tempo na temperatura de $1350{ }^{\circ} \mathrm{C}$. O intervalo de tempo estudado foi até 3,7 h (figura 2.6.3). 


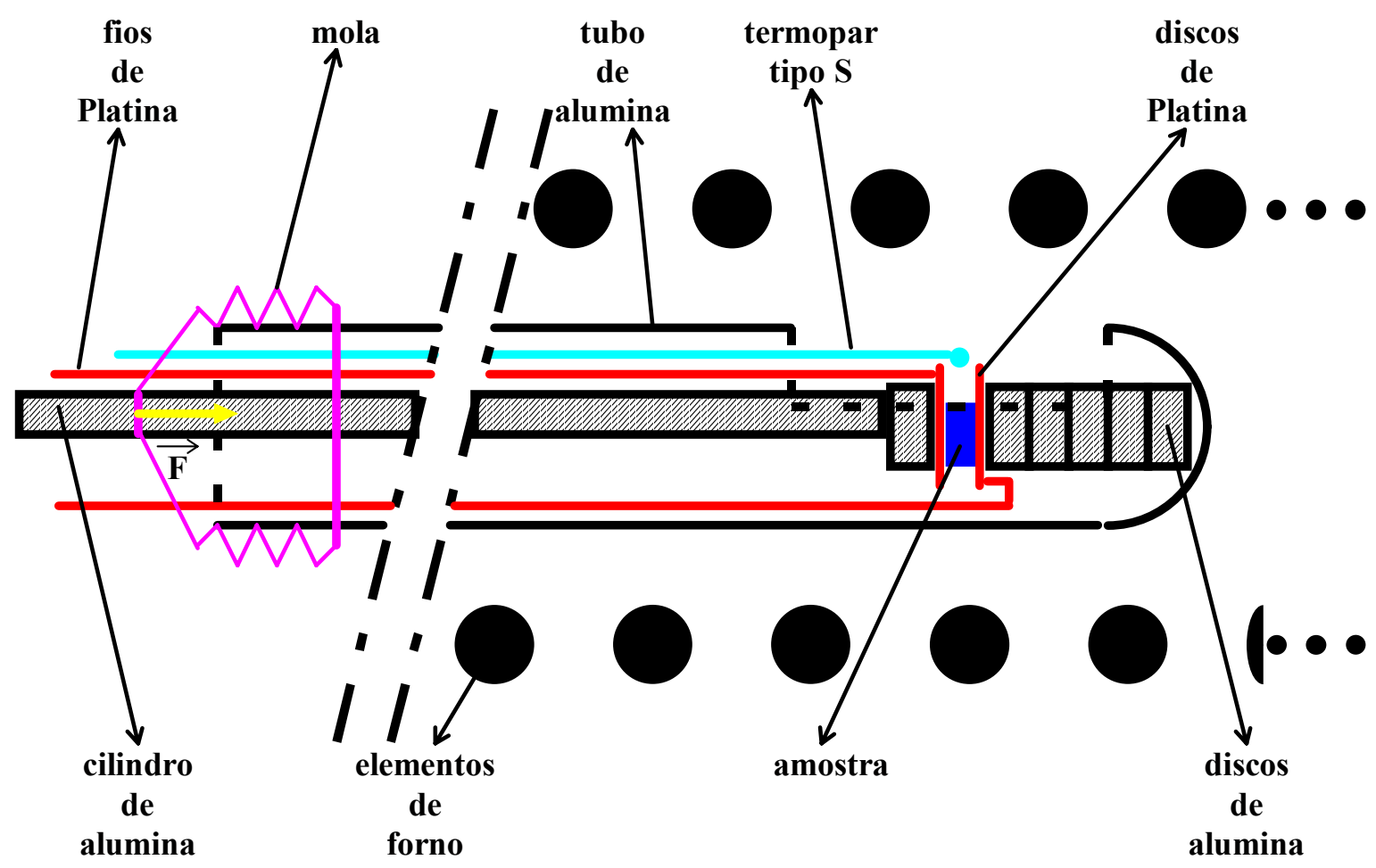

Figura 2.6.1: Câmara utilizada nas medidas de espectroscopia de impedância durante a sinterização.

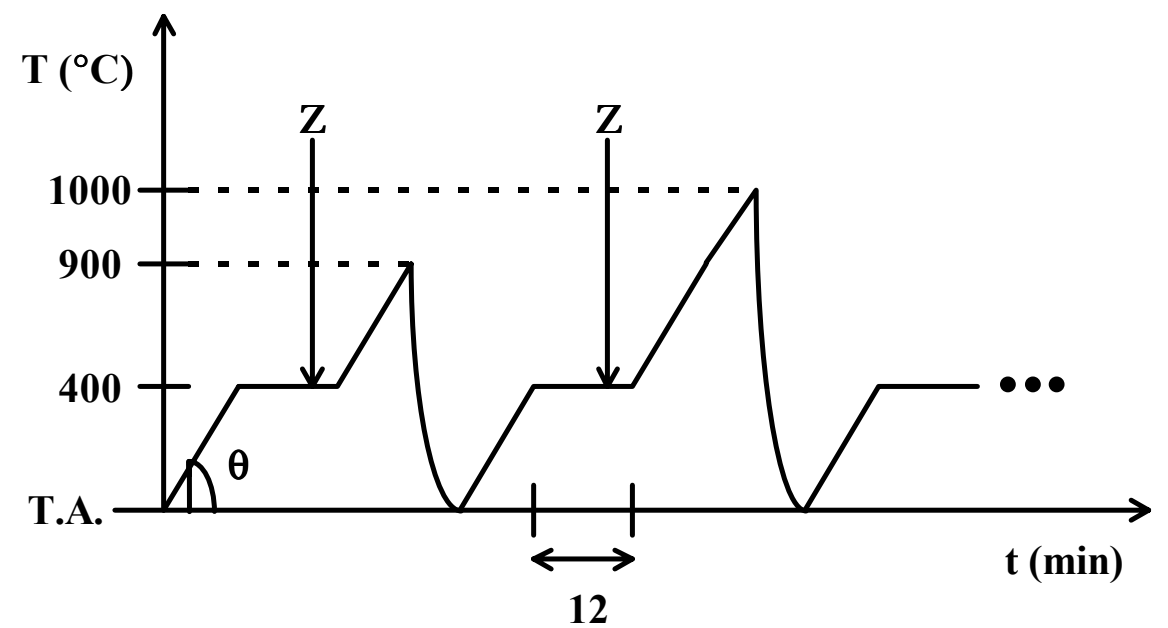

Figura 2.6.2: Perfis de temperatura e roteiro para a obtenção das medidas de espectroscopia de impedância durante a sinterização das amostras de $\mathrm{ZrO}_{2}: 8 \%$ mol $\mathrm{Y}_{2} \mathrm{O}_{3}$ em função da temperatura de sinterização. 


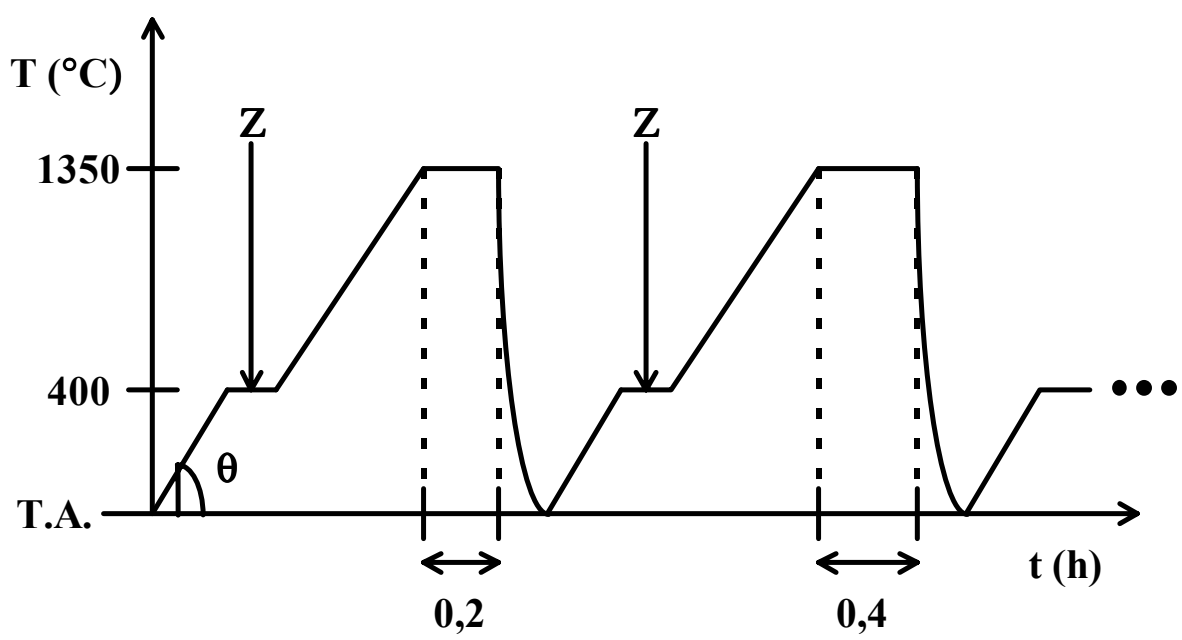

Figura 2.6.3: Perfis de temperatura e roteiro para a obtenção das medidas de espectroscopia de impedância durante a sinterização das amostras de $\mathrm{ZrO}_{2}: 8 \%$ mol $\mathrm{Y}_{2} \mathrm{O}_{3}$ em função do tempo de sinterização na temperatura de $1350{ }^{\circ} \mathrm{C}$.

Superfícies de fratura e superfícies polidas de amostras sinterizadas simultaneamente à realização das medidas de espectroscopia de impedância, foram observadas em microscópio eletrônico de varredura, na tentativa de se estimar a evolução dos tamanhos médios de grão dessas amostras em função do tempo de sinterização a 1350 ${ }^{\circ} \mathrm{C}$. As superfícies polidas das amostras foram obtidas embutindo-se as mesmas em resina epoxi. Esse conjunto era previamente retificado em carbeto de silício e polido sucessivamente em pasta de diamante de $15 \mu \mathrm{m}, 6 \mu \mathrm{m}$ e $1 \mu \mathrm{m}$. Entre cada troca de pasta de polimento, o conjunto foi limpo em ultra-som por 2 min e seco com ar quente por $15 \mathrm{~min}$; a seguir essas amostras foram tratadas termicamente a $1250{ }^{\circ} \mathrm{C} / 0,5 \mathrm{~h}$ com têmpera, e as superfícies polidas recobertas com ouro depositado por "sputtering". 


\subsection{MOAGEM DO PÓ DE ZIRCÔNIA - IPEN}

A moagem do pó de $\mathrm{ZrO}_{2}$-IPEN resultou em uma efetiva redução, de aproximadamente $11 \mu \mathrm{m}$ para aproximadamente $1 \mu \mathrm{m}$, do tamanho médio de partículas, ou de aglomerados, como mostra a figura 3.1.1.

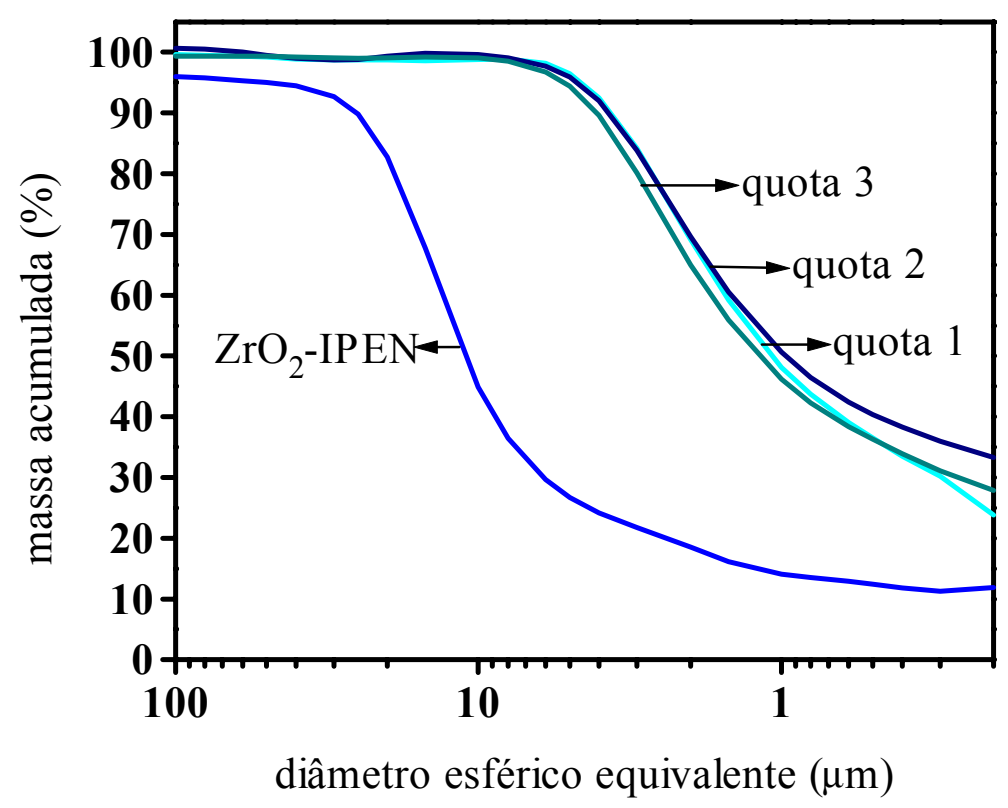

Figura 3.1.1: Distribuição do tamanho de partículas, ou de aglomerados, por sedimentação com raios $\mathrm{X}$ do pó de $\mathrm{ZrO}_{2}$-IPEN, antes e depois da moagem. 


\subsection{CARACTERIZAÇÃo dOS PÓS}

Os resultados das análises de espectrografia de emissão semiquantitativa dos pós de $\mathrm{ZrO}_{2}: \mathrm{Y}_{2} \mathrm{O}_{3}$ comercial e coprecipitado e do pó de $\mathrm{ZrO}_{2}+\mathrm{Y}_{2} \mathrm{O}_{3}$ obtido por mistura de óxidos são apresentados nas tabelas 3.2.1 a 3.2.3. Podemos notar que todos os pós têm o mesmo teor de impurezas, com exceção do teor de Si no pó comercial, o qual possui aproximadamente um quarto do teor de Si dos outros pós.

Na tabela 3.2.4 são mostrados os teores de $\mathrm{Y}_{2} \mathrm{O}_{3}$ dos pós utilizados na preparação das amostras, calculados a partir dos resultados das medidas obtidas pela técnica de espectrometria de fluorescência de raios $\mathrm{X}$ por dispersão de comprimento de onda. Podemos notar que a amostra obtida pela rota química (coprecipitação dos hidróxidos) apresenta o maior desvio em relação a composição nominal $(8 \% \mathrm{~mol})$ de $\mathrm{Y}_{2} \mathrm{O}_{3}$ dos pós.

Na figura 3.2.1 o valor de condutividade do grão das amostras na temperatura de, aproximadamente, $400{ }^{\circ} \mathrm{C}$, é mostrado em função do teor de $\mathrm{Y}_{2} \mathrm{O}_{3}$ encontrado na tabela 3.2.4. Podemos notar que a amostra preparada com o pó obtido por mistura de óxidos apresenta o valor de condutividade do grão aproximadamente igual ao valor obtido para a amostra coprecipitada. Supondo que o teor de ítrio determinado por fluorescência de raios $\mathrm{X}$ esteja correto, esse resultado sugere que nem todos os $\mathrm{Y}^{3+}$ formaram solução sólida substitucional, já que era de se esperar que amostras com maiores teores de dopante, nesta faixa de concentração, fossem menos condutoras [3, 45].

A caracterização de fases dos pós foi feita por difração de raios X. Nas amostras comercial e coprecipitada foram identificadas as raias pertencentes à estrutura cúbica do $\mathrm{ZrO}_{2}$ (figuras 3.2.2 a 3.2.4). O resultado da medida de difração de raios X para a amostra 
preparada por mistura de óxidos não é apresentado pois este não é constituído de zircônia estabilizada.

Tabela 3.2.1: Teor de impurezas no pó de $\mathrm{ZrO}_{2}: \mathrm{Y}_{2} \mathrm{O}_{3}$ comercial.

\begin{tabular}{|c|c|}
\hline elemento & teor $(\%)$ \\
\hline $\mathrm{B}$ & $<0,003$ \\
\hline $\mathrm{P}$ & $<0,15$ \\
\hline $\mathrm{Fe}$ & $<0,0075$ \\
\hline $\mathrm{Cr}$ & $<0,0045$ \\
\hline $\mathrm{Ni}$ & $<0,0045$ \\
\hline $\mathrm{Zn}$ & $<0,15$ \\
\hline $\mathrm{Si}$ & 0,006 \\
\hline $\mathrm{Al}$ & $<0,006$ \\
\hline $\mathrm{Mn}$ & $<0,0015$ \\
\hline $\mathrm{Mg}$ & $<0,0045$ \\
\hline $\mathrm{Pb}$ & $<0,0045$ \\
\hline $\mathrm{Sn}$ & $<0,003$ \\
\hline $\mathrm{Bi}$ & $<0,0015$ \\
\hline V & $<0,003$ \\
\hline $\mathrm{Cu}$ & $<0,0045$ \\
\hline $\mathrm{Ba}$ & $<0,015$ \\
\hline Co & $<0,0045$ \\
\hline $\mathrm{Ca}$ & $<0,0075$ \\
\hline $\mathrm{Sb}$ & $<0,0045$ \\
\hline
\end{tabular}


Tabela 3.2.2: Teor de impurezas no pó de $\mathrm{ZrO}_{2}: \mathrm{Y}_{2} \mathrm{O}_{3}$ coprecipitado.

\begin{tabular}{|c|c|}
\hline elemento & teor $(\%)$ \\
\hline B & $<0,003$ \\
\hline $\mathrm{P}$ & $<0,15$ \\
\hline $\mathrm{Fe}$ & $<0,0075$ \\
\hline $\mathrm{Cr}$ & $<0,0045$ \\
\hline $\mathrm{Ni}$ & $<0,0045$ \\
\hline $\mathrm{Zn}$ & $<0,15$ \\
\hline $\mathrm{Si}$ & 0,02 \\
\hline $\mathrm{Al}$ & $<0,006$ \\
\hline Mn & $<0,0015$ \\
\hline $\mathrm{Mg}$ & $<0,0045$ \\
\hline $\mathrm{Pb}$ & $<0,0045$ \\
\hline $\mathrm{Sn}$ & $<0,003$ \\
\hline $\mathrm{Bi}$ & $<0,0015$ \\
\hline $\mathrm{V}$ & $<0,003$ \\
\hline $\mathrm{Cu}$ & $<0,0045$ \\
\hline $\mathrm{Ba}$ & $<0,015$ \\
\hline $\mathrm{Co}$ & $<0,0045$ \\
\hline $\mathrm{Ca}$ & $<0,0075$ \\
\hline $\mathrm{Sb}$ & $<0,0045$ \\
\hline
\end{tabular}


Tabela 3.2.3: Teor de impurezas no pó de $\mathrm{ZrO}_{2}+\mathrm{Y}_{2} \mathrm{O}_{3}$ obtido por mistura de óxidos.

\begin{tabular}{|c|c|}
\hline elemento & teor $(\%)$ \\
\hline B & $<0,003$ \\
\hline $\mathrm{P}$ & $<0,15$ \\
\hline $\mathrm{Fe}$ & $<0,0075$ \\
\hline $\mathrm{Cr}$ & $<0,0045$ \\
\hline $\mathrm{Ni}$ & $<0,0045$ \\
\hline $\mathrm{Zn}$ & $<0,15$ \\
\hline $\mathrm{Si}$ & 0,02 \\
\hline $\mathrm{Al}$ & $<0,006$ \\
\hline $\mathrm{Mn}$ & $<0,0015$ \\
\hline $\mathrm{Mg}$ & $<0,0045$ \\
\hline $\mathrm{Pb}$ & $<0,0045$ \\
\hline $\mathrm{Sn}$ & $<0,003$ \\
\hline $\mathrm{Bi}$ & $<0,0015$ \\
\hline $\mathrm{V}$ & $<0,003$ \\
\hline $\mathrm{Cu}$ & $<0,0045$ \\
\hline $\mathrm{Ba}$ & $<0,015$ \\
\hline $\mathrm{Co}$ & $<0,0045$ \\
\hline $\mathrm{Ca}$ & $<0,0075$ \\
\hline $\mathrm{Sb}$ & $<0,0045$ \\
\hline
\end{tabular}

Tabela 3.2.4: Teores de $\mathrm{Y}_{2} \mathrm{O}_{3}$ nos pós cerâmicos de $\mathrm{ZrO}_{2}: \mathrm{Y}_{2} \mathrm{O}_{3}$ (8\% mol nominal) calculados a partir dos resultados das medidas obtidas pela técnica de espectrometria de fluorescência de raios X por dispersão de comprimento de onda.

\begin{tabular}{ccc}
\hline material & $\%{\mathrm{~mol} \mathrm{de} \mathrm{Y}_{2} \mathrm{O}_{3} \text { (nominal) }}$ & $\% \mathrm{~mol} \mathrm{de} \mathrm{Y}_{2} \mathrm{O}_{3}(\mathrm{FRX})$ \\
\hline comercial & 8,00 & $8,24 \pm 0,08$ \\
coprecipitado & 8,00 & $9,75 \pm 0,06$ \\
mistura de óxidos & 8,00 & $8,91 \pm 0,03$ \\
\hline
\end{tabular}




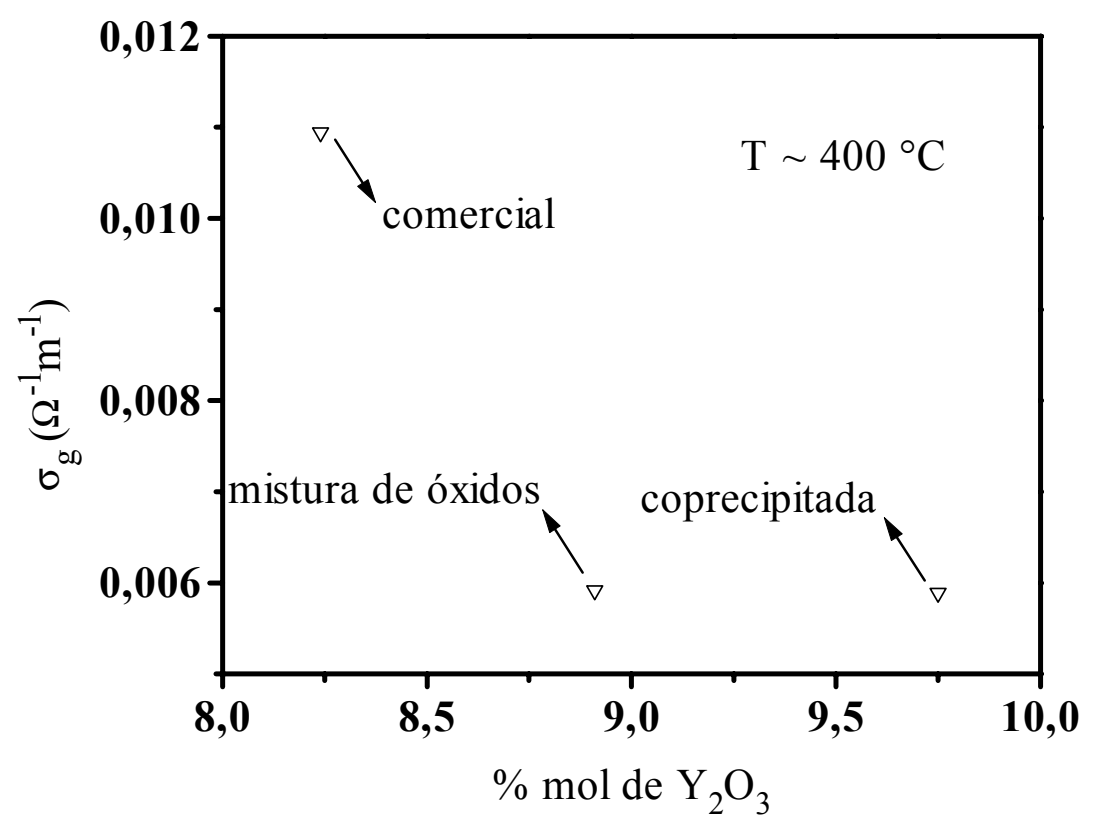

Figura 3.2.1: Condutividade do grão das amostras de $\mathrm{ZrO}_{2}: \mathrm{Y}_{2} \mathrm{O}_{3}(8 \%$ mol nominal) em função do teor de $\mathrm{Y}_{2} \mathrm{O}_{3}$.

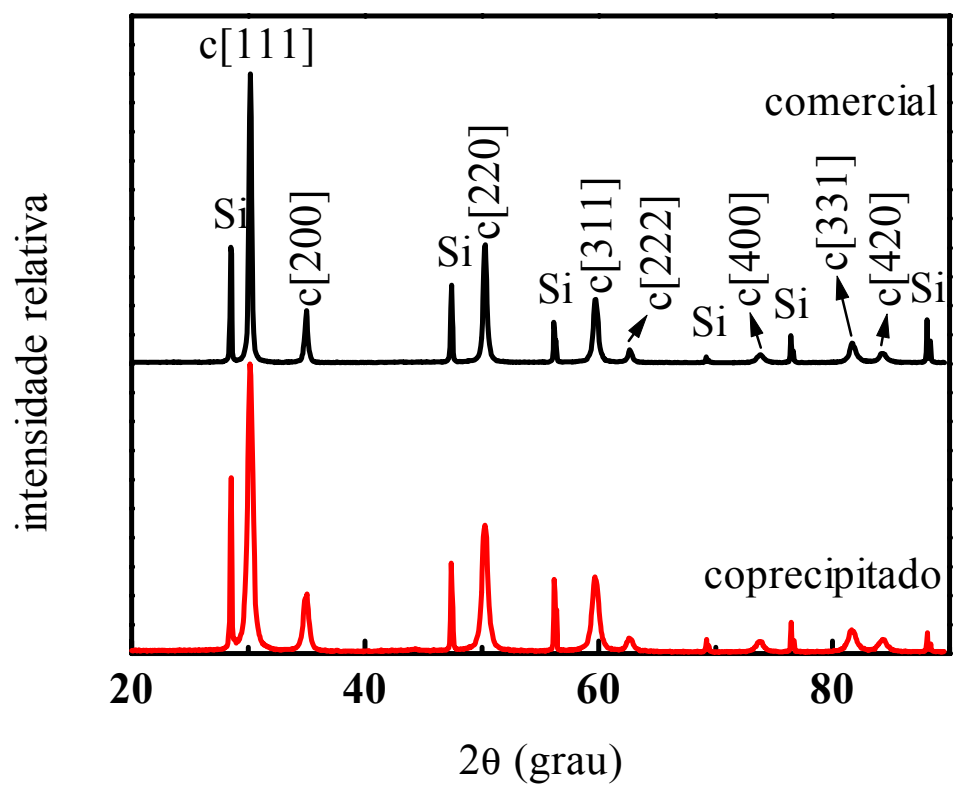

Figura 3.2.2: Difratograma de raios $\mathrm{X}$ dos pós comercial e coprecipitado de $\mathrm{ZrO}_{2}: 8 \%$ mol $\mathrm{Y}_{2} \mathrm{O}_{3}$ mostrando a estrutura cúbica da zircônia. 


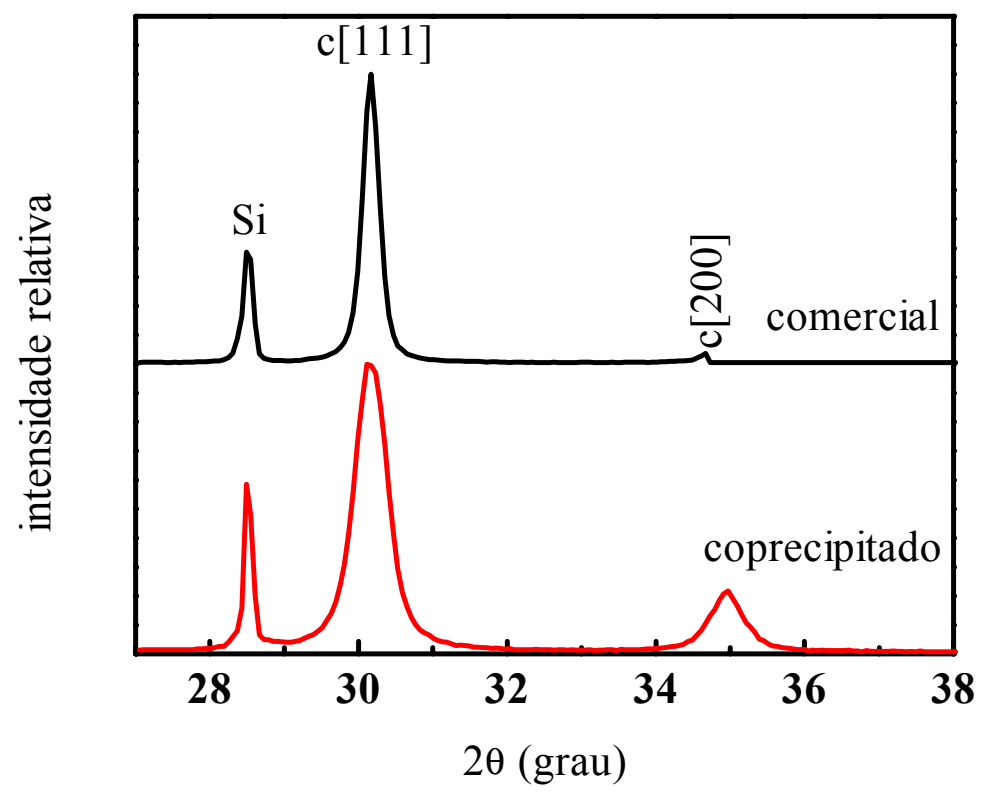

Figura 3.2.3: Difratograma de raios $\mathrm{X}$ dos pós comercial e coprecipitado de $\mathrm{ZrO}_{2}: 8 \% \mathrm{~mol} \mathrm{Y}_{2} \mathrm{O}_{3}$ mostrando a estrutura cúbica da zircônia (detalhe da figura 3.2.2).

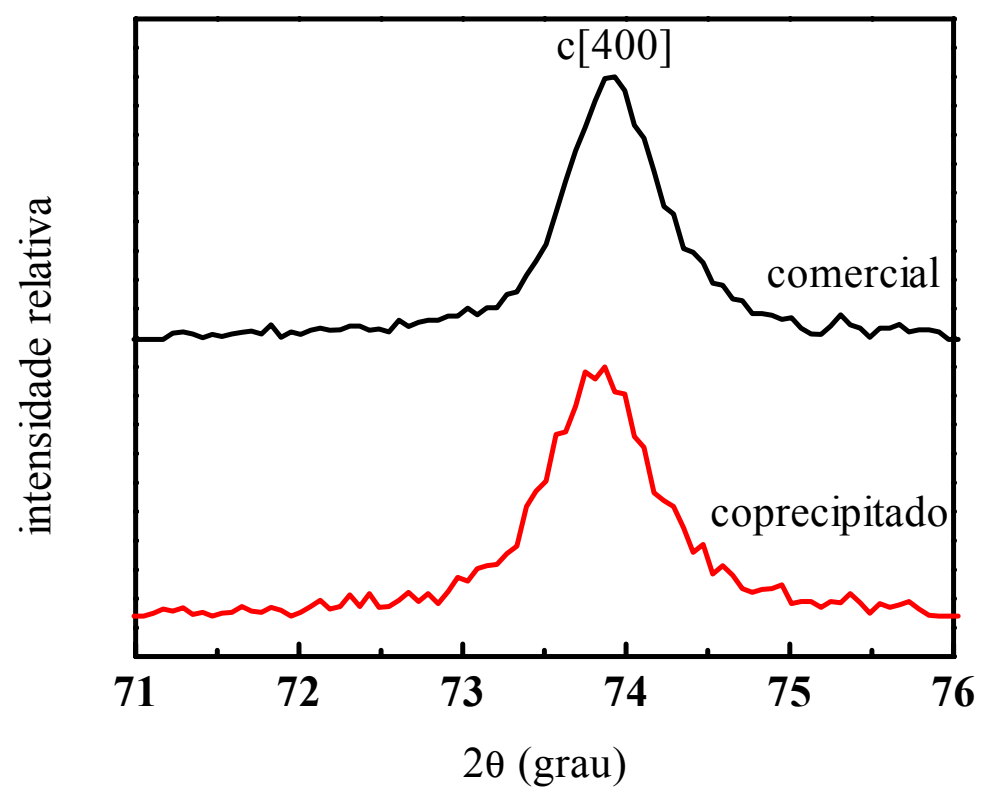

Figura 3.2.4: Difratograma de raios $\mathrm{X}$ dos pós comercial e coprecipitado de $\mathrm{ZrO}_{2}: 8 \%$ mol $\mathrm{Y}_{2} \mathrm{O}_{3}$ mostrando a estrutura cúbica da zircônia (detalhe da figura 3.2.2). 
Os parâmetros de rede das estruturas cúbicas dos pós de $\mathrm{ZrO}_{2}: 8 \%$ mol $\mathrm{Y}_{2} \mathrm{O}_{3}$ foram calculados usando-se o programa AFI e comparados com seus valores esperados y (nm), determinados a partir da relação linear [46]:

$$
y=0,5114+0,000283 \cdot x
$$

na qual x é o teor de $\mathrm{Y}_{2} \mathrm{O}_{3}$ em \% mol. Os teores de $\mathrm{Y}_{2} \mathrm{O}_{3}$ apresentados na tabela 3.2.4 foram utilizados nesses cálculos.

Estes resultados são apresentados na tabela 3.2.5. Os valores calculados apresentam concordância de até duas casas decimais com os valores esperados.

Tabela 3.2.5: Valores dos parâmetros de rede das estruturas cúbicas das zircônias identificadas nas figuras 3.2.2 a 3.2.4.

\begin{tabular}{ccc}
\hline material & \multicolumn{2}{c}{ parâmetro de rede $(\AA)$} \\
\cline { 2 - 3 } & valor calculado & valor esperado \\
\hline comercial & 5,139 & $5,1373 \pm 0,0002$ \\
coprecipitado & 5,144 & $5,1416 \pm 0,0002$ \\
\hline
\end{tabular}

Os resultados das análises para determinação do tamanho de partículas, ou de aglomerados, por sedimentação (raios X e LASER) são mostrados nas figuras 3.2.5 e 3.2.6, respectivamente. 


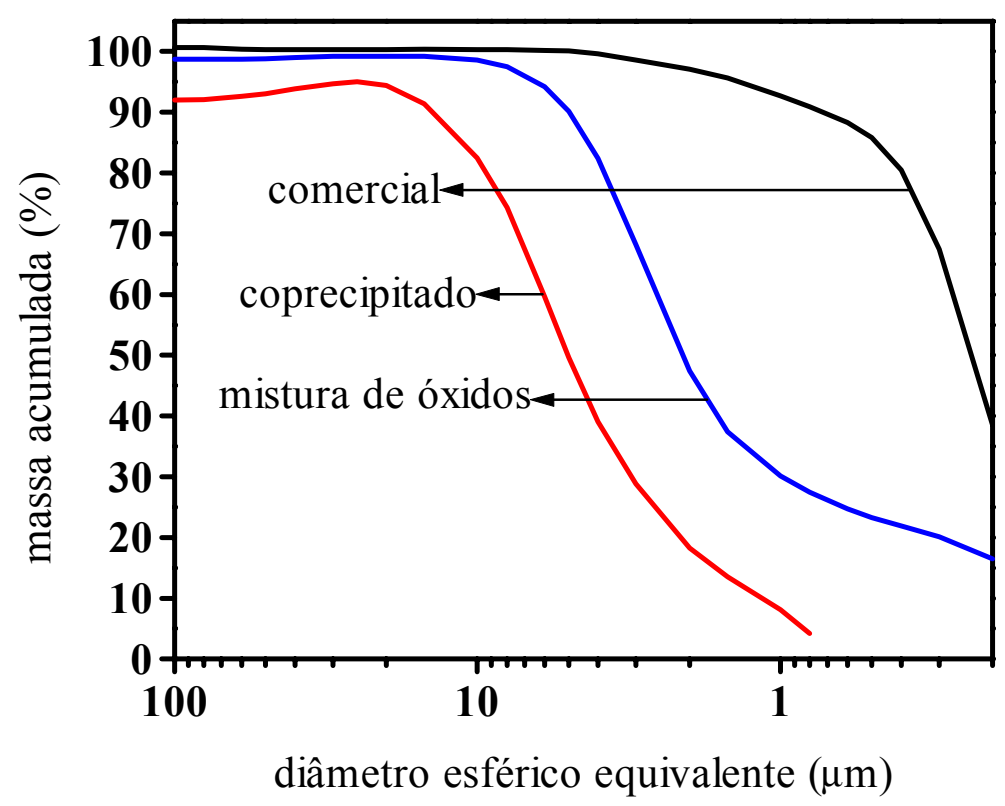

Figura 3.2.5: Distribuição do tamanho de partículas, ou de aglomerados, por sedimentação (raios X) dos pós utilizados na preparação das amostras.

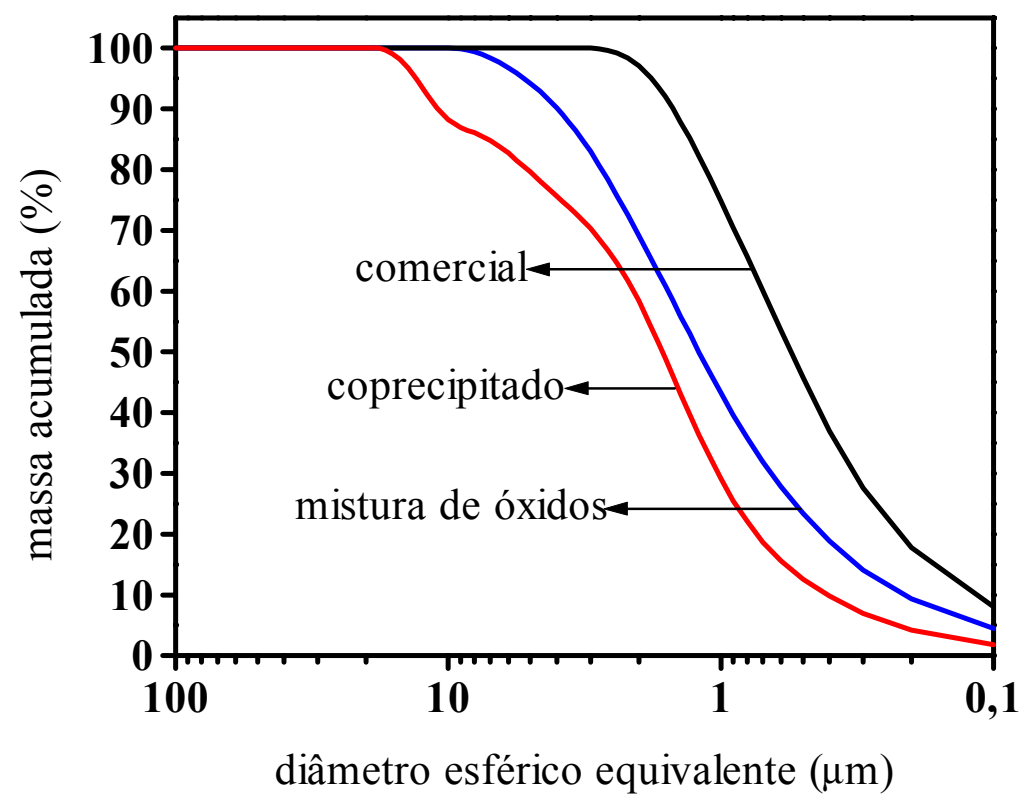

Figura 3.2.6: Distribuição do tamanho de partículas, ou de aglomerados, por sedimentação (LASER) dos pós utilizados na preparação das amostras. 
Os resultados das medidas, pelo método de BET, da área de superfície específica das partículas (S) são mostrados na tabela 3.2.6. Também são apresentados os valores obtidos para o diâmetro médio da partícula (d) calculados a partir dos valores obtidos para S.

Tabela 3.2.6: Valores da área de superfície específica e diâmetro médio da partícula dos pós utilizados na preparação das amostras.

\begin{tabular}{ccc}
\hline material & $\mathrm{S}\left(\mathrm{m}^{2} / \mathrm{g}\right)$ & $\mathrm{d}(\mu \mathrm{m})$ \\
\hline comercial & 8,40 & 0,12 \\
coprecipitada & 42,94 & 0,023 \\
mistura de óxidos & 35,82 & 0,028 \\
\hline
\end{tabular}

As micrografias das dispersões dos pós (figuras 3.2.7 a 3.2.9) mostram que estes são compostos por partículas submicrométricas e que os tamanhos de partícula observados na microscopia são concordantes com os valores determinados a partir dos resultados de BET. Esses tamanhos de partícula se encontram fora, ou no limite, da faixa de medida dos equipamentos de sedigrafia $(0,18-300 \mu \mathrm{m}$, raios $\mathrm{X}$ e $0,1-500 \mu \mathrm{m}$, LASER); dessa forma os resultados apresentados pelas medidas de sedimentação devem se referir ao tamanho médio de aglomerados de partículas dos pós.

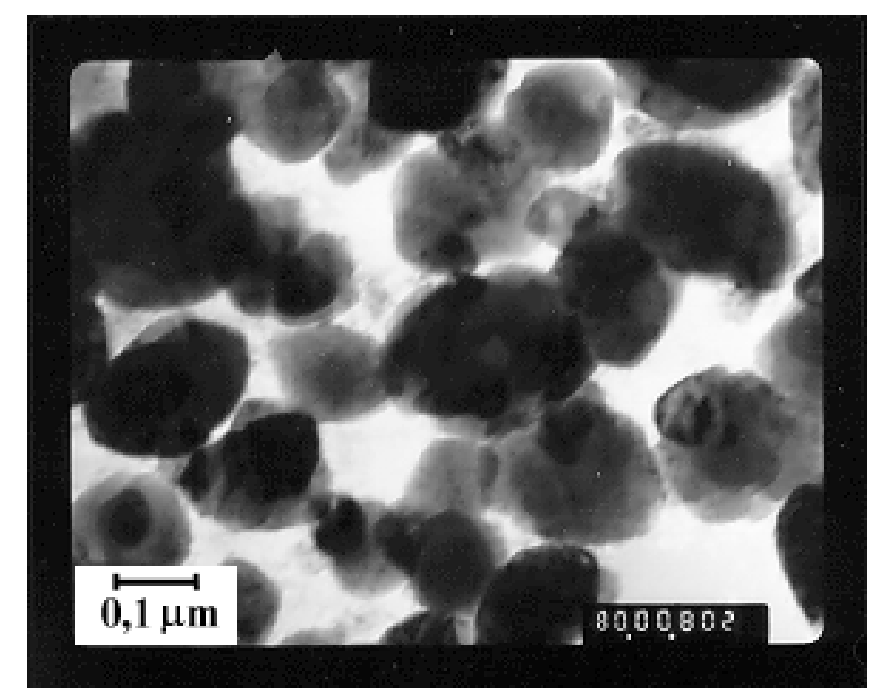

Figura 3.2.7: Micrografia obtida por microscopia eletrônica de transmissão do pó de $\mathrm{ZrO}_{2}: 8 \%$ mol $\mathrm{Y}_{2} \mathrm{O}_{3}$ comercial utilizado na preparação das amostras. 


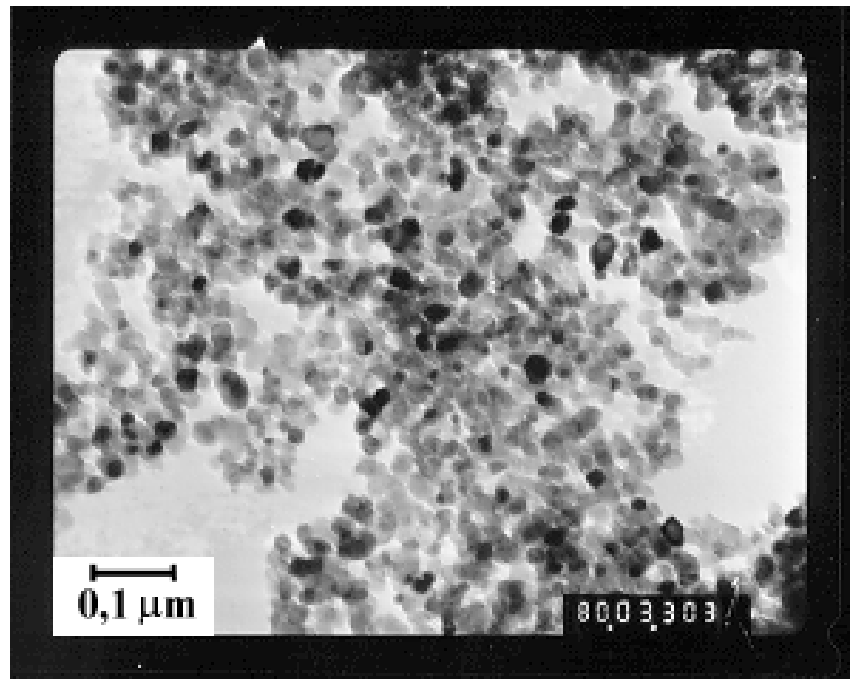

Figura 3.2.8: Micrografia obtida por microscopia eletrônica de transmissão do pó $\mathrm{ZrO}_{2}: 8 \%$ mol $\mathrm{Y}_{2} \mathrm{O}_{3}$ obtido por coprecipitação do hidróxidos utilizado na preparação das amostras.

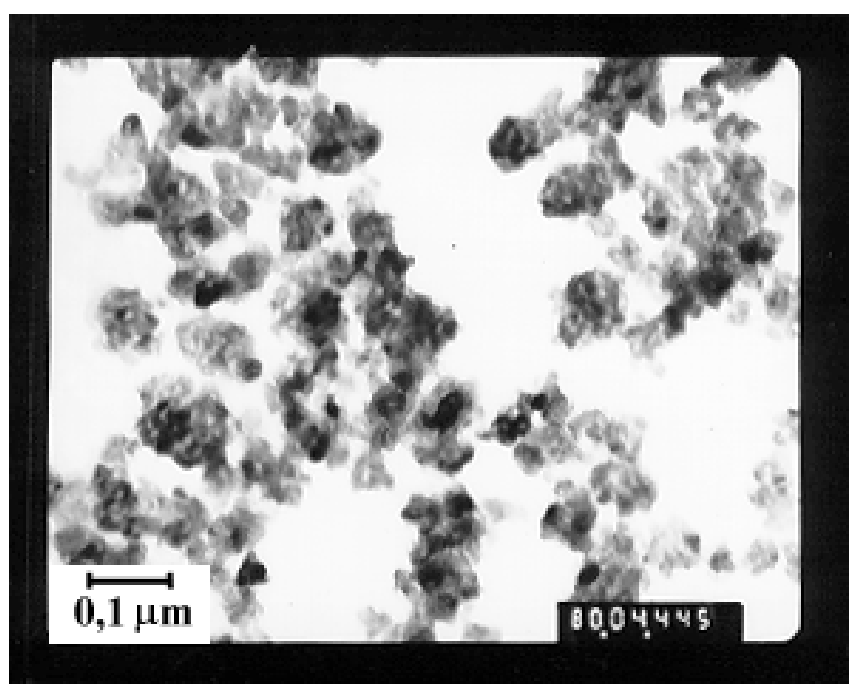

Figura 3.2.9: Micrografia obtida por microscopia eletrônica de transmissão do pó $\mathrm{ZrO}_{2}+8 \%$ mol $\mathrm{Y}_{2} \mathrm{O}_{3}$ obtido por mistura de óxidos utilizado na preparação das amostras. 


\subsection{CARACTERIZAÇÃo dOS ELETRÓLITOS SÓLIDOS}

Nas tabelas 3.3.1 a 3.3.3 são mostrados os valores de densidade a verde, geométrica e hidrostática das amostras, preparadas por conformação seguida de tratamento térmico de sinterização a $1600{ }^{\circ} \mathrm{C} / 1 \mathrm{~h}$, bem como sua relação com a densidade teórica da amostra preparada com o pó comercial.

Tabela 3.3.1: Densidade a verde das amostras de $\mathrm{ZrO}_{2}: 8 \%$ mol $\mathrm{Y}_{2} \mathrm{O}_{3}$ compactadas.

\begin{tabular}{ccc}
\hline Material & $\rho_{\text {verde }}\left(\mathrm{g} / \mathrm{cm}^{3}\right)$ & $\rho_{\text {verde }} / \rho_{\text {teórica }}(\%)$ \\
\hline comercial & $3,01 \pm 0,02$ & $50,1 \pm 0,3$ \\
coprecipitada & $2,12 \pm 0,01$ & $35,3 \pm 0,2$ \\
mistura de óxidos & $2,92 \pm 0,03$ & $48,6 \pm 0,5$ \\
\hline
\end{tabular}

Tabela 3.3.2: Densidade geométrica das amostras de $\mathrm{ZrO}_{2}: 8 \%$ mol $\mathrm{Y}_{2} \mathrm{O}_{3}$ compactadas e sinterizadas a $1600{ }^{\circ} \mathrm{C} / 1 \mathrm{~h}$.

\begin{tabular}{ccc}
\hline material & $\rho_{\text {geométrica }}\left(\mathrm{g} / \mathrm{cm}^{3}\right)$ & $\rho_{\text {geométrica }} / \rho_{\text {teórica }}(\%)$ \\
\hline comercial & $5,780 \pm 0,008$ & $96,2 \pm 0,1$ \\
coprecipitada & $5,707 \pm 0,003$ & $94,99 \pm 0,05$ \\
mistura de óxidos & $5,282 \pm 0,003$ & $87,91 \pm 0,05$ \\
\hline
\end{tabular}

Tabela 3.3.3: Densidade hidrostática das amostras de $\mathrm{ZrO}_{2}: 8 \%$ mol $\quad \mathrm{Y}_{2} \mathrm{O}_{3}$ compactadas e sinterizadas a $1600^{\circ} \mathrm{C} / 1 \mathrm{~h}$.

\begin{tabular}{ccc}
\hline material & $\rho_{\text {hidrostática }}\left(\mathrm{g} / \mathrm{cm}^{3}\right)$ & $\rho_{\text {hidrostática }} / \rho_{\text {teórica }}(\%)$ \\
\hline comercial & $5,934 \pm 0,008$ & $98,8 \pm 0,1$ \\
coprecipitada & $5,74 \pm 0,01$ & $95,5 \pm 0,2$ \\
mistura de óxidos & $5,27 \pm 0,01$ & $87,7 \pm 0,2$ \\
\hline
\end{tabular}

Na figura 3.3.1 são apresentados os resultados das medidas de dilatometria para as amostras comercial e coprecipitada. A amostra coprecipitada apresenta maior retração e temperatura de densificação máxima menor que a amostra comercial; porém, podemos 
notar nas tabelas 3.3.2 e 3.3.3 que a amostra comercial apresenta maior densidade final em relação a amostra coprecipitada quando são sinterizadas a $1600{ }^{\circ} \mathrm{C} / 1 \mathrm{~h}$.

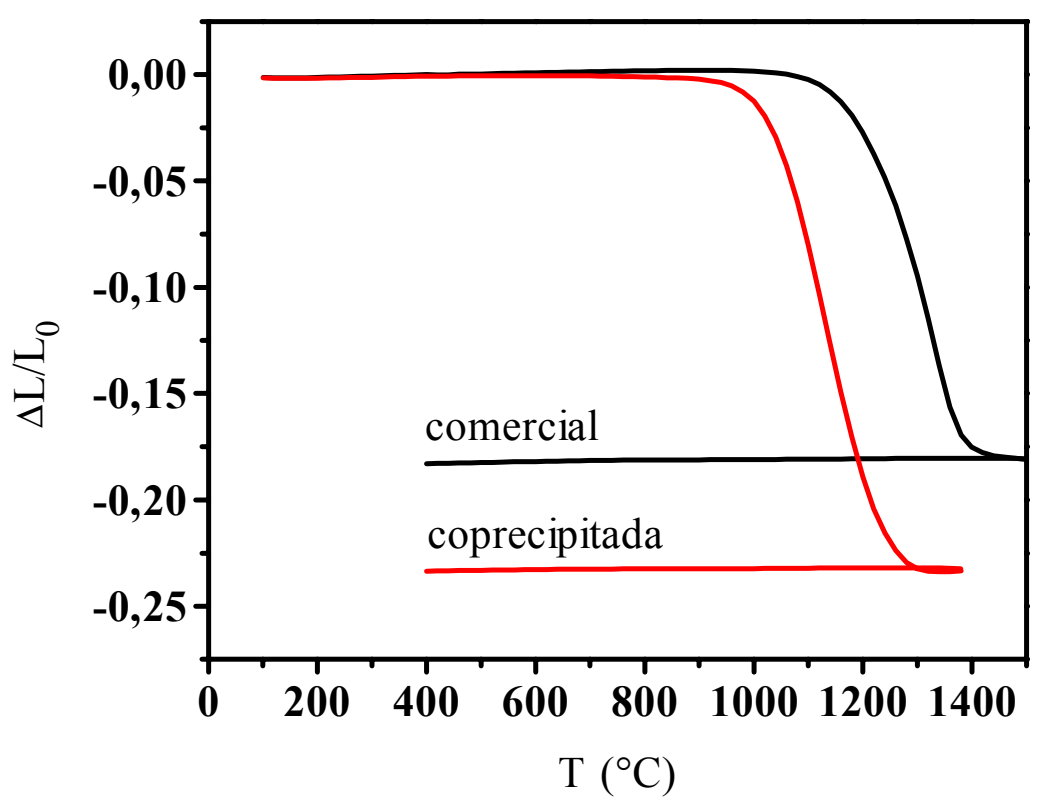

Figura 3.3.1: Retração linear por dilatometria das amostras de $\mathrm{ZrO}_{2}: 8 \%$ mol $\mathrm{Y}_{2} \mathrm{O}_{3}$ comercial e coprecipitada.

Na figura 3.3.2 são apresentados os valores de densidade geométrica e hidrostática da amostra preparada com o pó obtido por mistura de óxidos em função da temperatura de sinterização. O comportamento observado para a variação da densidade em função da temperatura de sinterização é análogo ao apresentado na literatura [47, 48]. 


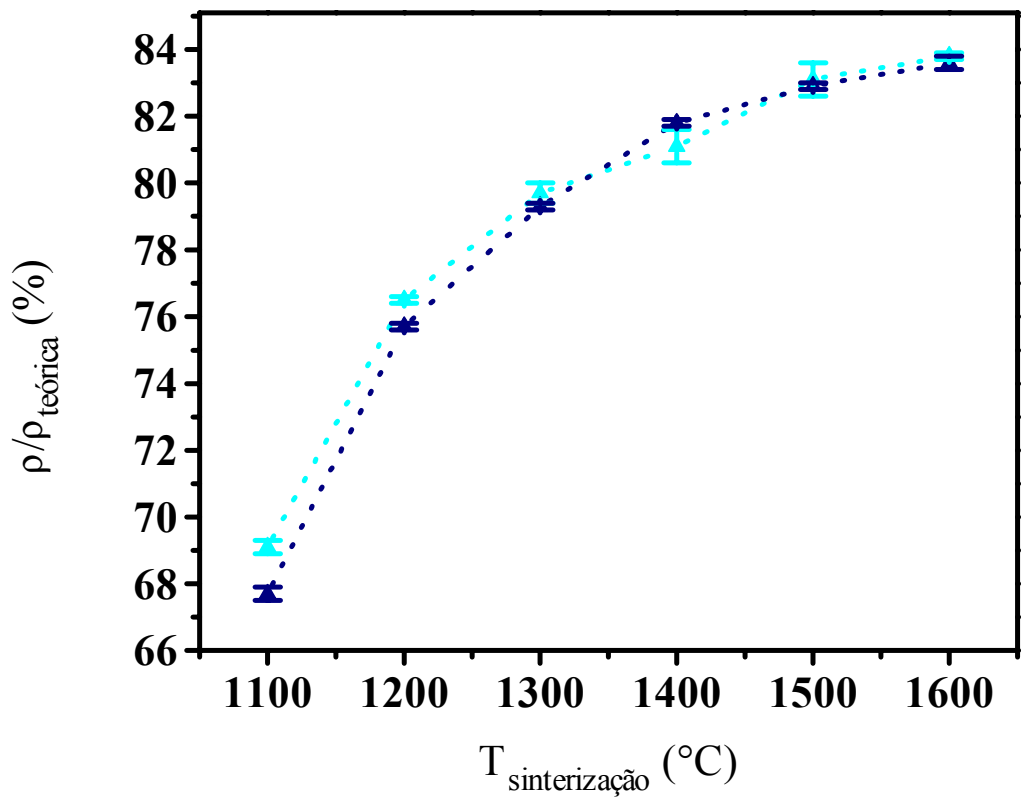

Figura 3.3.2: Valores de densidade geométrica (৯) e hidrostática $(\Delta)$, em relação a densidade teórica da amostra preparada com o pó comercial, da amostra de $\mathrm{ZrO}_{2}: 8 \%$ mol $\mathrm{Y}_{2} \mathrm{O}_{3}$ preparada com o pó obtido por mistura de óxidos em função da temperatura de sinterização.

Nas figuras 3.3.3 e 3.3.4 são apresentados os resultados das medidas de difração de raios $\mathrm{X}$ para as amostras. A estrutura cúbica foi identificada em todas as amostras. $\mathrm{Na}$ figura 3.3.4, a raia de difração [400] se apresenta dividida em dois máximos para as amostras comercial e coprecipitada; isto se deve à presença das raias $k \alpha_{1}$ e $k \alpha_{2}$ do $\mathrm{Cu}$ no feixe de raios X utilizado nos experimentos de difração [49]. 


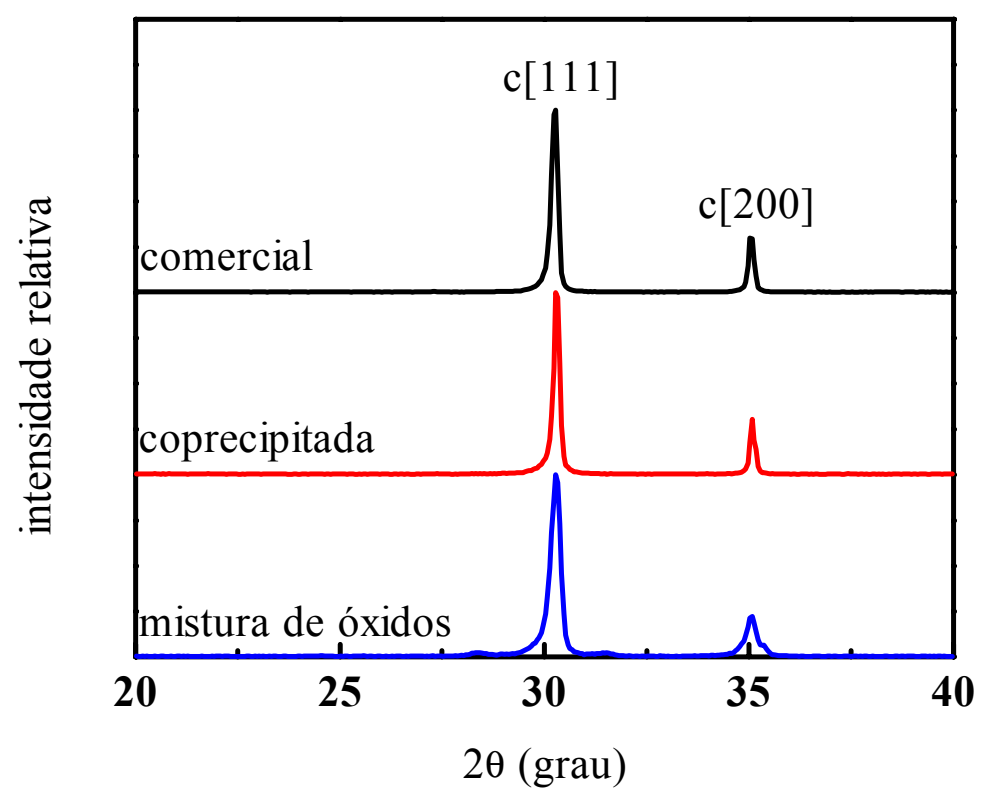

Figura 3.3.3: Difratograma de raios $\mathrm{X}$ das amostras de $\mathrm{ZrO}_{2}: 8 \%$ mol $\mathrm{Y}_{2} \mathrm{O}_{3}$, de várias origens, mostrando a estabilização da fase cúbica da zircônia em todas as amostras.

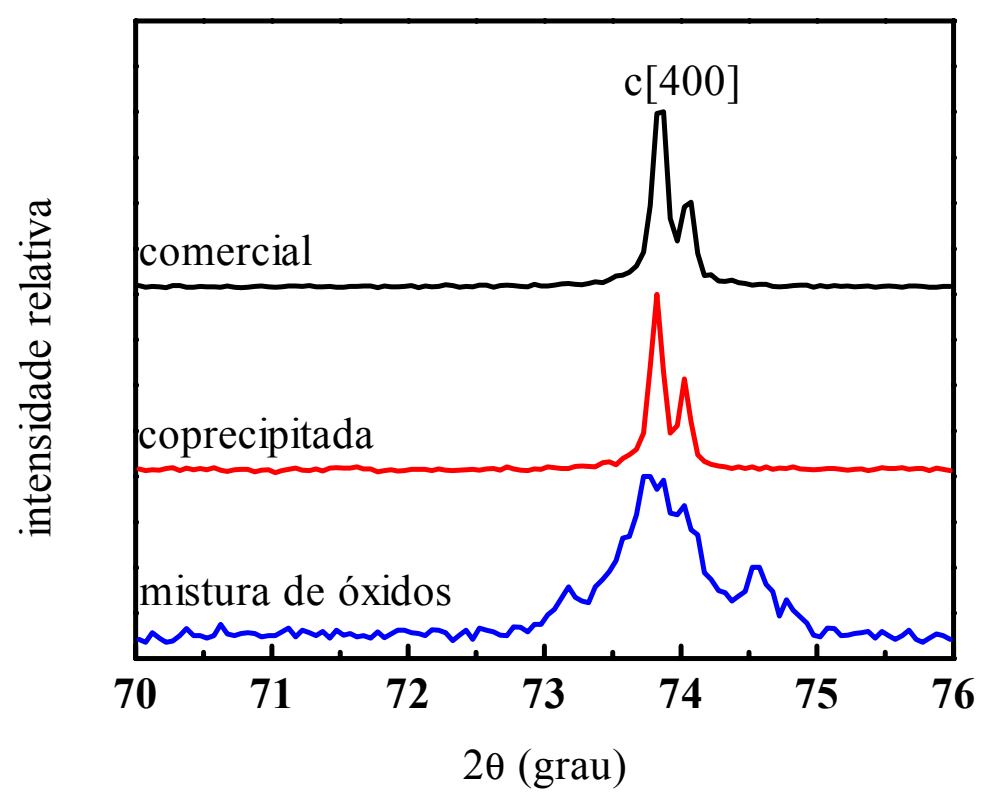

Figura 3.3.4: Difratograma de raios $\mathrm{X}$ das amostras de $\mathrm{ZrO}_{2}: 8 \%$ mol $\mathrm{Y}_{2} \mathrm{O}_{3}$, de várias origens, mostrando a estabilização da fase cúbica da zircônia em todas as amostras. 
Nas figuras 3.3.5 a 3.3.7 são mostradas as micrografias obtidas por microscopia eletrônica de varredura da superfície de fratura das amostras utilizadas nas medidas elétricas. Todas apresentam poros localizados preferencialmente no contorno de grão e fratura mista, intragranular e intergranular. A amostra preparada com o pó obtido por mistura de óxidos apresenta uma distribuição bimodal de tamanho de grão, indicando a possível presença de fase tetragonal e/ou monoclínica nessa amostra [50].

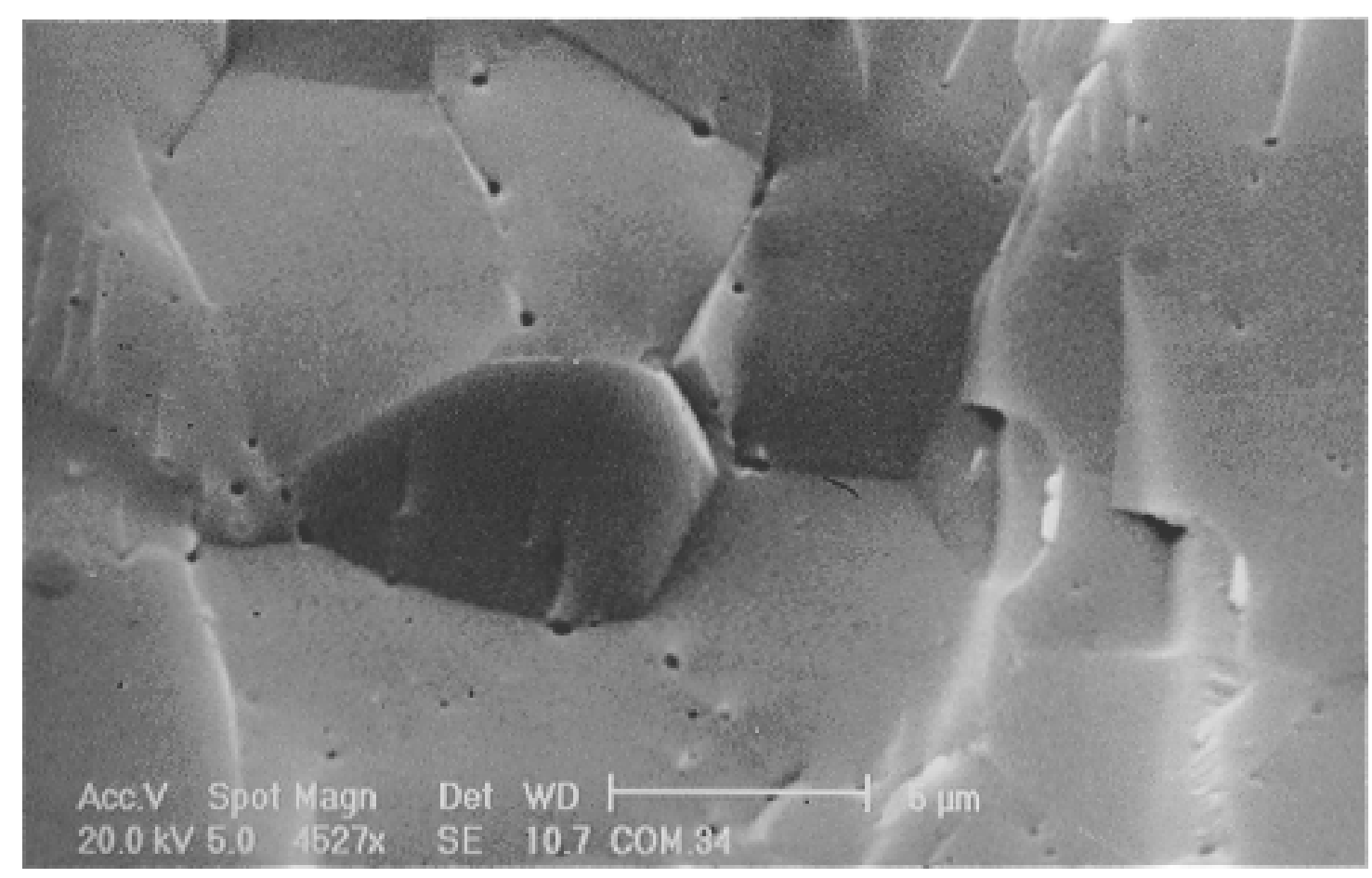

Figura 3.3.5: Micrografia da superfície de fratura da amostra de $\mathrm{ZrO}_{2}: 8 \% \mathrm{~mol}_{2} \mathrm{O}_{3}$ comercial. 


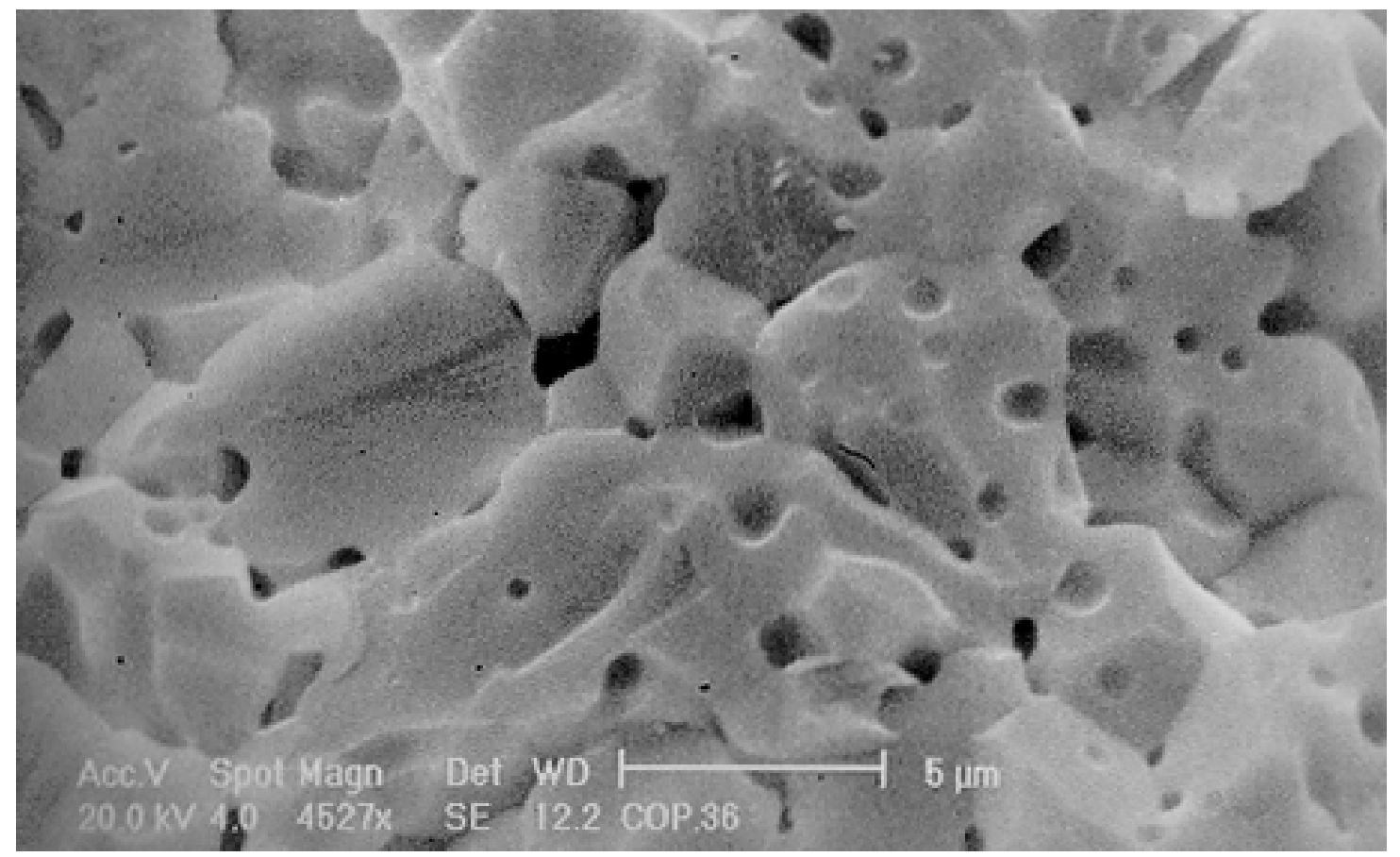

Figura 3.3.6: Micrografia da superfície de fratura da amostra de $\mathrm{ZrO}_{2}: 8 \%$ mol $\mathrm{Y}_{2} \mathrm{O}_{3}$ coprecipitada.

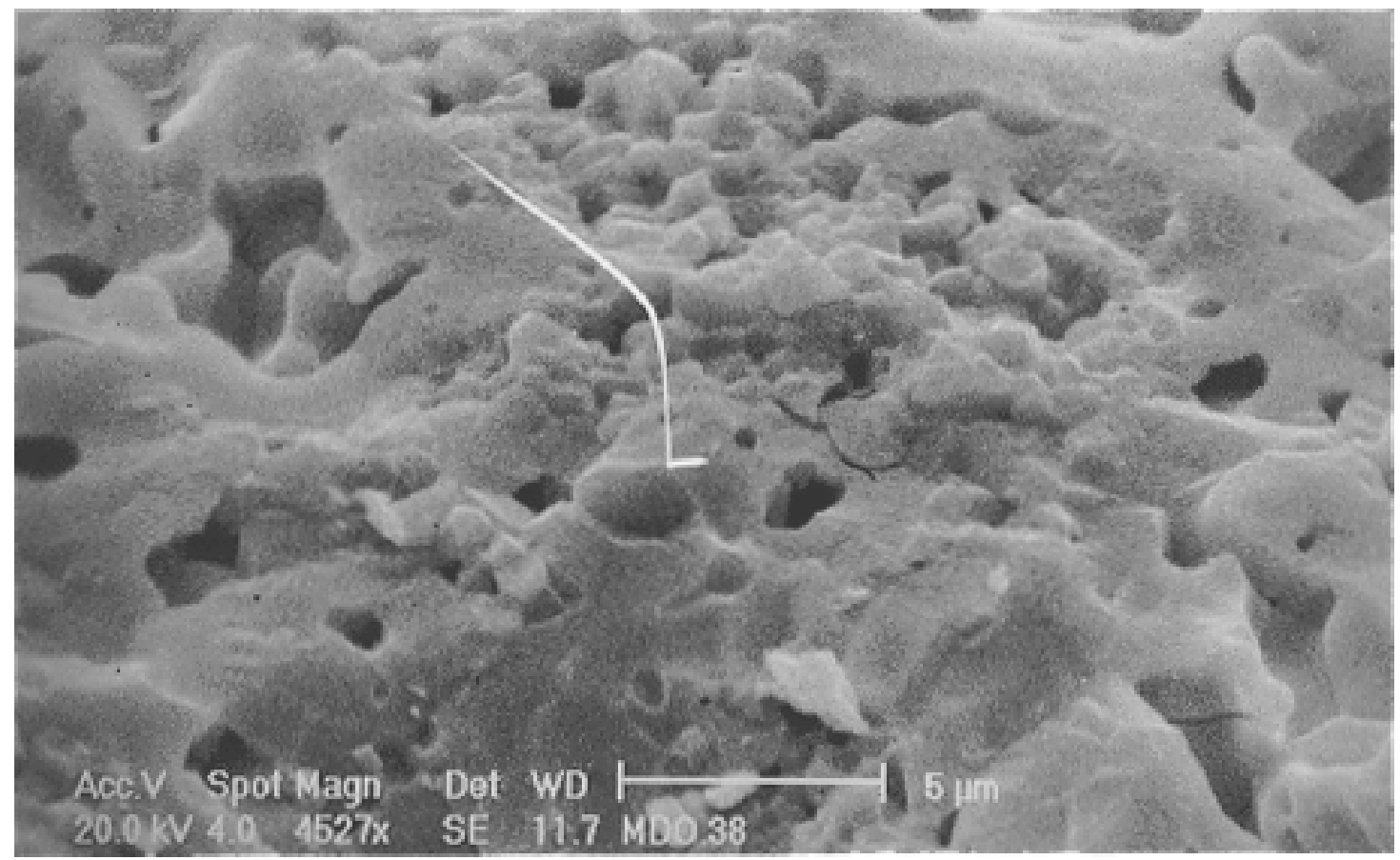

Figura 3.3.7: Micrografia da superfície de fratura da amostra de $\mathrm{ZrO}_{2}: 8 \%$ mol $\mathrm{Y}_{2} \mathrm{O}_{3}$ obtida por mistura de óxidos. 


\subsubsection{CARACTERIZAÇÃo ElÉTRICA}

A contribuição dos eletrodos no diagrama de impedância pode se sobrepor aos arcos de semicírculo em estudo, dificultando dessa forma a análise desses resultados, principalmente em baixas freqüências. Esse efeito é mostrado na figura 3.3.1.1. A diferença entre os valores de resistência do grão se deve a uma pequena diferença na temperatura de medida. O uso de prata como eletrodo permite uma melhor resolução dos $\operatorname{arcos}$ de semicírculo devidos às contribuições do contorno de grão, porém os eletrodos de prata não apresentam a estabilidade necessária em temperaturas relativamente baixas durante longos períodos de tempo ou em altas temperaturas.

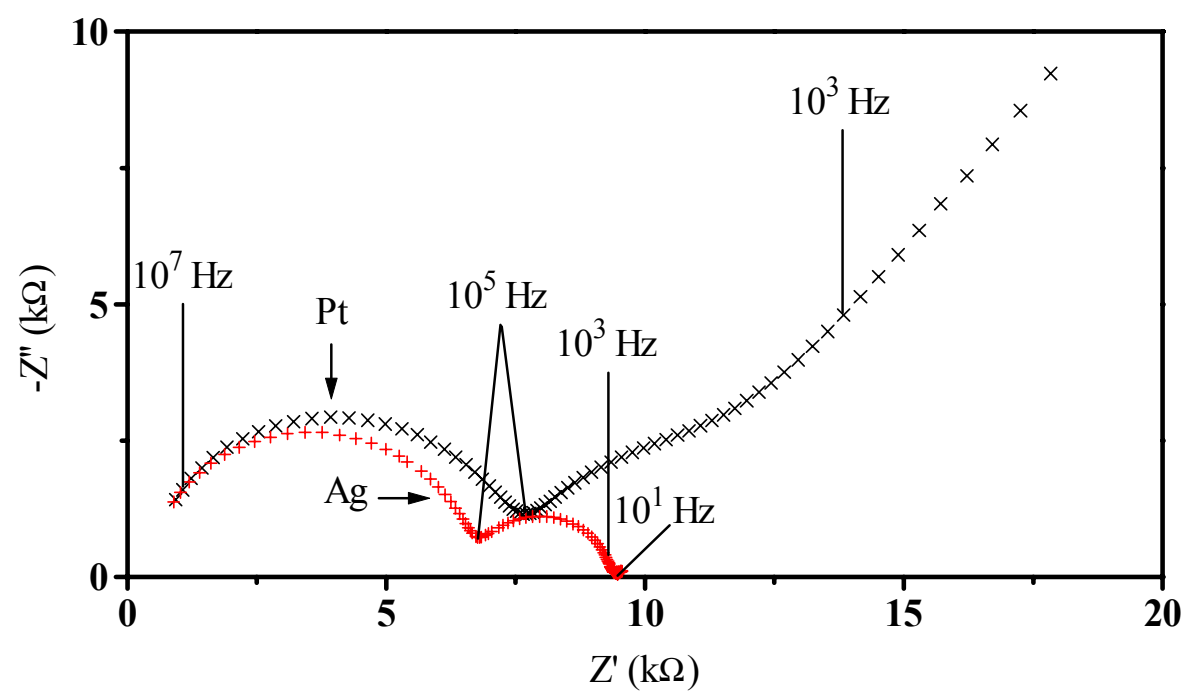

Figura 3.3.1.1: Efeito dos eletrodos de platina $(x)$ e prata $(+)$ nos diagramas de impedância. 
Nas figura 3.3.1.2 a 3.3.1.4 são mostrados os valores do logaritmo neperiano da condutividade total, do grão e do contorno de grão, respectivamente, das amostras de $\mathrm{ZrO}_{2}: 8 \%$ mol $\mathrm{Y}_{2} \mathrm{O}_{3}$ em função do inverso da temperatura absoluta. Todas as amostras apresentam comportamento elétrico do tipo Arrhenius. A partir dos coeficientes angulares das retas ajustadas para os pontos experimentais foram calculados os valores das energias de ativação para a condutividade, mostrados na tabela 3.3.1.1, bem como os valores encontrados na literatura para a mesma grandeza. Podemos notar que os valores determinados concordam com os valores conhecidos [35, 51]. A condutividade das amostras é diretamente proporcional à sua densidade final, dessa forma, a amostra preparada com o pó comercial, que tem a maior densidade final entre os três tipos de amostras estudadas, tem também, a maior condutividade.

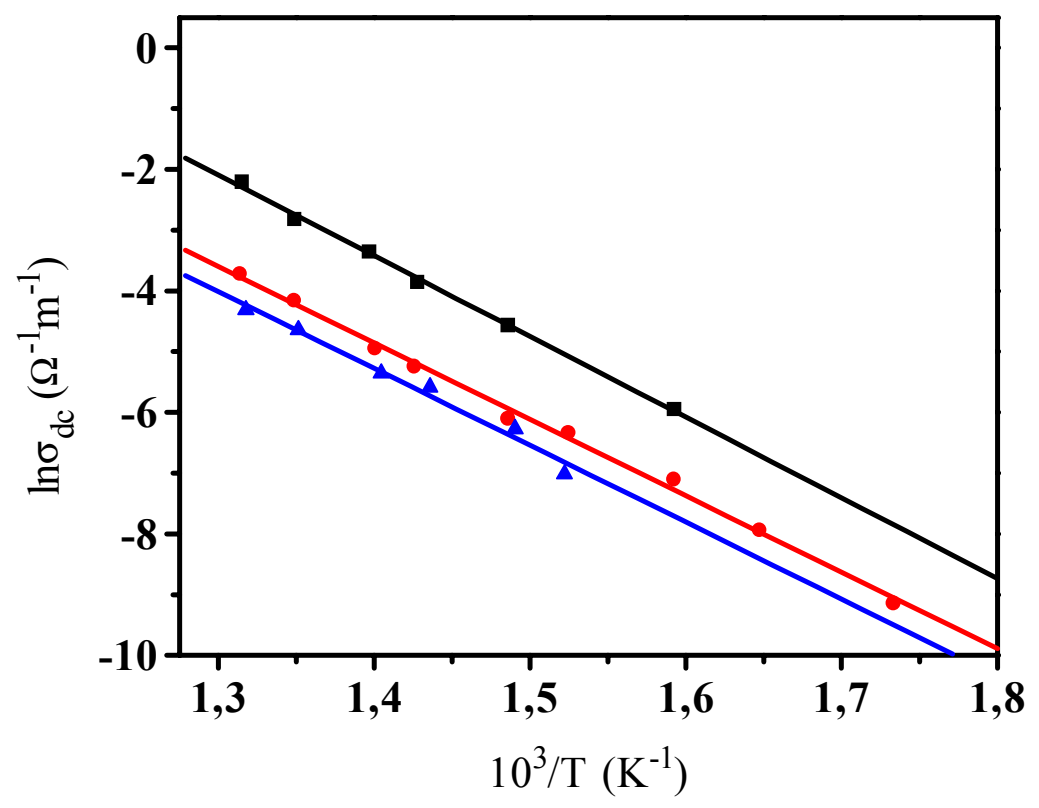

Figura 3.3.1.2: Gráfico de Arrhenius para a condutividade total das amostras de

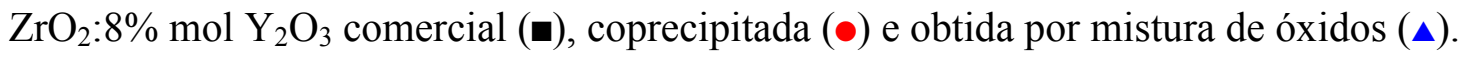




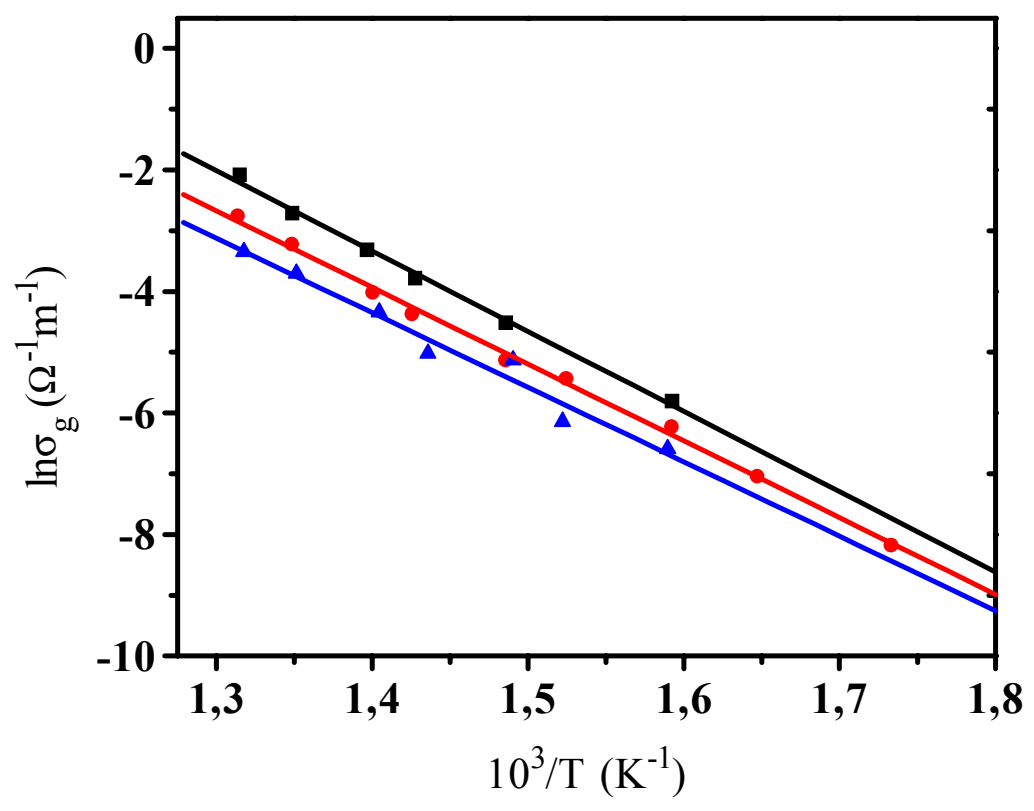

Figura 3.3.1.3: Gráfico de Arrhenius para a condutividade do grão das amostras de

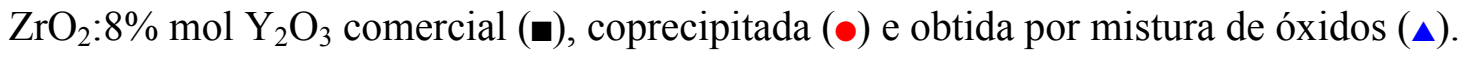

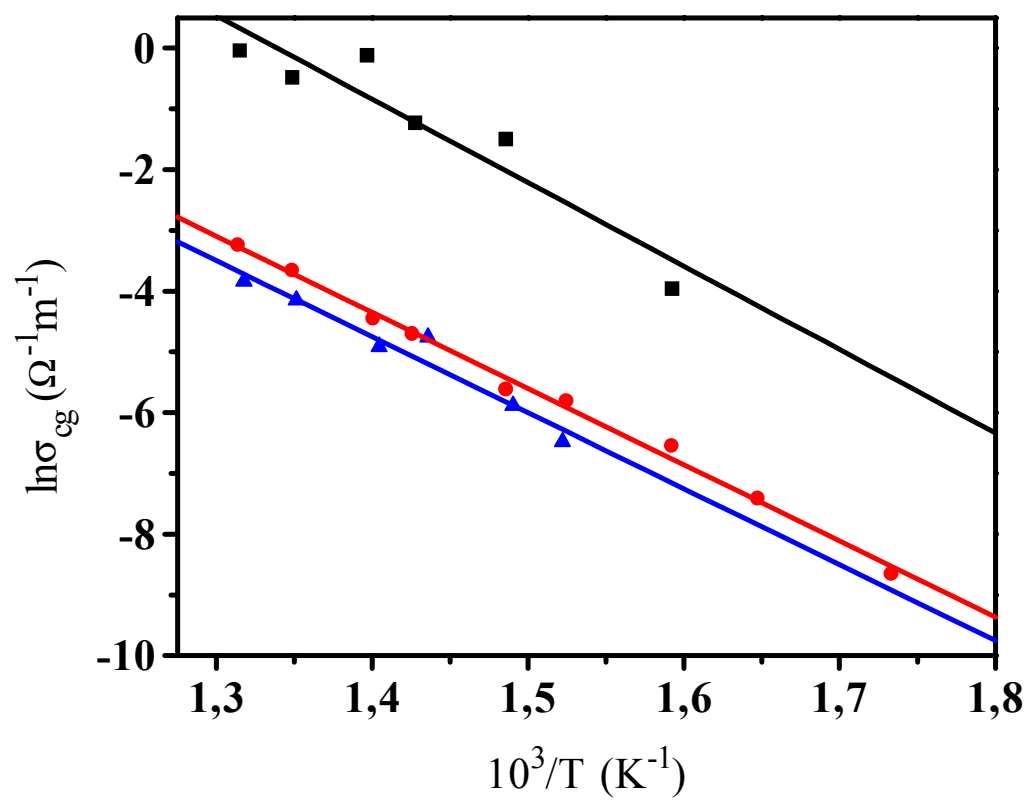

Figura 3.3.1.4: Gráfico de Arrhenius para a condutividade do contorno de grão das amostras de $\mathrm{ZrO}_{2}: 8 \%$ mol $\mathrm{Y}_{2} \mathrm{O}_{3}$ comercial (๘), coprecipitada (๑) e obtida por mistura de óxidos (४). 
Tabela 3.3.1.1: Valores de energia de ativação.

\begin{tabular}{cccc}
\hline amostra/referência & $\mathrm{E}_{\mathrm{dc}}(\mathrm{eV})$ & $\mathrm{E}_{\mathrm{g}}(\mathrm{eV})$ & $\mathrm{E}_{\mathrm{cg}}(\mathrm{eV})$ \\
\hline comercial & $1,15 \pm 0,03$ & $1,14 \pm 0,03$ & $1,2 \pm 0,2$ \\
coprecipitada & $1,09 \pm 0,03$ & $1,09 \pm 0,02$ & $1,08 \pm 0,03$ \\
mistura de óxidos & $1,09 \pm 0,07$ & $1,0 \pm 0,5$ & $1,12 \pm 0,09$ \\
{$[35]$} & $1,11 \pm 0,05$ & $1,08 \pm 0,05$ & $1,2 \pm 0,1$ \\
{$[51]$} & - & $1,00-1,03$ & $1,05-1,08$ \\
\hline
\end{tabular}

\subsection{ENVELHECIMENTO TÉRMICO}

Nesta secção são descritos os resultados das medidas de espectroscopia de impedância em cerâmicas de $\mathrm{ZrO}_{2}: 8 \% \mathrm{~mol} \mathrm{Y}_{2} \mathrm{O}_{3}$ sinterizadas submetidas a tratamento térmico de $600{ }^{\circ} \mathrm{C}$ por diferentes tempos. As amostras cerâmicas foram obtidas a partir dos três diferentes pós (comercial, coprecipitado e obtido por mistura de óxidos) compactados e sinterizados a $1600^{\circ} \mathrm{C} / 1 \mathrm{~h}$.

Na figura 3.4.1 é apresentada a dependência da condutividade da amostra de $\mathrm{ZrO}_{2}: 8 \%$ mol $\mathrm{Y}_{2} \mathrm{O}_{3}$, preparada com o pó obtido por mistura de óxidos, com o tempo, na temperatura de $600{ }^{\circ} \mathrm{C}$. Esses valores de condutividade foram calculados a partir de análises de medidas de espectroscopia de impedância efetuadas, também, a $600{ }^{\circ} \mathrm{C}$.

Podemos notar que a condutividade dessa amostra diminui com o aumento do tempo de tratamento térmico da cerâmica a $600{ }^{\circ} \mathrm{C}$. Isso significa que esse tratamento térmico promove modificações microestruturais nessa cerâmica. A diminuição da 
condutividade é acentuada nas primeiras $100 \mathrm{~h}$ de tratamento térmico, permanecendo aproximadamente constante após esse intervalo de tempo. Esse resultado tem grande importância tecnológica pois, pode-se concluir que cerâmicas de $\mathrm{ZrO}_{2}: 8 \%$ mol $\mathrm{Y}_{2} \mathrm{O}_{3}$ preparadas pela técnica de mistura dos óxidos + conformação + sinterização devem ser submetidas a um tratamento térmico de $600{ }^{\circ} \mathrm{C} / 100 \mathrm{~h}$ para serem utilizadas em dispositivos sensores de oxigênio, já que a força eletromotriz a $600{ }^{\circ} \mathrm{C}$ do eletrólito sólido de $\mathrm{ZrO}_{2}: 8 \%$ mol $\mathrm{Y}_{2} \mathrm{O}_{3}$ (usado em sensores de $\mathrm{O}_{2}$ ) processado pela técnica de mistura de óxidos + conformação + sinterização, só é constante após $100 \mathrm{~h}$ de operação do sensor nessa temperatura.

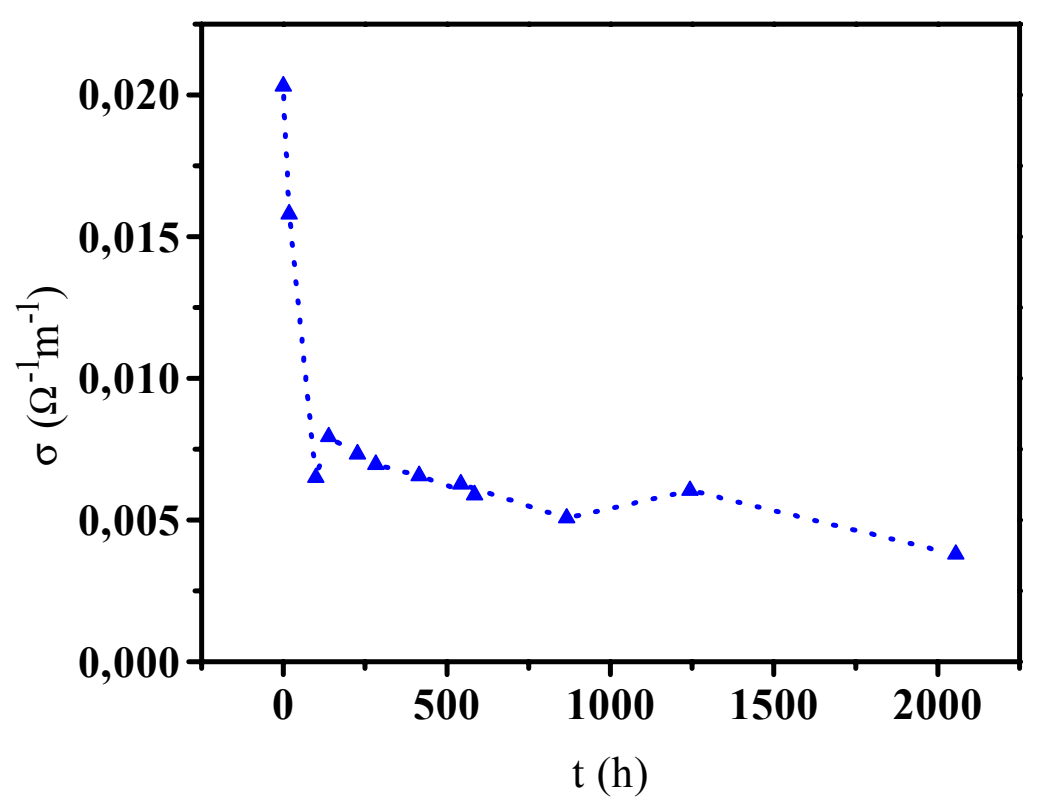

Figura 3.4.1: Variação da condutividade da amostra de $\mathrm{ZrO}_{2}: 8 \%$ mol $\mathrm{Y}_{2} \mathrm{O}_{3}$ obtida por mistura de óxidos com o tempo na temperatura de $600{ }^{\circ} \mathrm{C}$.

A fim de testar a reprodutibilidade dos resultados anteriores e avaliar o comportamento tanto do grão como do contorno de grão de cerâmicas de $\mathrm{ZrO}_{2}: 8 \%$ mol $\mathrm{Y}_{2} \mathrm{O}_{3}$ tratadas termicamente a $600{ }^{\circ} \mathrm{C}$, medidas de espectroscopia de impedância foram feitas a $400{ }^{\circ} \mathrm{C}$. As figuras 3.4.2 a 3.4.4 mostram diagramas de impedância obtidos a $400^{\circ}$ $\mathrm{C}$ para uma amostra de $\mathrm{ZrO}_{2}: 8 \%$ mol $\mathrm{Y}_{2} \mathrm{O}_{3}$ preparada com o pó obtido por mistura de óxidos, tratada termicamente a $600{ }^{\circ} \mathrm{C}$ antes do início do envelhecimento térmico $(\mathrm{t}=0) \mathrm{e}$ 
após 75 h e 170 h de envelhecimento térmico respectivamente. As resistências do grão e do contorno de grão aumentam com o aumento do tempo de tratamento térmico a $600{ }^{\circ} \mathrm{C}$ nas primeiras $100 \mathrm{~h}$, permanecendo praticamente constante após esse intervalo de tempo.

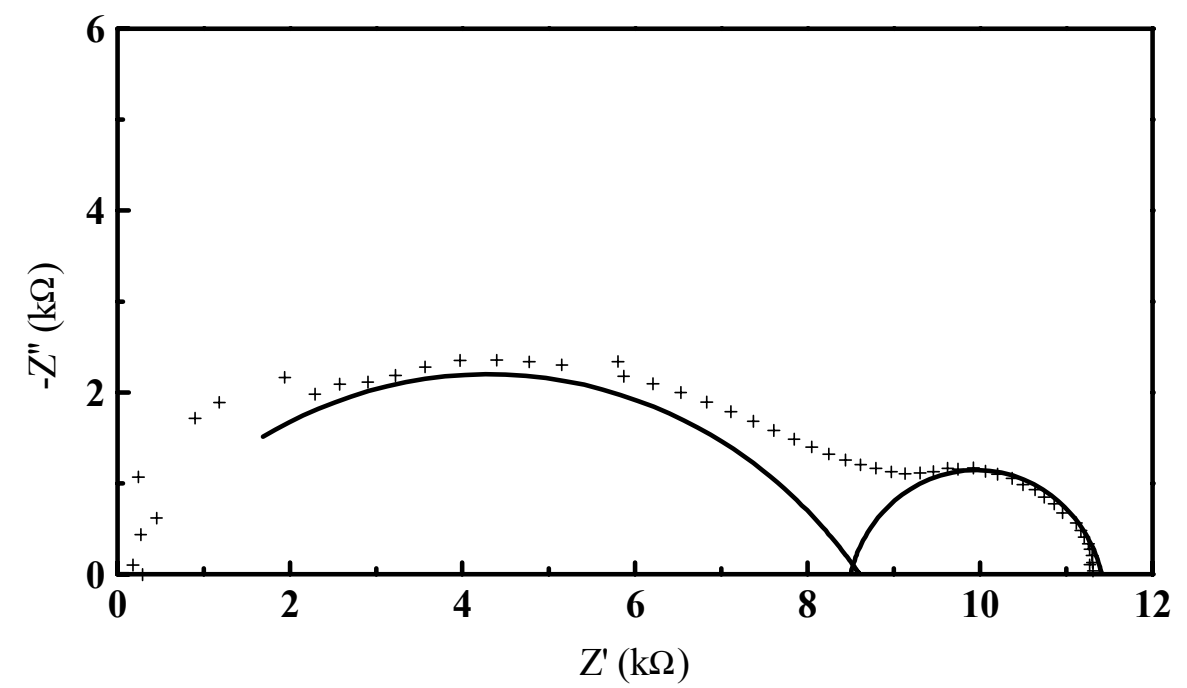

Figura 3.4.2: Diagrama de impedância da amostra de $\mathrm{ZrO}_{2}: 8 \%$ mol $\mathrm{Y}_{2} \mathrm{O}_{3}$ antes do início $(\mathrm{t}=0)$ do envelhecimento térmico a $600{ }^{\circ} \mathrm{C}$ (a contribuição dos eletrodos foi subtraída). 


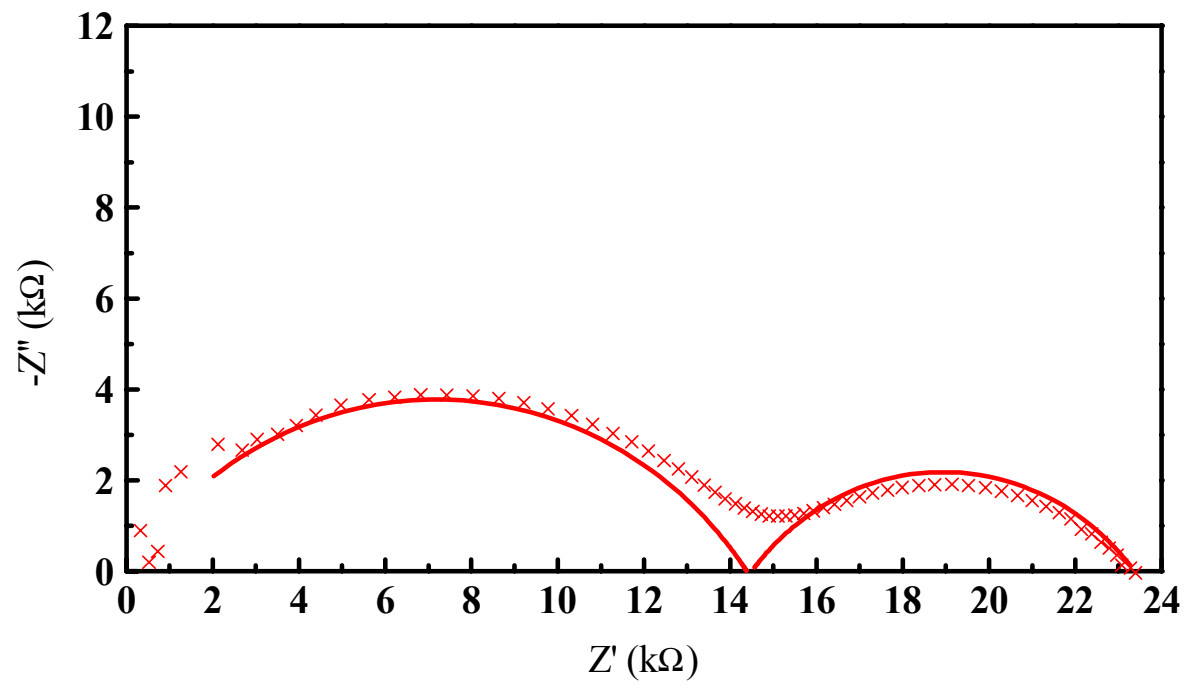

Figura 3.4.3: Diagrama de impedância da amostra de $\mathrm{ZrO}_{2}: 8 \%$ mol $\mathrm{Y}_{2} \mathrm{O}_{3}$ após $75 \mathrm{~h}$ de envelhecimento térmico a $600{ }^{\circ} \mathrm{C}$ (a contribuição dos eletrodos foi subtraída).

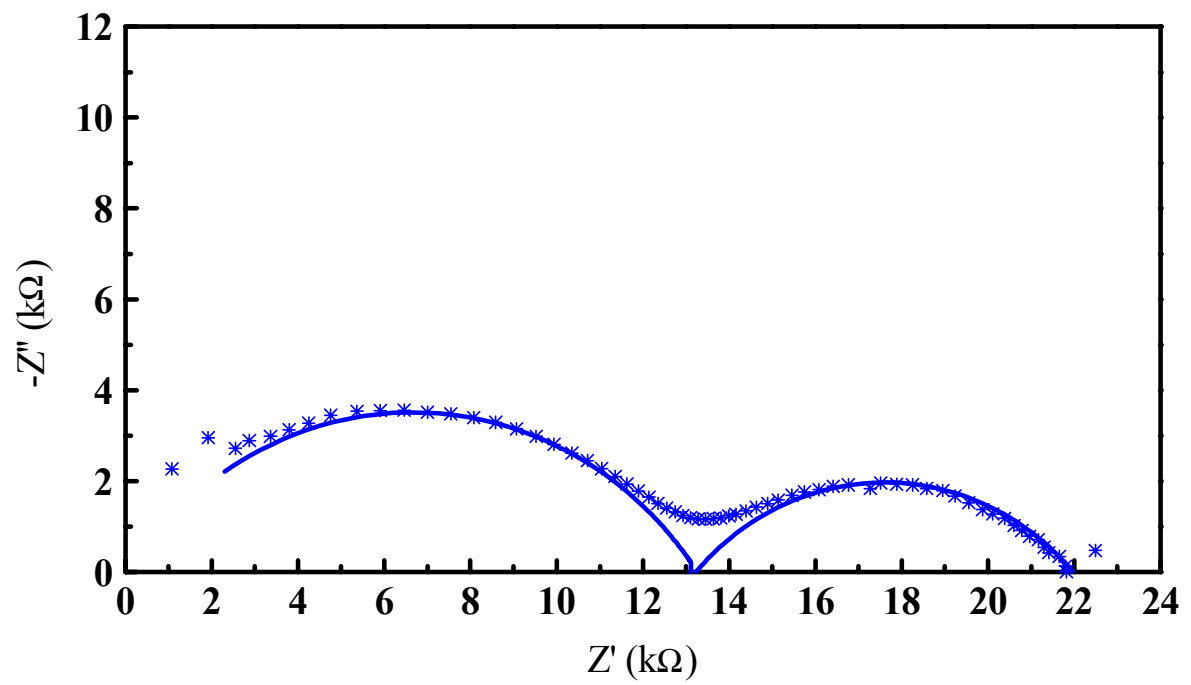

Figura 3.4.4: Diagrama de impedância da amostra de $\mathrm{ZrO}_{2}: 8 \%$ mol $\mathrm{Y}_{2} \mathrm{O}_{3}$ após 170 h de envelhecimento térmico a $600{ }^{\circ} \mathrm{C}$ (a contribuição dos eletrodos foi subtraída).

Nas figuras 3.4.5 a 3.4.7 são apresentadas a dependência com o tempo das condutividades total, do grão e do contorno de grão, respectivamente, para amostra de $\mathrm{ZrO}_{2}: 8 \%$ mol $\mathrm{Y}_{2} \mathrm{O}_{3}$, preparada com o pó obtido por mistura de óxidos. O comportamento 
das 3 condutividades elétricas é semelhante, mostrando que ambos, grão e contorno de grão, contribuem para esse processo de diminuição da condutividade da amostra.

Comportamento análogo foi reportado anteriormente para a condutividade total de $\mathrm{ZrO}_{2}: 8 \%$ mol $\mathrm{Y}_{2} \mathrm{O}_{3}$ com uma diminuição de aproximadamente 1,7 vezes nas primeiras 72 $\mathrm{h}$ de envelhecimento térmico, a $1000{ }^{\circ} \mathrm{C}$. Esses valores concordam com os valores extraídos da figura 3.4.4 (diminuição de aproximadamente 1,5 vezes para a condutividade total nas primeiras $75 \mathrm{~h}$ de envelhecimento térmico) [45].

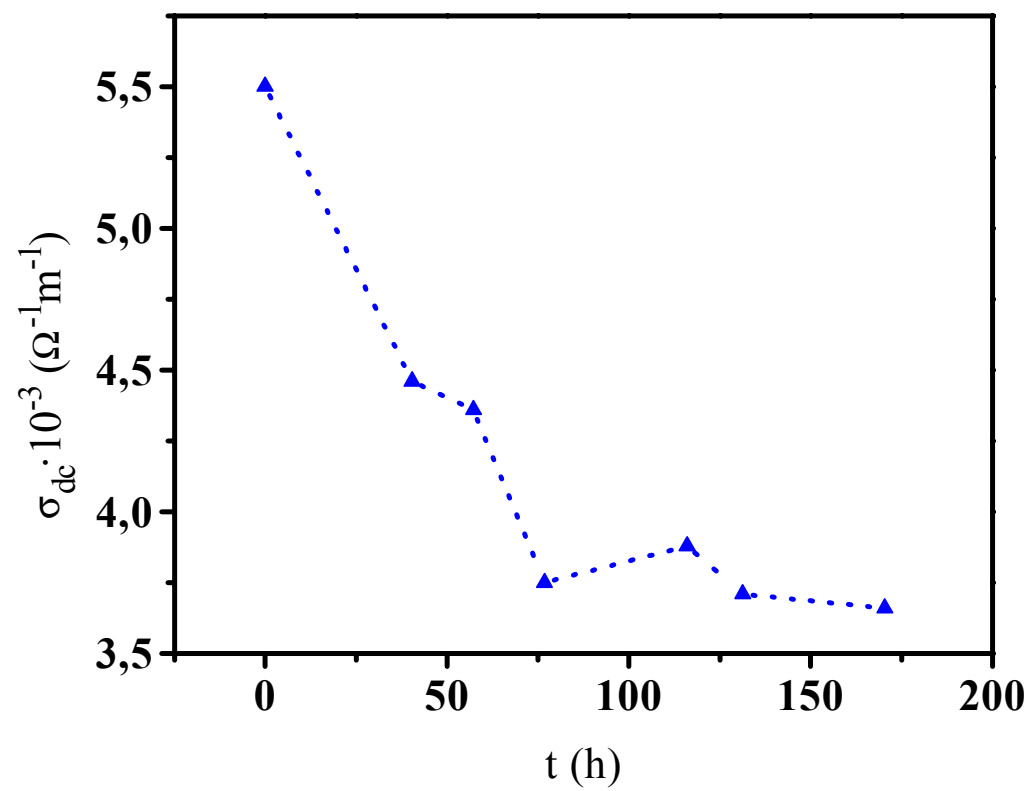

Figura 3.4.5: Variação da condutividade total da amostra de $\mathrm{ZrO}_{2}: 8 \%$ mol $\mathrm{Y}_{2} \mathrm{O}_{3}$ obtida por mistura de óxidos com o tempo na temperatura de $600{ }^{\circ} \mathrm{C}$. 


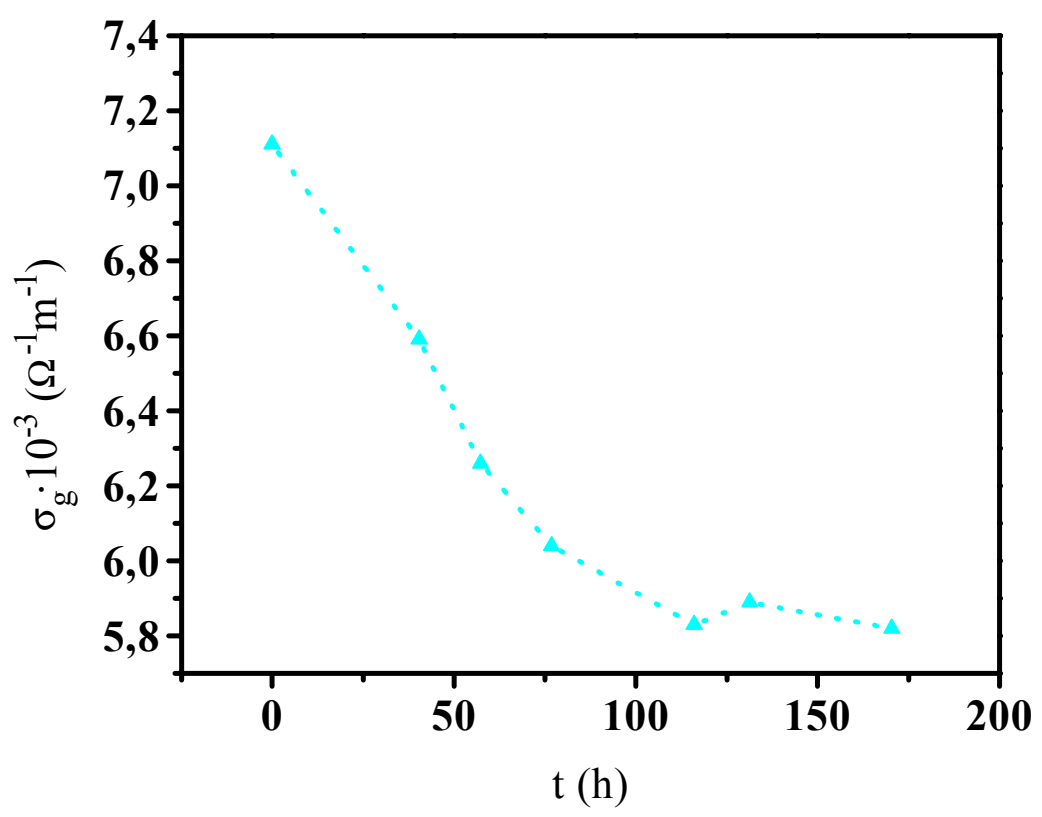

Figura 3.4.6: Variação da condutividade do grão da amostra de $\mathrm{ZrO}_{2}: 8 \%$ mol $\mathrm{Y}_{2} \mathrm{O}_{3}$ obtida por mistura de óxidos com o tempo na temperatura de $600{ }^{\circ} \mathrm{C}$.

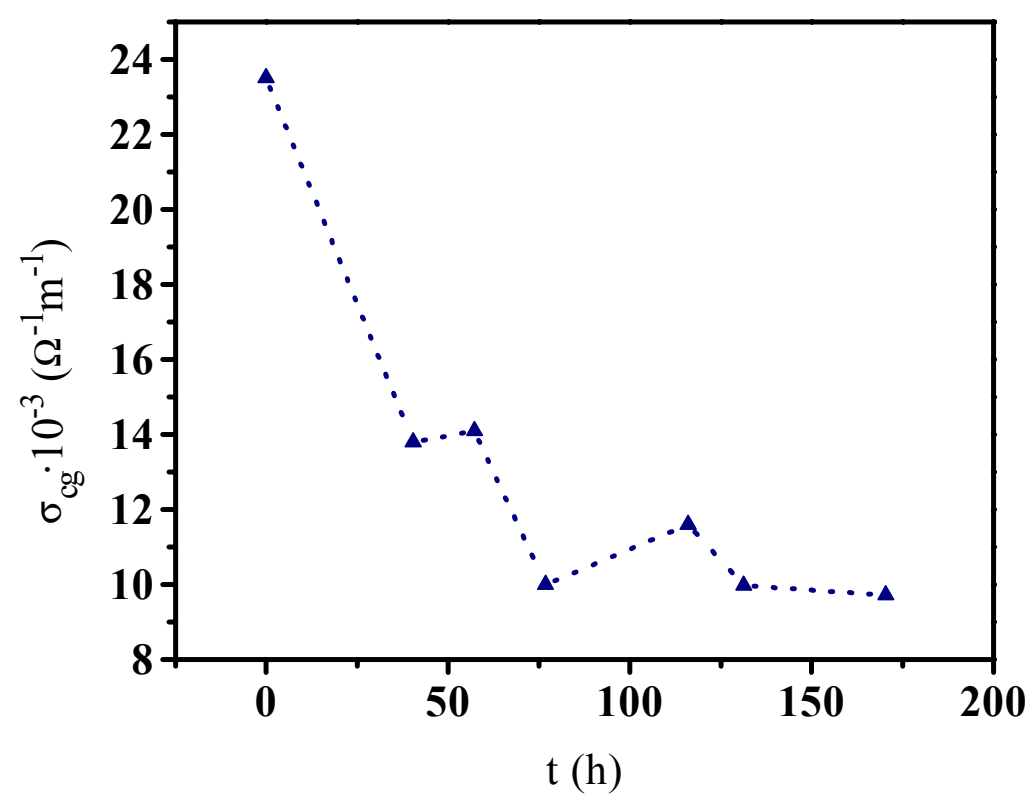

Figura 3.4.7: Variação da condutividade do contorno de grão da amostra de $\mathrm{ZrO}_{2}: 8 \%$ mol $\mathrm{Y}_{2} \mathrm{O}_{3}$ obtida por mistura de óxidos com o tempo na temperatura de $600{ }^{\circ} \mathrm{C}$. 
Na figura 3.4.8 é apresentada a dependência da condutividade total da amostra, normalizada para o seu valor inicial $(\mathrm{t}=0)$, com a raiz quadrada do tempo de envelhecimento térmico [52, 53]. Também são mostradas, a dependência da condutividade total de uma amostra similar, em condições, também, similares às utilizadas nos experimentos aqui descritos, e a dependência da condutância total de um sensor comercial durante envelhecimento térmico a $700{ }^{\circ} \mathrm{C}$ [54]. Há uma boa concordância entre os valores obtidos neste trabalho e os retirados das referências [52, 54]. A dependência linear mostrada na figura 3.4.8 sugere que durante o tratamento térmico a $600{ }^{\circ} \mathrm{C}$ dessas cerâmicas deve ocorrer um processo de difusão, no qual impurezas são segregadas nos contornos de grão, já que a solubilidade das principais impurezas nessas amostras são maiores durante a sinterização do que na temperatura de $600{ }^{\circ} \mathrm{C}$ [52].

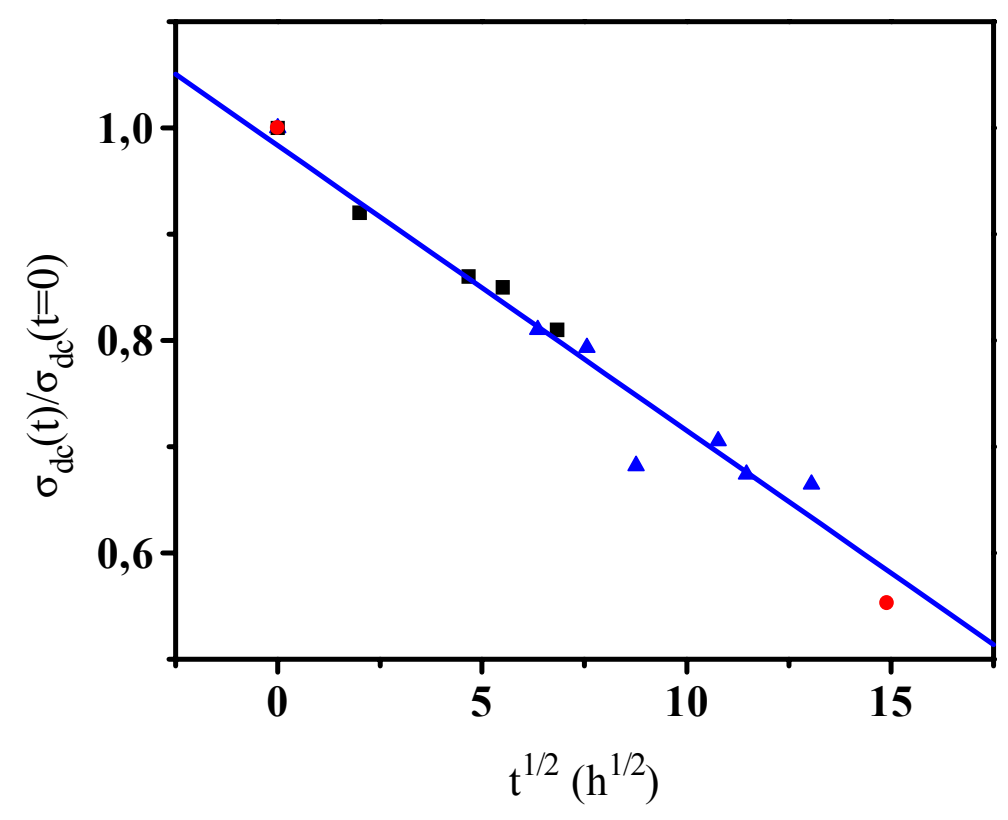

Figura 3.4.8: Variação da condutividade total da amostra, normalizada para o seu valor inicial $(\mathrm{t}=0)$, com a raiz quadrada do tempo de envelhecimento térmico. Este trabalho $(\mathbf{\Delta}),[52](\mathbf{\bullet})$ e [54] (๑).

Na figura 3.4.9 é apresentada a dependência do logaritmo da condutividade atribuída ao grão da amostra com o tempo de envelhecimento térmico. $\mathrm{O}$ valor do coeficiente angular determinado para a reta ajustada aos pontos experimentais é - 0,015 \pm 
0,005; esse valor é da mesma ordem de grandeza que o reportado em trabalhos anteriores, 0,009. Essa dependência da condutividade intragranular com o tempo deve corresponder a formação de uma fase parcialmente ordenada nos grãos da amostra [52].

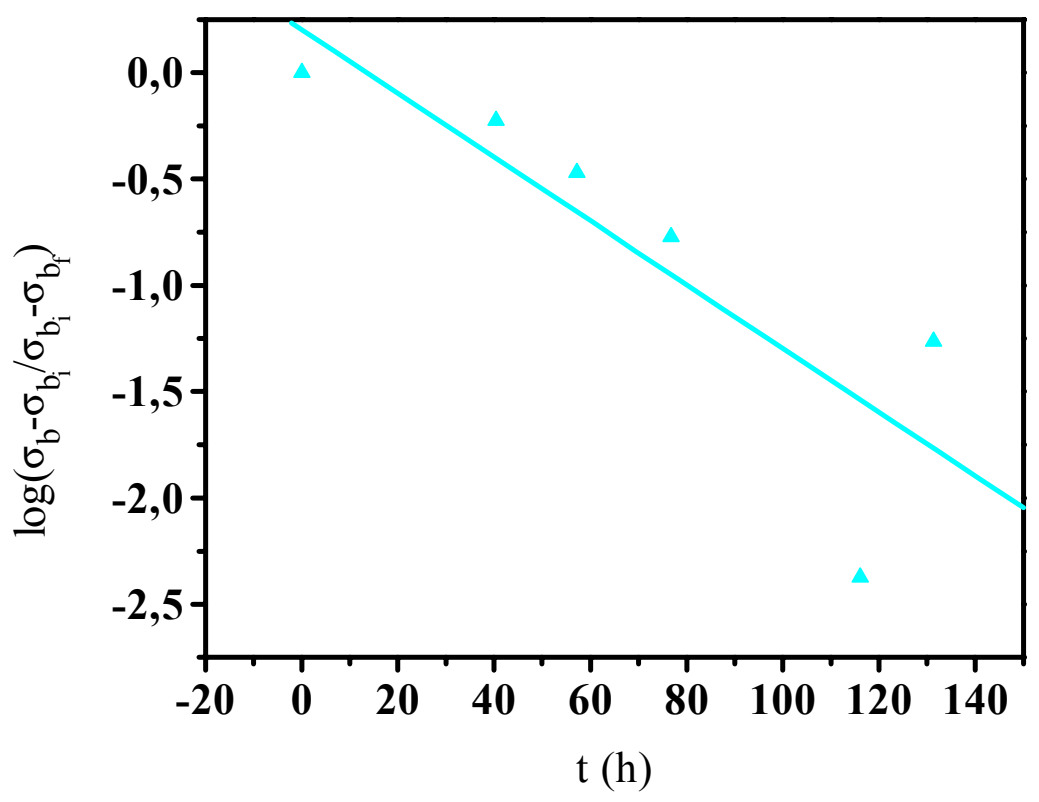

Figura 3.4.9: Variação do logaritmo da condutividade atribuída ao grão da amostra de $\mathrm{ZrO}_{2}: 8 \%$ mol $\mathrm{Y}_{2} \mathrm{O}_{3}$ com o tempo de envelhecimento térmico a $600{ }^{\circ} \mathrm{C}$.

Análises de difração de raios $\mathrm{X}$ foram feitas nas amostras cerâmicas submetidas a envelhecimento térmico. Na figura 3.4.10 são mostrados os difratogramas de raios $\mathrm{X}$ da amostra de $\mathrm{ZrO}_{2}: 8 \%$ mol $\mathrm{Y}_{2} \mathrm{O}_{3}$, preparada com o pó obtido por mistura de óxidos, antes e depois das $2000 \mathrm{~h}$ de envelhecimento térmico. O teor de fase monoclínica, praticamente desprezível na amostra após sinterização, aumenta com o tratamento térmico de envelhecimento térmico a $600{ }^{\circ} \mathrm{C}$.

A fração volumétrica de fase monoclínica na amostra $\mathrm{ZrO}_{2}: 8 \%$ mol $\mathrm{Y}_{2} \mathrm{O}_{3}$, preparada com o pó obtido por mistura de óxidos, após $2000 \mathrm{~h}$ de envelhecimento térmico é de $21 \%$. Portanto, pelo menos uma das razões para o diminuição da condutividade dessa 
cerâmica é o decréscimo do teor de fase cúbica em favor do aumento de fase monoclínica ( $\left.\sigma_{\mathrm{c}} \gg \sigma_{\mathrm{m}}\right)[55,56]$.

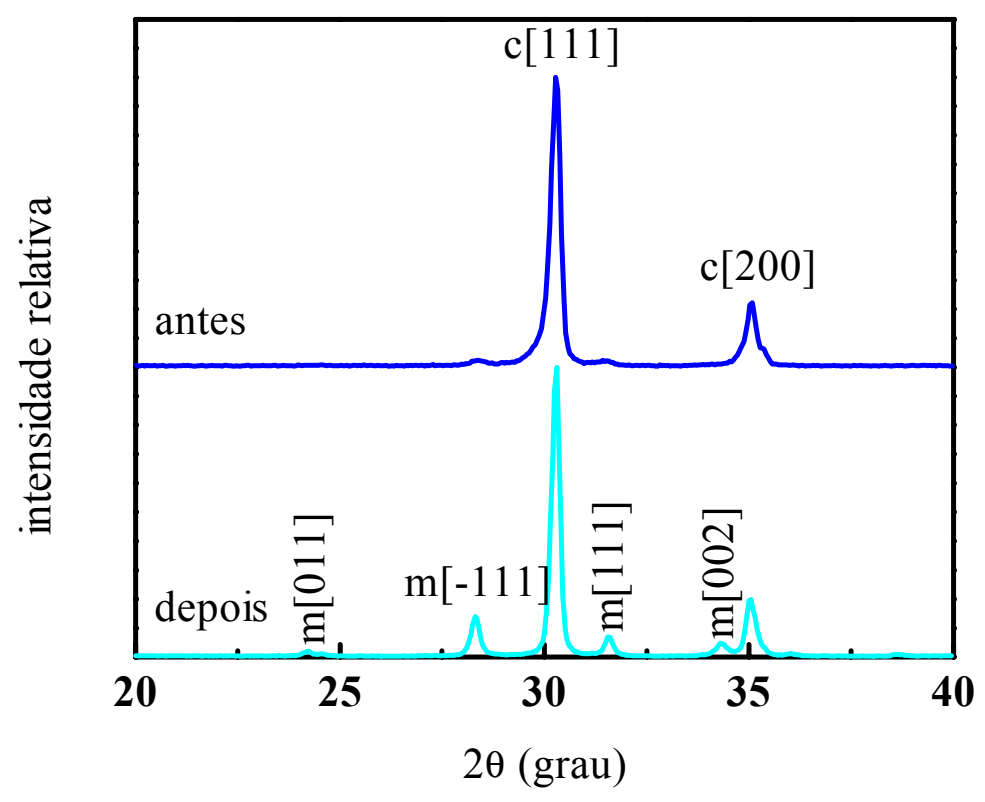

Figura 3.4.10: Difratograma de raios $\mathrm{X}$ da amostra de $\mathrm{ZrO}_{2}: 8 \%$ mol $\mathrm{Y}_{2} \mathrm{O}_{3}$ obtida por mistura de óxidos antes e depois de $2000 \mathrm{~h}$ de envelhecimento térmico a $600{ }^{\circ} \mathrm{C}$.

Análise microestrutural, por meio de microscopia eletrônica de varredura, foi feita a fim de se verificar possíveis alterações nas cerâmicas de $\mathrm{ZrO}_{2}: 8 \%$ mol $\mathrm{Y}_{2} \mathrm{O}_{3}$ após envelhecimento térmico a $600{ }^{\circ} \mathrm{C}$. Na figura 3.4.11 é mostrada uma micrografia, obtida em microscópio eletrônico de varredura, da superfície de fratura da amostra de $\mathrm{ZrO}_{2}: 8 \%$ mol $\mathrm{Y}_{2} \mathrm{O}_{3}$, preparada com o pó obtido por mistura de óxidos, após envelhecimento térmico a $600{ }^{\circ} \mathrm{C}$ durante 2000 h. Nenhuma evidência de mudança microestrutural nessa amostra pode ser avaliada com base nessa micrografia comparada com da figura 3.3.7. 


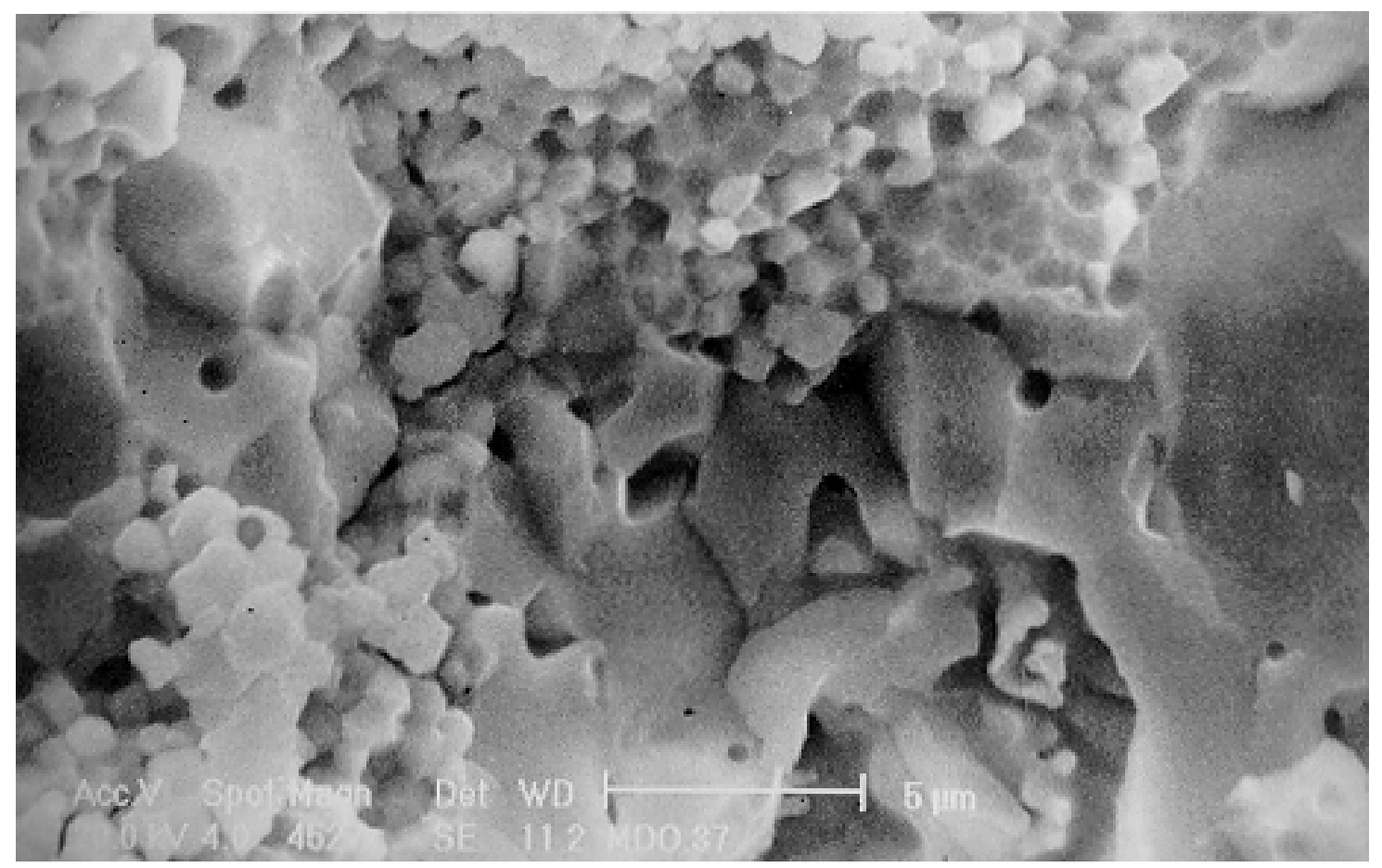

Figura 3.4.11: Micrografia, obtida em microscópio eletrônico de varredura, da superfície de fratura da amostra de $\mathrm{ZrO}_{2}: 8 \%$ mol $\mathrm{Y}_{2} \mathrm{O}_{3}$ obtida por mistura de óxidos após envelhecimento térmico a $600{ }^{\circ} \mathrm{C}$ por $2000 \mathrm{~h}$.

\subsection{ESPECTROSCOPIA DE IMPEDÂNCIA E SINTERIZAÇÃo}

A sinterização de cerâmicas de $\mathrm{ZrO}_{2}: 8 \% \mathrm{~mol}_{2} \mathrm{O}_{3}$ foi estudada por meio de análise dilatométrica e espectroscopia de impedância.

Os resultados das medidas de espectroscopia de impedância das amostras de $\mathrm{ZrO}_{2}: 8 \%$ mol $\mathrm{Y}_{2} \mathrm{O}_{3}$ comercial e coprecipitada, obtidos a aproximadamente $400{ }^{\circ} \mathrm{C}$, em função das temperaturas de sinterização, escolhidas a partir da figura 3.3.1, são 
apresentadas nas figuras 3.5.1 até 3.5.8 para a amostra comercial e nas figuras 3.5.9 até 3.5.16 para a amostra coprecipitada. Essas seqüências de figuras mostram a evolução do comportamento elétrico, determinado pelos diagramas de espectroscopia de impedância, com a temperatura de sinterização.

Como observado por Badwal e Drennan [57] a sinterização da $\mathrm{ZrO}_{2}: \mathrm{Y}_{2} \mathrm{O}_{3}$ começa em temperaturas tão baixas quanto $1200{ }^{\circ} \mathrm{C}$, apesar das baixas densidades relativas das amostras nessa temperatura (55\% para a amostra comercial e $77 \%$ para a amostra coprecipitada). Nesse trabalho são apresentados resultados de espectroscopia de impedância para amostras sinterizadas nessa temperatura (figuras 3.5.5 e 3.5.13) nos quais se observa claramente o início da separação dos arcos de semicírculo dos grãos e dos contornos de grão. Badwal e Drennan também observaram, por meio de microscopia eletrônica de varredura, a formação de pescoço entre as partículas do material sinterizado nessa temperatura; nenhuma evidência clara dessa formação foi observada em temperaturas inferiores a $1200^{\circ} \mathrm{C}$.

Os resultados de dilatometria são apresentados na figura 3.5.17, que são as derivadas das funções apresentadas na figura 3.3.1. O mínimo dessas derivadas revelam as temperaturas de densificação máxima das amostras $\left(1130{ }^{\circ} \mathrm{C}\right.$ para a amostra coprecipitada e $1330{ }^{\circ} \mathrm{C}$ para a amostra comercial), próximas de $1200{ }^{\circ} \mathrm{C}$.

Nas figuras 3.5.18 e 3.5.19 são apresentadas a variação da condutância total, das amostras comercial e coprecipitada, respectivamente, calculadas a partir das medidas de espectroscopia de impedância, em função da temperatura de sinterização. Utilizando uma normalização conveniente podemos notar que o comportamento da condutância do material apresenta uma dependência com a temperatura semelhante à da retração linear relativa. 
Esses resultados mostram a possibilidade do uso de parâmetros, obtidos por meio de medidas elétricas, como indicadores das mudanças que ocorrem durante a sinterização de materiais.

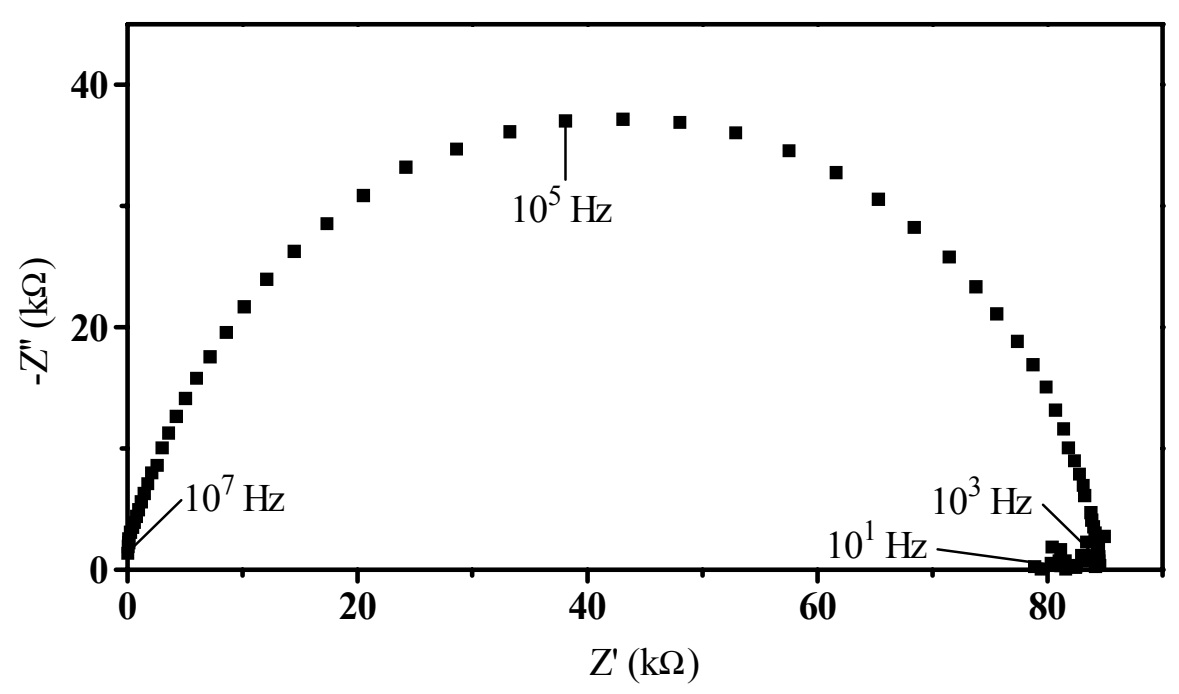

Figura 3.5.1: Diagrama de impedância, obtido a aproximadamente $400{ }^{\circ} \mathrm{C}$, da amostra de $\mathrm{ZrO}_{2}: 8 \%$ mol $\mathrm{Y}_{2} \mathrm{O}_{3}$, comercial, tratada termicamente a $800{ }^{\circ} \mathrm{C}$.

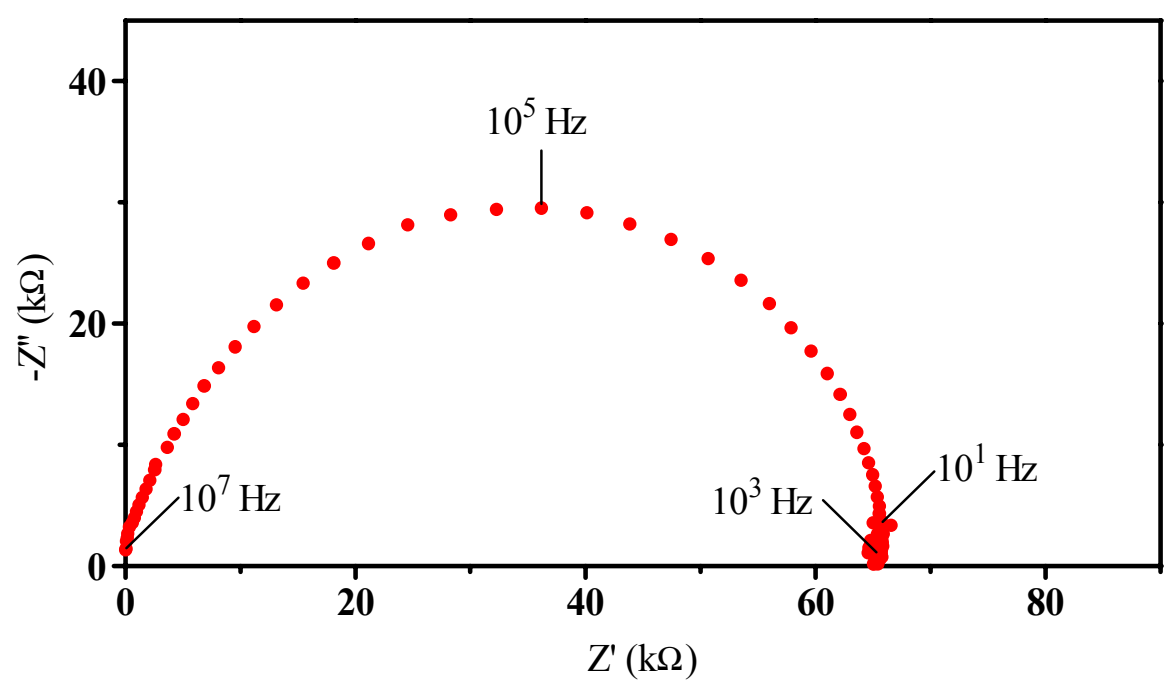

Figura 3.5.2: Diagrama de impedância, obtido a aproximadamente $400{ }^{\circ} \mathrm{C}$, da amostra de $\mathrm{ZrO}_{2}: 8 \%$ mol $\mathrm{Y}_{2} \mathrm{O}_{3}$, comercial, tratada termicamente a $900{ }^{\circ} \mathrm{C}$. 


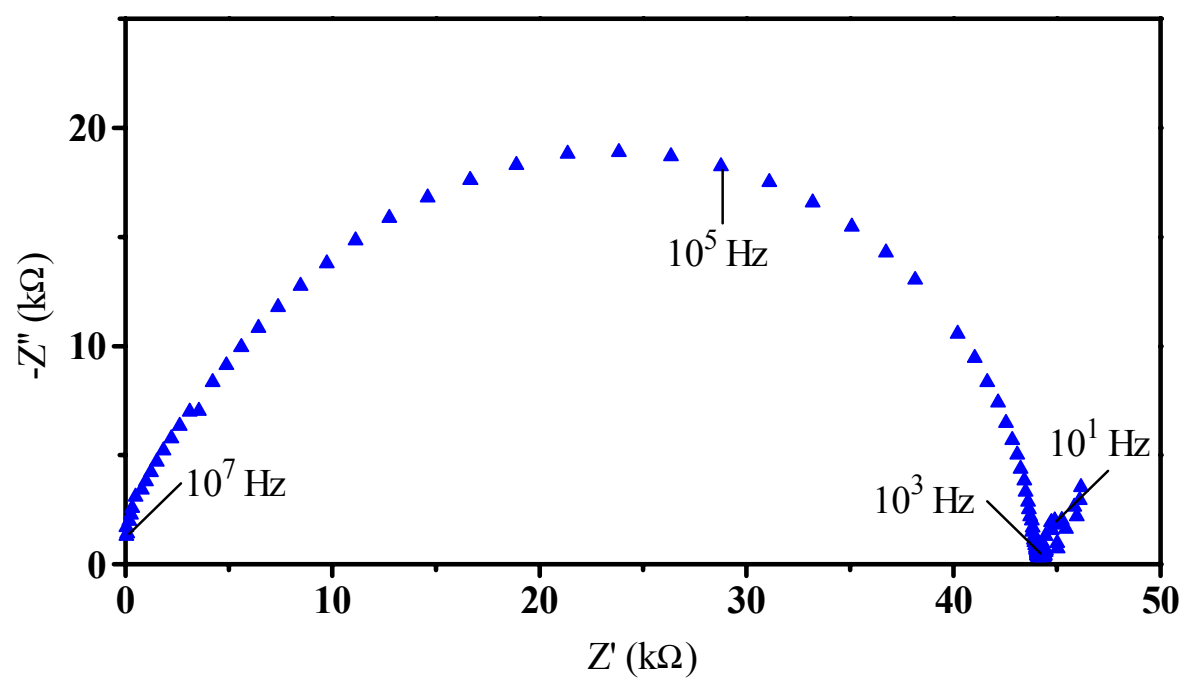

Figura 3.5.3: Diagrama de impedância, obtido a aproximadamente $400{ }^{\circ} \mathrm{C}$, da amostra de $\mathrm{ZrO}_{2}: 8 \%$ mol $\mathrm{Y}_{2} \mathrm{O}_{3}$, comercial, tratada termicamente a $1000{ }^{\circ} \mathrm{C}$.

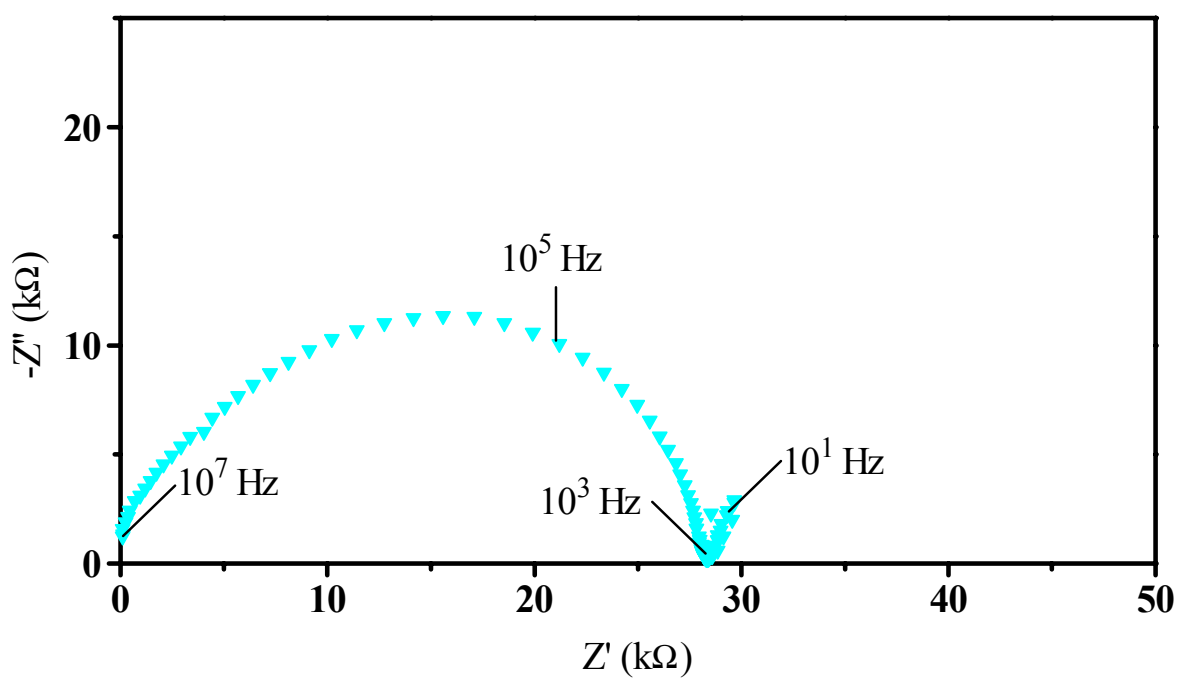

Figura 3.5.4: Diagrama de impedância, obtido a aproximadamente $400{ }^{\circ} \mathrm{C}$, da amostra de $\mathrm{ZrO}_{2}: 8 \%$ mol $\mathrm{Y}_{2} \mathrm{O}_{3}$, comercial, tratada termicamente a $1100{ }^{\circ} \mathrm{C}$. 


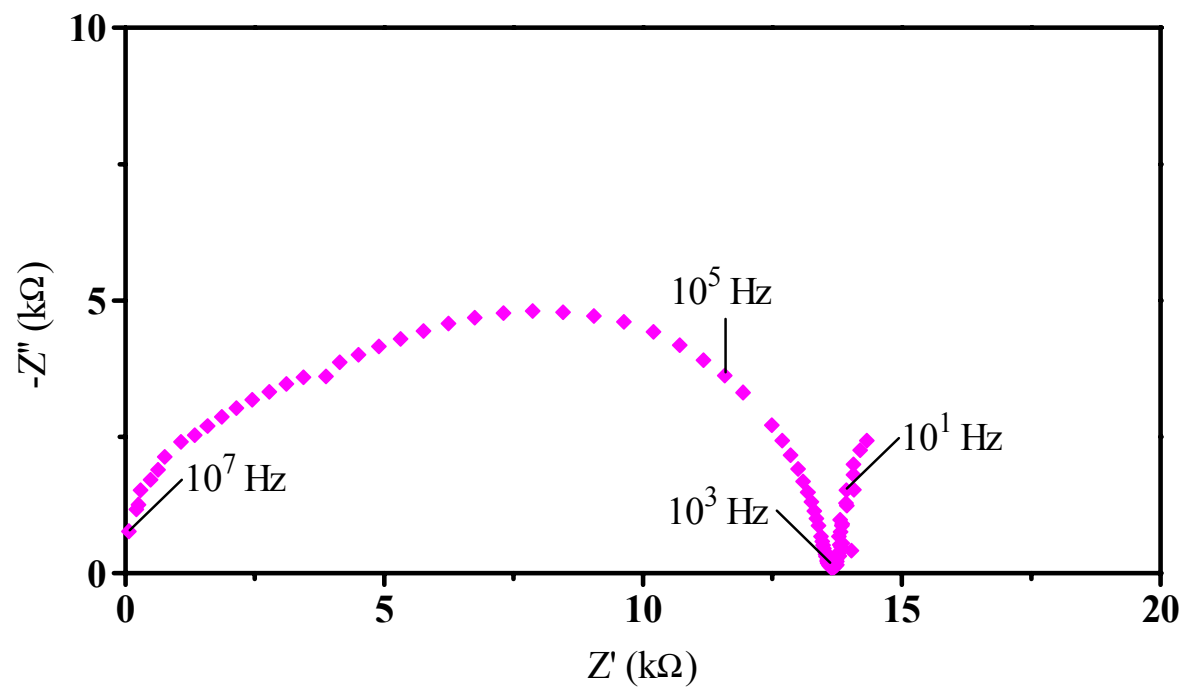

Figura 3.5.5: Diagrama de impedância, obtido a aproximadamente $400{ }^{\circ} \mathrm{C}$, da amostra de $\mathrm{ZrO}_{2}: 8 \%$ mol $\mathrm{Y}_{2} \mathrm{O}_{3}$, comercial, tratada termicamente a $1200{ }^{\circ} \mathrm{C}$.

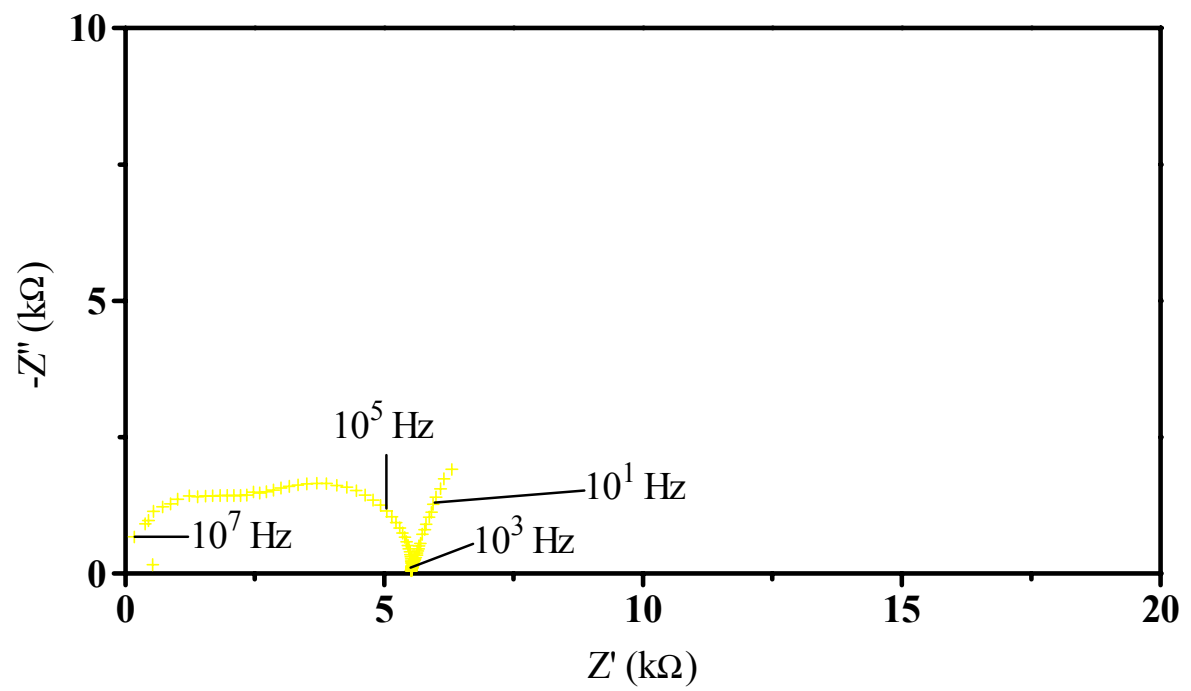

Figura 3.5.6: Diagrama de impedância, obtido a aproximadamente $400{ }^{\circ} \mathrm{C}$, da amostra de $\mathrm{ZrO}_{2}: 8 \%$ mol $\mathrm{Y}_{2} \mathrm{O}_{3}$, comercial, tratada termicamente a $1300{ }^{\circ} \mathrm{C}$. 


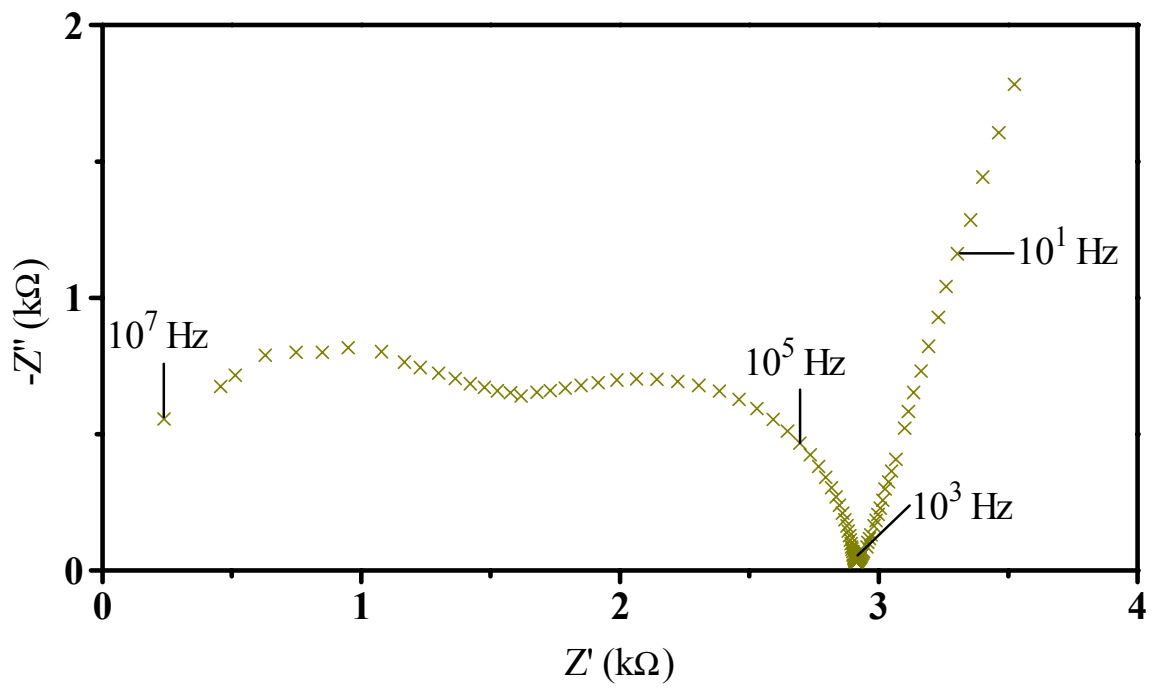

Figura 3.5.7: Diagrama de impedância, obtido a aproximadamente $400{ }^{\circ} \mathrm{C}$, da amostra de $\mathrm{ZrO}_{2}: 8 \%$ mol $\mathrm{Y}_{2} \mathrm{O}_{3}$, comercial, tratada termicamente a $1350{ }^{\circ} \mathrm{C}$.

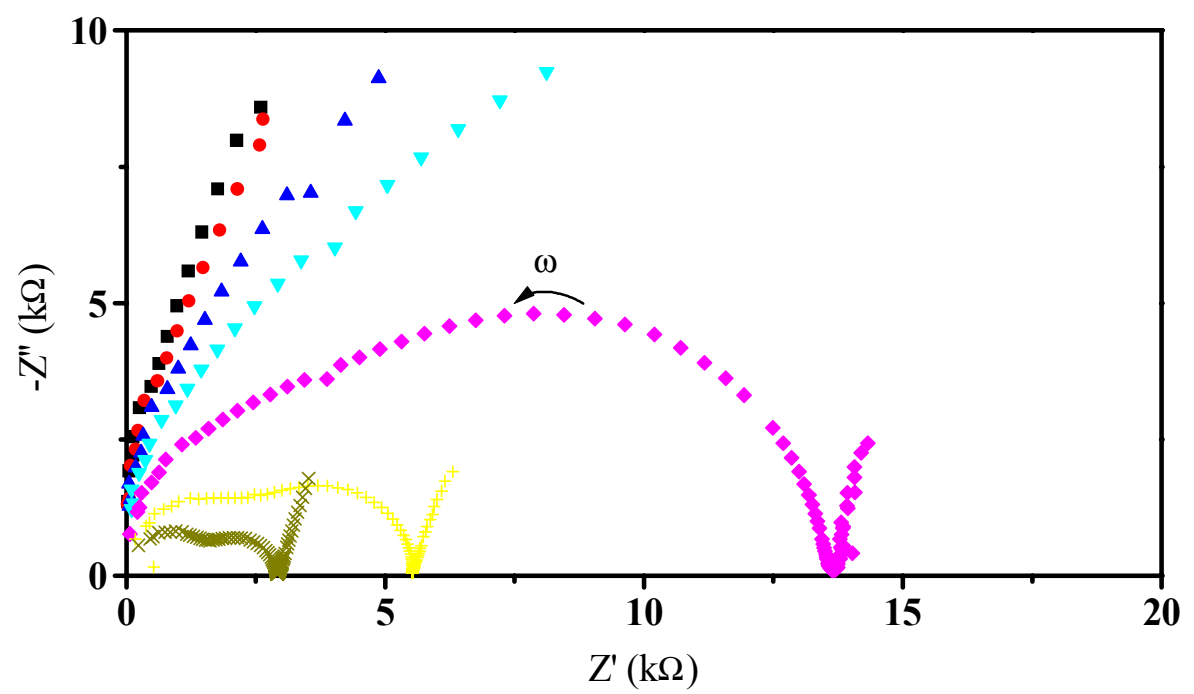

Figura 3.5.8: Sobreposição dos diagramas de impedância apresentados nas figuras 3.5.1 a 3.5.7. As temperaturas de tratamento térmico foram: $800^{\circ} \mathrm{C}(\mathbf{\bullet}), 900{ }^{\circ} \mathrm{C}(\bullet), 1000^{\circ}$ $\mathrm{C}(\Delta), 1100^{\circ} \mathrm{C}(\nabla), 1200^{\circ} \mathrm{C}(\diamond), 1300^{\circ} \mathrm{C}(+), 1350{ }^{\circ} \mathrm{C}(\times)$. 


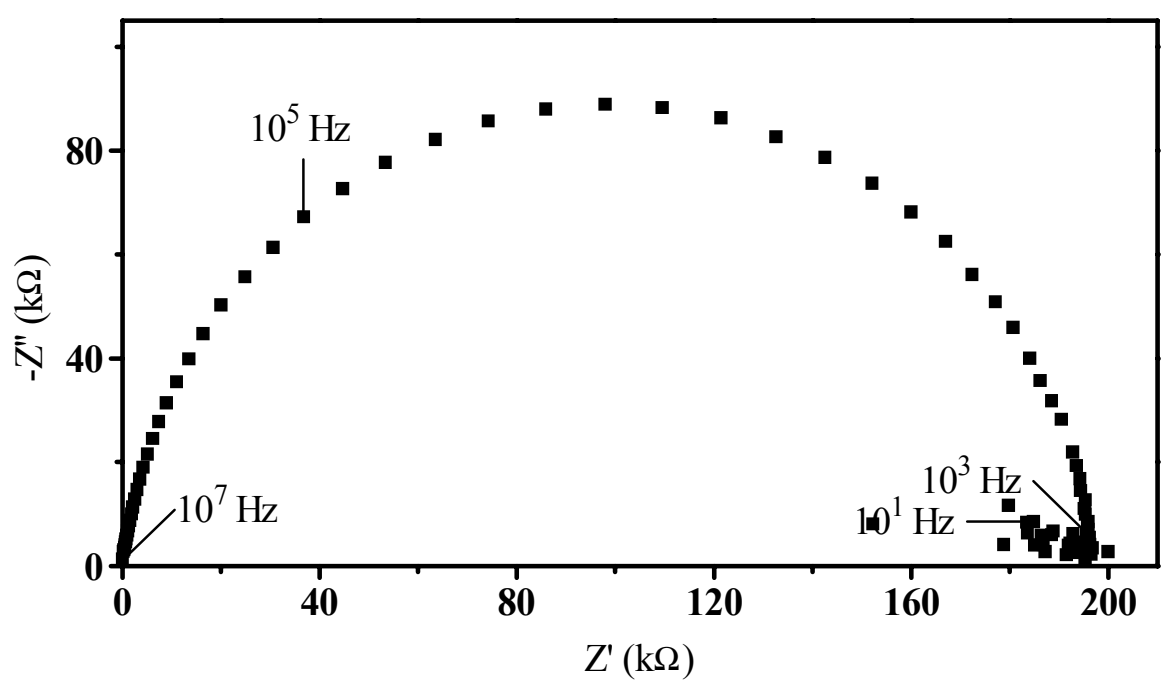

Figura 3.5.9: Diagrama de impedância, obtido a aproximadamente $400{ }^{\circ} \mathrm{C}$, da amostra de $\mathrm{ZrO}_{2}: 8 \%$ mol $\mathrm{Y}_{2} \mathrm{O}_{3}$, coprecipitada, tratada termicamente a $800{ }^{\circ} \mathrm{C}$.

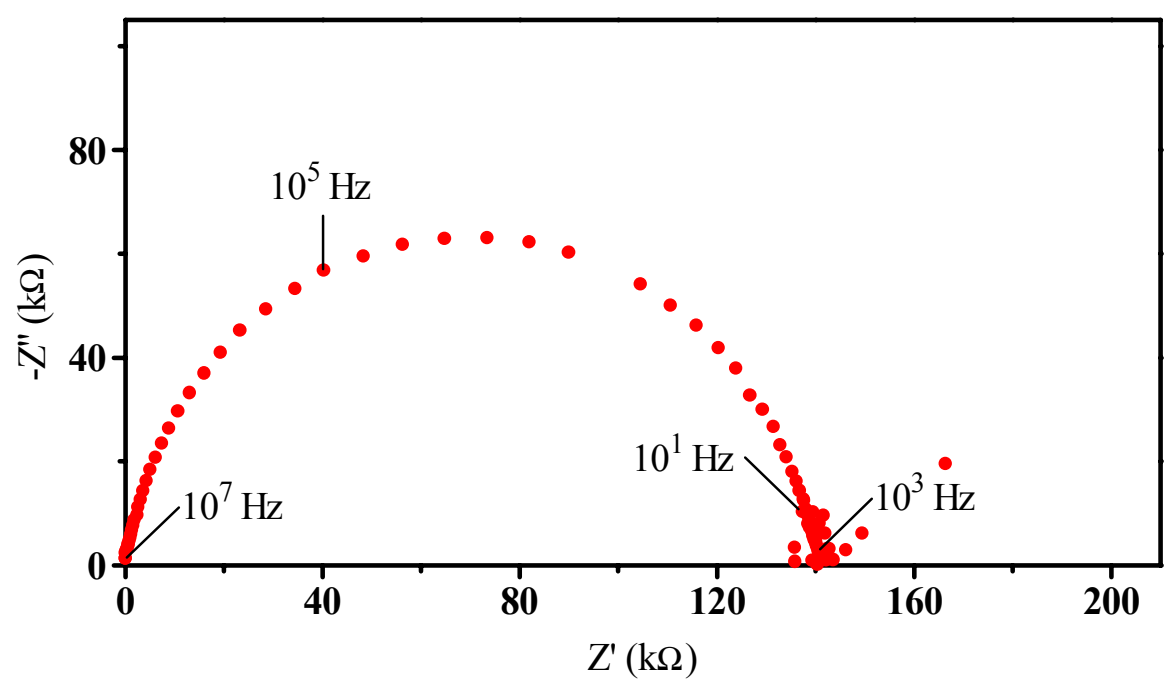

Figura 3.5.10: Diagrama de impedância, obtido a aproximadamente $400{ }^{\circ} \mathrm{C}$, da amostra de $\mathrm{ZrO}_{2}: 8 \%$ mol $\mathrm{Y}_{2} \mathrm{O}_{3}$, coprecipitada, tratada termicamente a $900{ }^{\circ} \mathrm{C}$. 


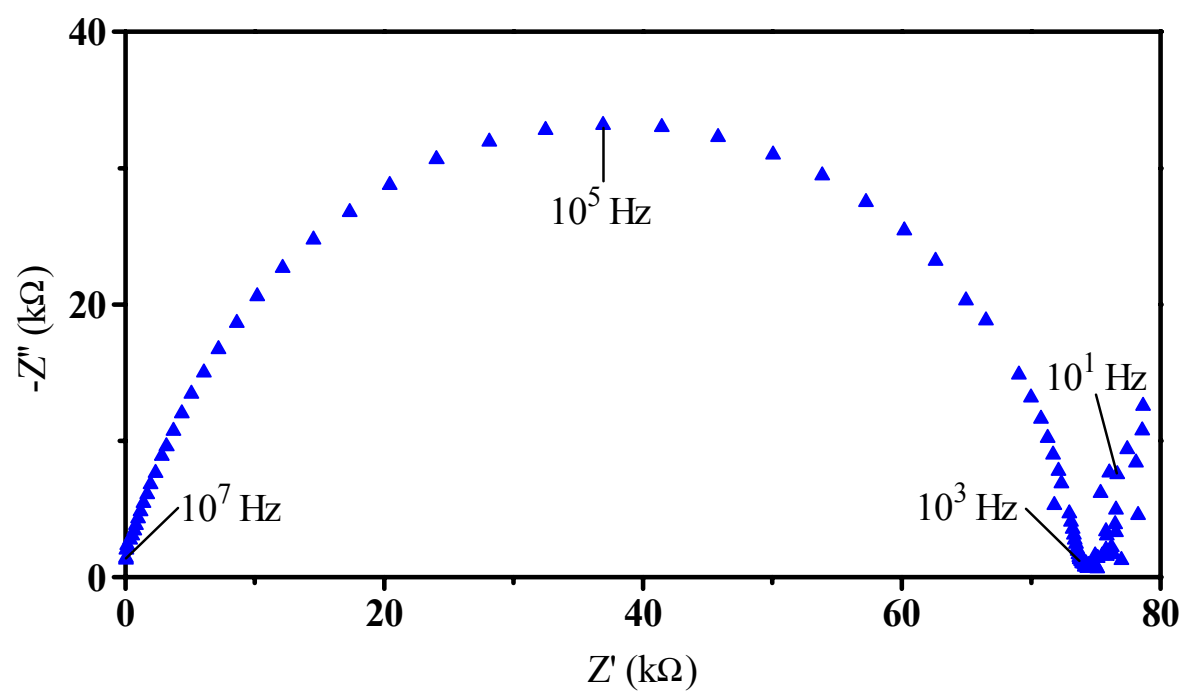

Figura 3.5.11: Diagrama de impedância, obtido a aproximadamente $400{ }^{\circ} \mathrm{C}$, da amostra de $\mathrm{ZrO}_{2}: 8 \%$ mol $\mathrm{Y}_{2} \mathrm{O}_{3}$, coprecipitada, tratada termicamente a $1000{ }^{\circ} \mathrm{C}$.

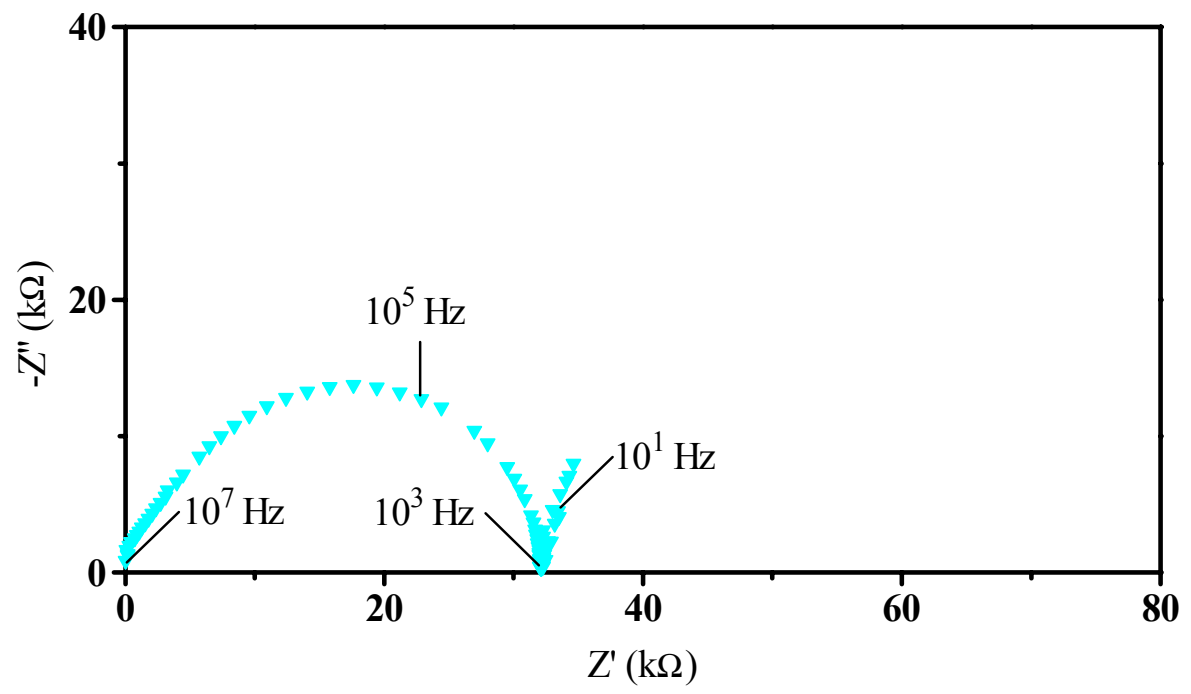

Figura 3.5.12: Diagrama de impedância, obtido a aproximadamente $400{ }^{\circ} \mathrm{C}$, da amostra de $\mathrm{ZrO}_{2}: 8 \%$ mol $\mathrm{Y}_{2} \mathrm{O}_{3}$, coprecipitada, tratada termicamente a $1100{ }^{\circ} \mathrm{C}$. 


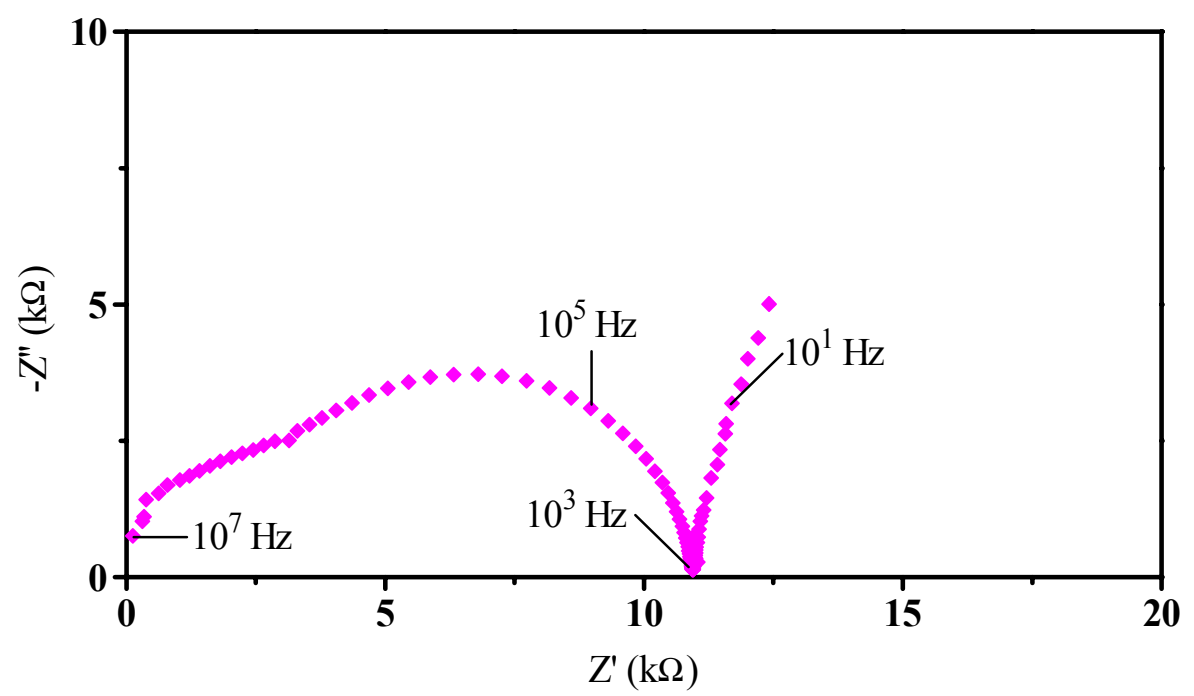

Figura 3.5.13: Diagrama de impedância, obtido a aproximadamente $400{ }^{\circ} \mathrm{C}$, da amostra de $\mathrm{ZrO}_{2}: 8 \%$ mol $\mathrm{Y}_{2} \mathrm{O}_{3}$, coprecipitada, tratada termicamente a $1200{ }^{\circ} \mathrm{C}$.

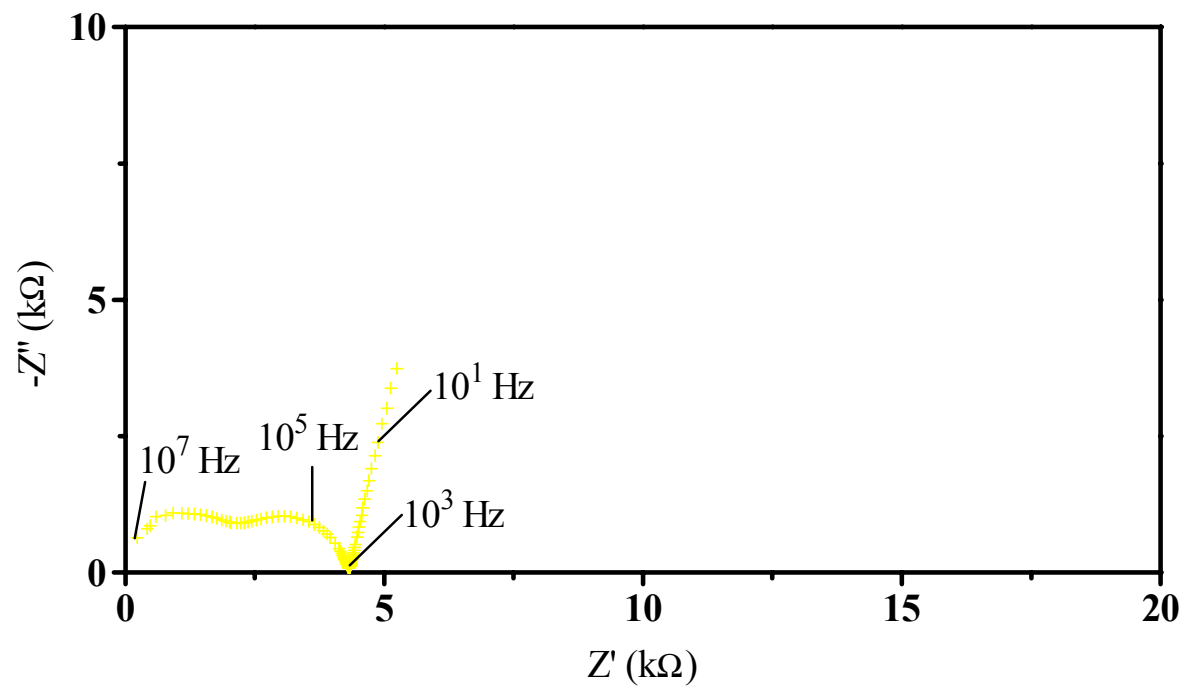

Figura 3.5.14: Diagrama de impedância, obtido a aproximadamente $400{ }^{\circ} \mathrm{C}$, da amostra de $\mathrm{ZrO}_{2}: 8 \%$ mol $\mathrm{Y}_{2} \mathrm{O}_{3}$, coprecipitada, tratada termicamente a $1300{ }^{\circ} \mathrm{C}$. 


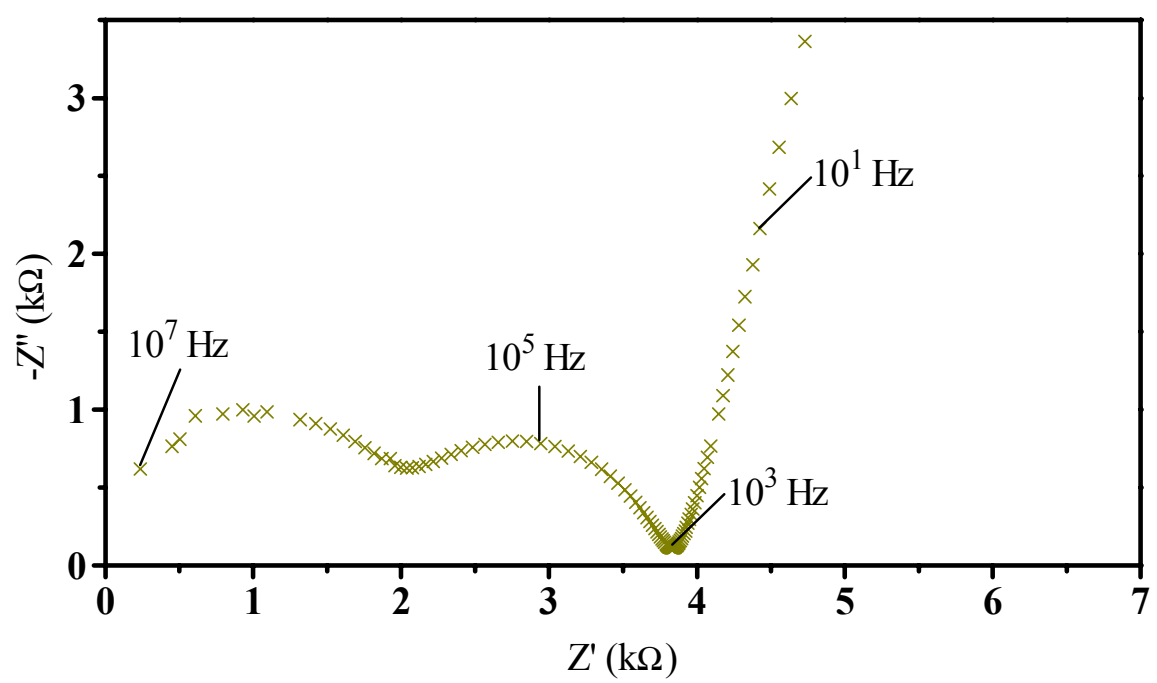

Figura 3.5.15: Diagrama de impedância, obtido a aproximadamente $400{ }^{\circ} \mathrm{C}$, da amostra de $\mathrm{ZrO}_{2}: 8 \%$ mol $\mathrm{Y}_{2} \mathrm{O}_{3}$, coprecipitada, tratada termicamente a $1350{ }^{\circ} \mathrm{C}$.

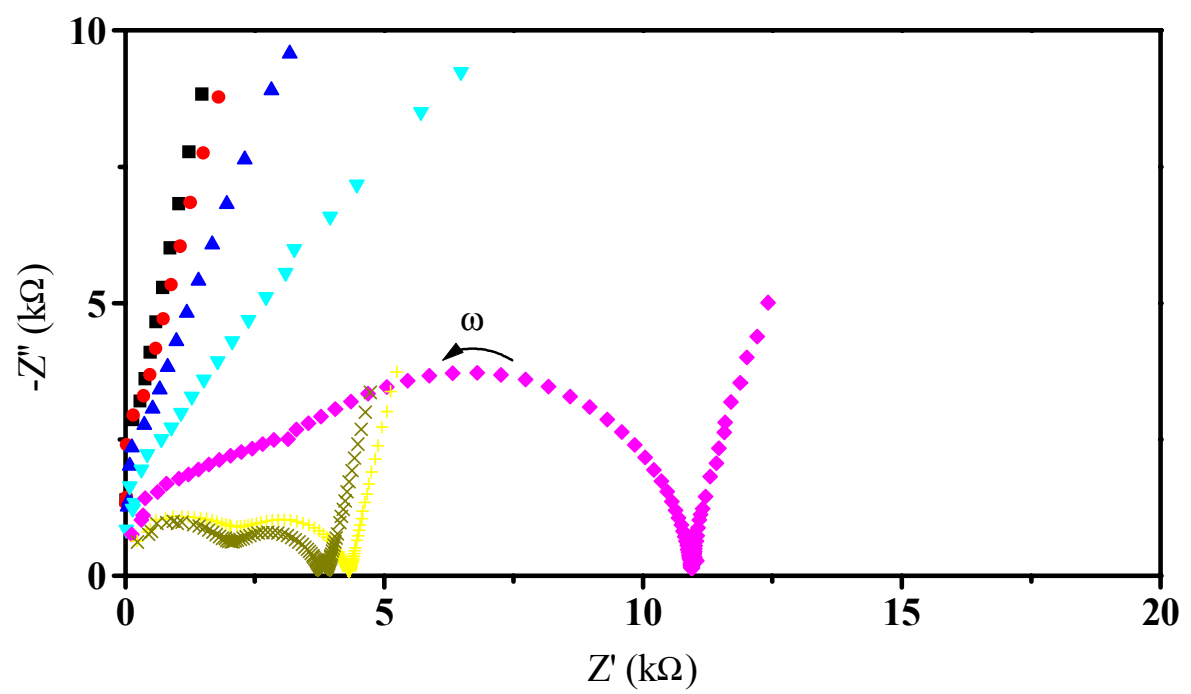

Figura 3.5.16: Sobreposição dos diagramas de impedância apresentados nas figuras 3.5.9 a 3.5.15. As temperaturas de tratamento térmico foram: $800^{\circ} \mathrm{C}(\mathbf{\bullet}), 900{ }^{\circ} \mathrm{C}(\bullet), 1000$ ${ }^{\circ} \mathrm{C}(\Delta), 1100^{\circ} \mathrm{C}(\nabla), 1200{ }^{\circ} \mathrm{C}(\diamond), 1300{ }^{\circ} \mathrm{C}(+), 1350{ }^{\circ} \mathrm{C}(\times)$. 


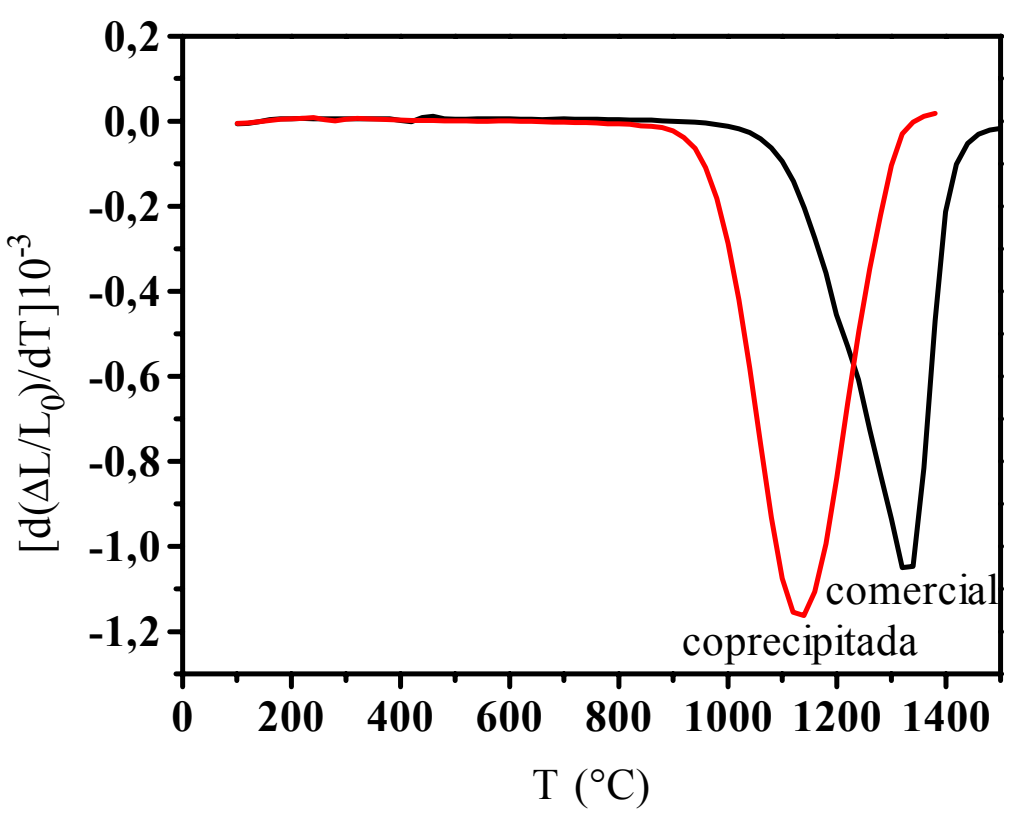

Figura 3.5.17: Derivada da função apresentada na figura 3.3.1 para as amostras de $\mathrm{ZrO}_{2}: 8 \%$ mol $\mathrm{Y}_{2} \mathrm{O}_{3}$, comercial e coprecipitada.

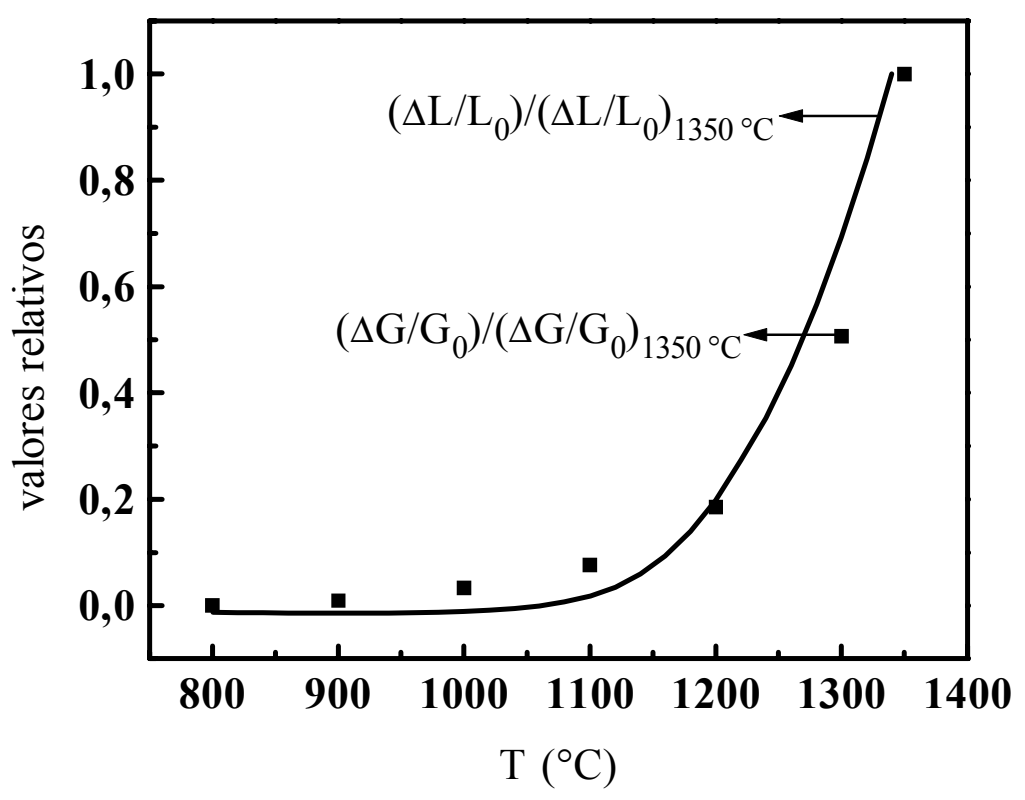

Figura 3.5.18: Variação da condutância total e da retração linear da amostra de $\mathrm{ZrO}_{2}: 8 \%$ mol $\mathrm{Y}_{2} \mathrm{O}_{3}$, comercial, com a temperatura de sinterização. 


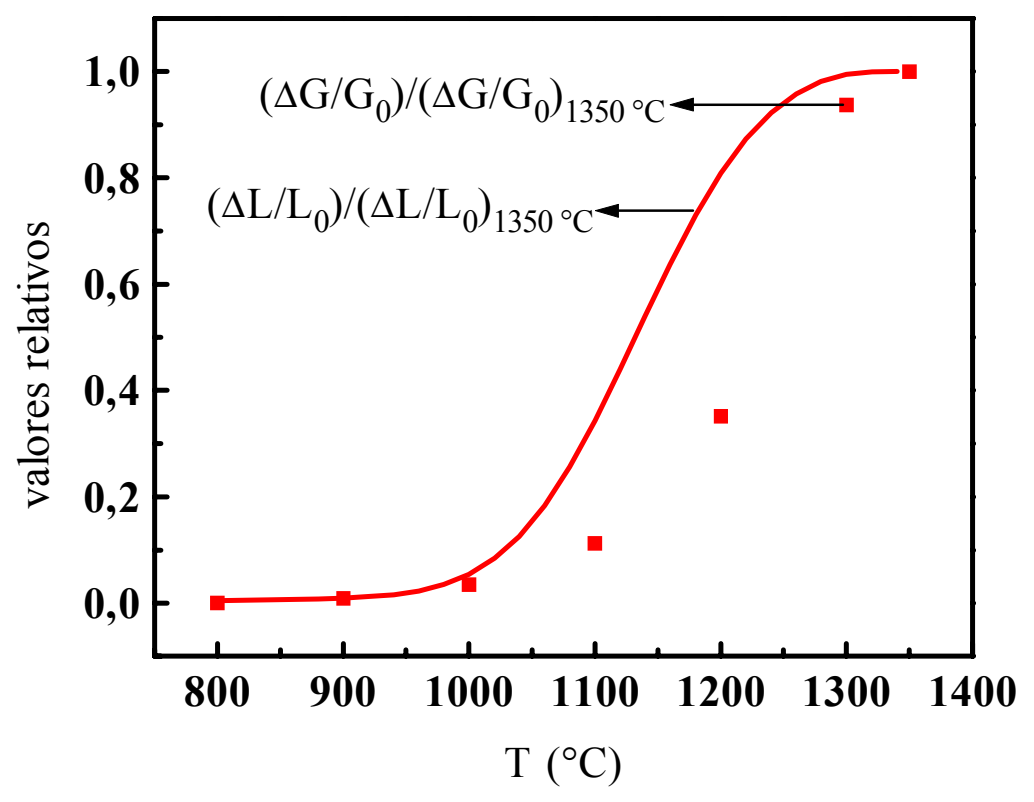

Figura 3.5.19: Variação da condutância total e da retração linear da amostra de $\mathrm{ZrO}_{2}: 8 \% \mathrm{~mol} \mathrm{Y}_{2} \mathrm{O}_{3}$, coprecipitada, com a temperatura de sinterização.

Utilizando-se a relação [16]:

$$
\rho(T)=\rho_{0} \cdot\left(\frac{L_{0}}{L_{T}}\right)^{3}
$$


na qual $\rho(T)$ é a densidade da amostra em uma determinada temperatura $T, \rho_{0}$ é a densidade a verde da amostra, $\mathrm{L}_{0}$ é o comprimento inicial da amostra e $\mathrm{L}_{\mathrm{T}}$ é o comprimento da amostra na mesma temperatura $\mathrm{T}$, foi determinada a variação da densidade das amostras em função da temperatura de sinterização.

Na figura 3.5.20 valores de densidade aparente são apresentados em função da resistência elétrica de amostras de $\mathrm{ZrO}_{2}: 8 \%$ mol $\mathrm{Y}_{2} \mathrm{O}_{3}$ nas temperaturas de sinterização indicadas: $800^{\circ} \mathrm{C}, 900{ }^{\circ} \mathrm{C}, 1000^{\circ} \mathrm{C}, 1100{ }^{\circ} \mathrm{C}, 1200^{\circ} \mathrm{C}, 1300^{\circ} \mathrm{C}$ e $1350{ }^{\circ} \mathrm{C}$.

Já se sabe que amostras de alta resistência inicial atingem os estágios finais de sinterização mais rapidamente que amostras "análogas" mas com baixa resistência inicial [24]. Podemos notar que, principalmente no início da sinterização, a variação de densidade é praticamente nula, enquanto que a variação de resistência é grande, além da resistência apresentar uma rápida variação em função da temperatura de sinterização.

Podemos interpretar esta rápida e precisa resposta da resistência do material em função da temperatura de sinterização, como uma medida das variações das resistências de cada componente da microestrutura do material. Dessa forma temos, no início da sinterização, principalmente, a eliminação de gases (ar), e a mudança na forma dos poros sem que ocorra mudança no volume desses mesmos poros. Medidas elétricas, determinando basicamente a resposta elétrica do material à aplicação de um estímulo elétrico, usam o deslocamento de portadores de carga como pontas de prova no volume do material. Como cada componente microestrutural responde diferentemente a esse estímulo, pode-se afirmar que a medida de resistência elétrica é "sensível” a mudanças microestruturais enquanto que as medidas de densidade não. 


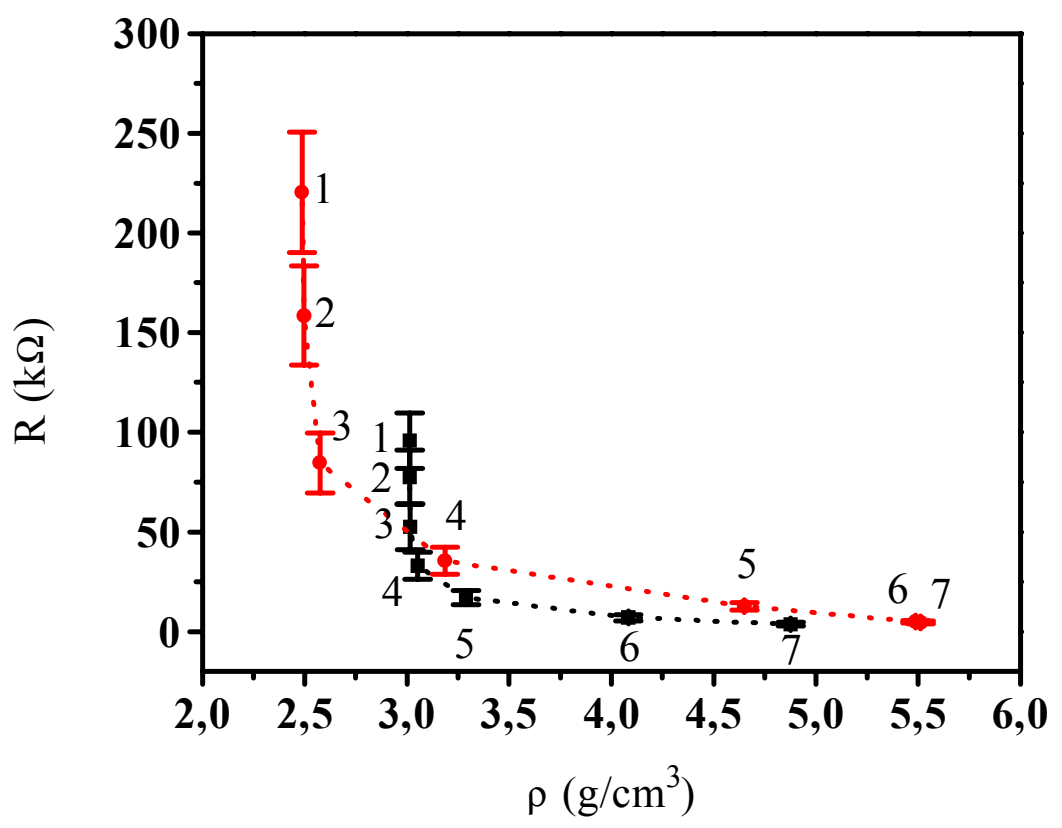

Figura 3.5.20: Variação da resistência com a densidade das amostras de $\mathrm{ZrO}_{2}: 8 \%$ mol $\mathrm{Y}_{2} \mathrm{O}_{3}$, comercial (ם) e coprecipitada (๑); os números indicam a temperatura de sinterização, como segue: $1 \rightarrow \mathrm{T}_{\text {sinterização }}=800^{\circ} \mathrm{C}, 2 \rightarrow \mathrm{T}_{\text {sinterização }}=900{ }^{\circ} \mathrm{C}, 3 \rightarrow \mathrm{T}_{\text {sinterização }}=$ $1000{ }^{\circ} \mathrm{C}, 4 \rightarrow \mathrm{T}_{\text {sinterização }}=1100{ }^{\circ} \mathrm{C}, 5 \rightarrow \mathrm{T}_{\text {sinterização }}=1200{ }^{\circ} \mathrm{C}, 6 \rightarrow \mathrm{T}_{\text {sinterização }}=1300{ }^{\circ} \mathrm{C}$ e $7 \rightarrow$ $\mathrm{T}_{\text {sinterização }}=1350^{\circ} \mathrm{C}$.

Os trabalhos publicados envolvendo o estudo da sinterização da $\mathrm{ZrO}_{2}: \mathrm{Y}_{2} \mathrm{O}_{3}$ utilizando espectroscopia de impedância foram feitos em função da temperatura de sinterização [47, 48, 57-63]. Geralmente os estudos sobre teorias de sinterização, principalmente nos estágios finais deste processo, se fazem com sinterizações isotérmicas em variados intervalos de tempo. As sinterizações isotérmicas favorecem a eliminação dos poros do material, um requisito importante para a maioria das aplicações desses materiais em dispositivos elétricos [60].

Os resultados das medidas de espectroscopia de impedância durante a sinterização das amostras de $\mathrm{ZrO}_{2}: 8 \%$ mol $\mathrm{Y}_{2} \mathrm{O}_{3}$, obtidos a aproximadamente $400{ }^{\circ} \mathrm{C}$, em função do tempo de sinterização na temperatura de $1350{ }^{\circ} \mathrm{C}$ são apresentados nas figuras 3.5.21 até 3.5.29 para a amostra comercial e nas figuras 3.5.30 até 3.5.37 para a amostra 
coprecipitada. Pelo menos dois arcos de semicírculo são evidentes em todas essas figuras: o arco de semicírculo na região de altas freqüências, devido à resistência elétrica dos grãos e o arco de semicírculo de freqüências intermediárias devido à resistência elétrica dos contornos de grão. O segmento de reta ou início de desenvolvimento de um arco de semicírculo a freqüências mais baixas se deve à polarização dos eletrodos.

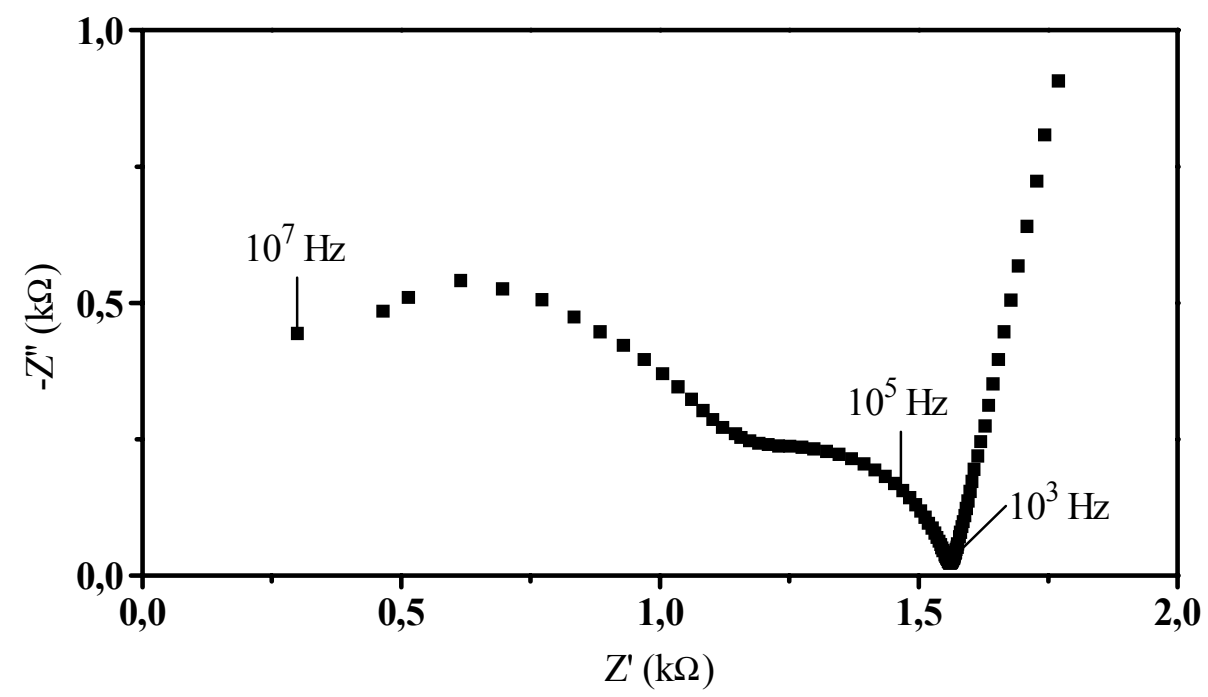

Figura 3.5.21: Diagrama de impedância, obtido a aproximadamente $400{ }^{\circ} \mathrm{C}$, da amostra de $\mathrm{ZrO}_{2}: 8 \%$ mol $\mathrm{Y}_{2} \mathrm{O}_{3}$, comercial, sinterizada a $1350{ }^{\circ} \mathrm{C}$ por $0,2 \mathrm{~h}$. 


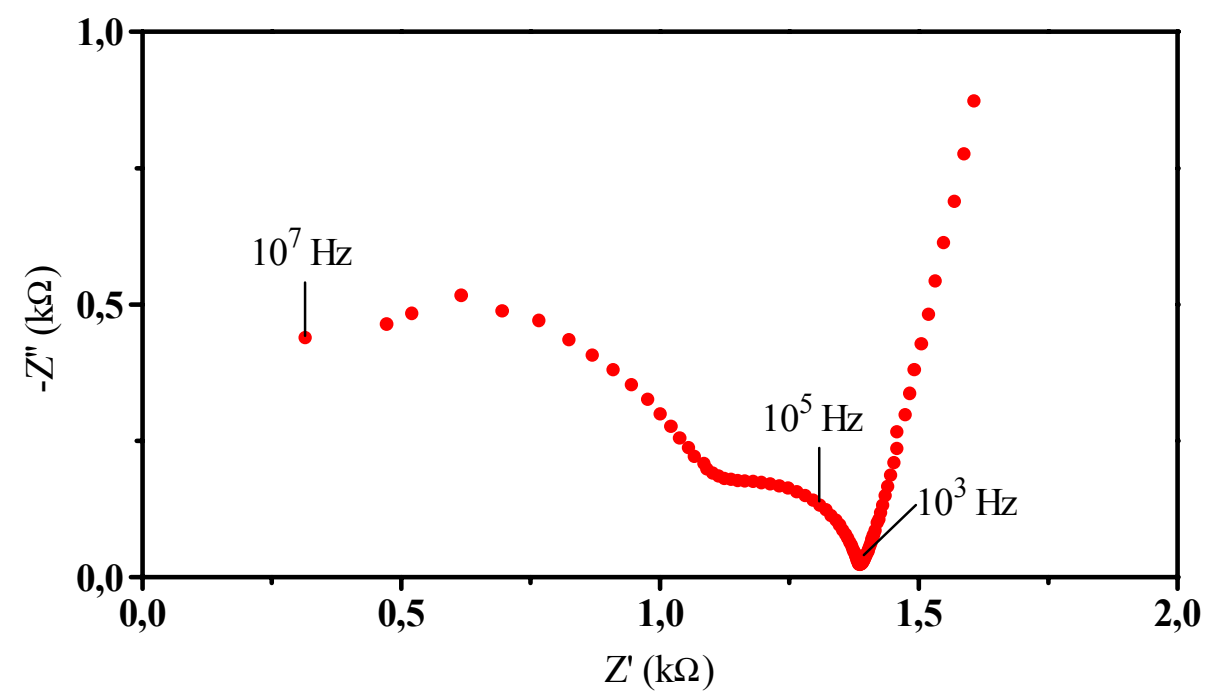

Figura 3.5.22: Diagrama de impedância, obtido a aproximadamente $400{ }^{\circ} \mathrm{C}$, da amostra de $\mathrm{ZrO}_{2}: 8 \%$ mol $\mathrm{Y}_{2} \mathrm{O}_{3}$, comercial, sinterizada a $1350{ }^{\circ} \mathrm{C}$ por $0,6 \mathrm{~h}$.

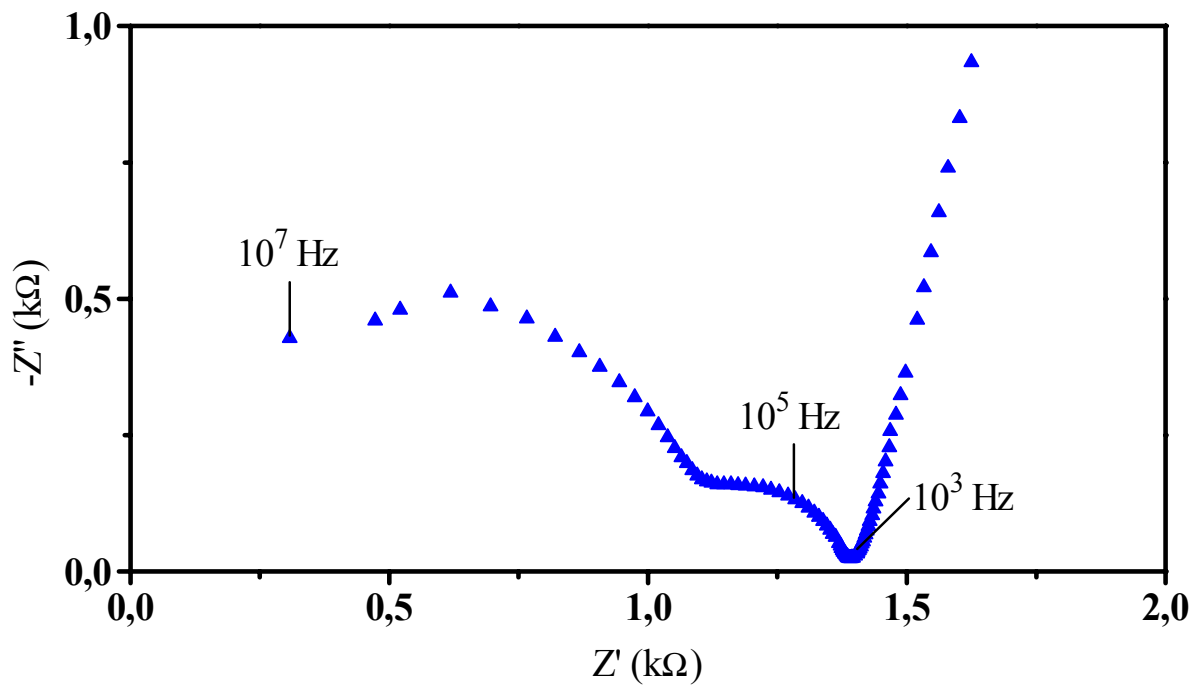

Figura 3.5.23: Diagrama de impedância, obtido a aproximadamente $400{ }^{\circ} \mathrm{C}$, da amostra de $\mathrm{ZrO}_{2}: 8 \%$ mol $\mathrm{Y}_{2} \mathrm{O}_{3}$, comercial, sinterizada a $1350{ }^{\circ} \mathrm{C}$ por $1,2 \mathrm{~h}$. 


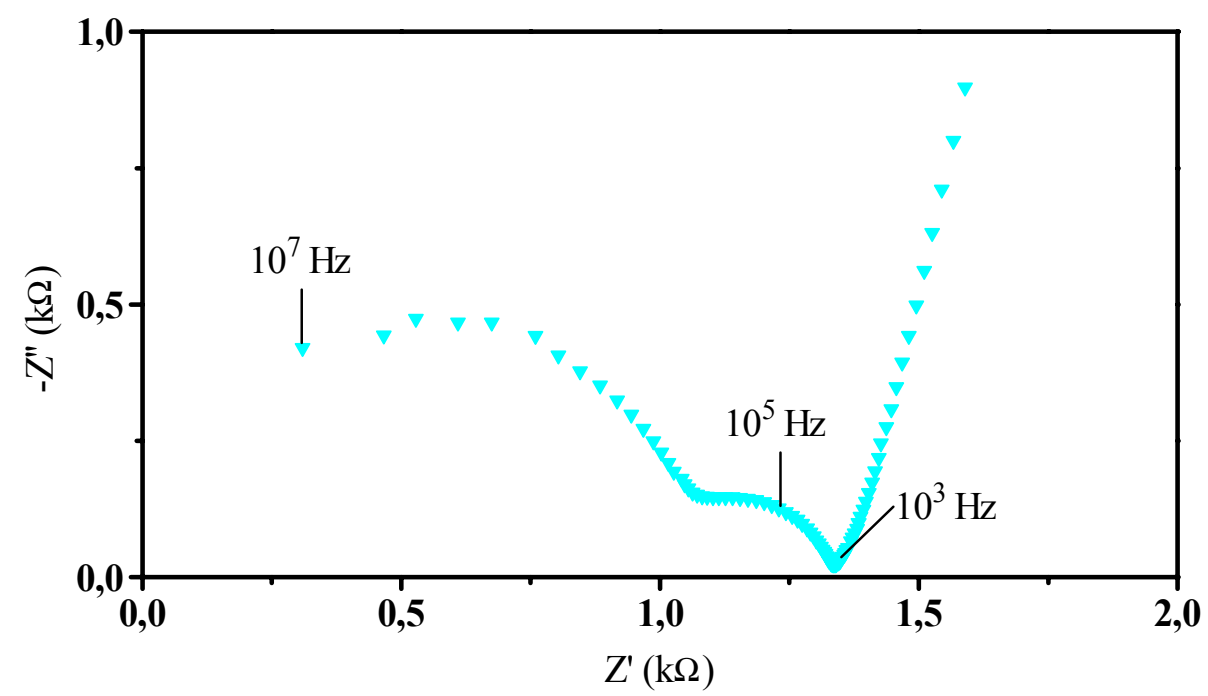

Figura 3.5.24: Diagrama de impedância, obtido a aproximadamente $400{ }^{\circ} \mathrm{C}$, da amostra de $\mathrm{ZrO}_{2}: 8 \%$ mol $\mathrm{Y}_{2} \mathrm{O}_{3}$, comercial, sinterizada a $1350{ }^{\circ} \mathrm{C}$ por $1,7 \mathrm{~h}$.

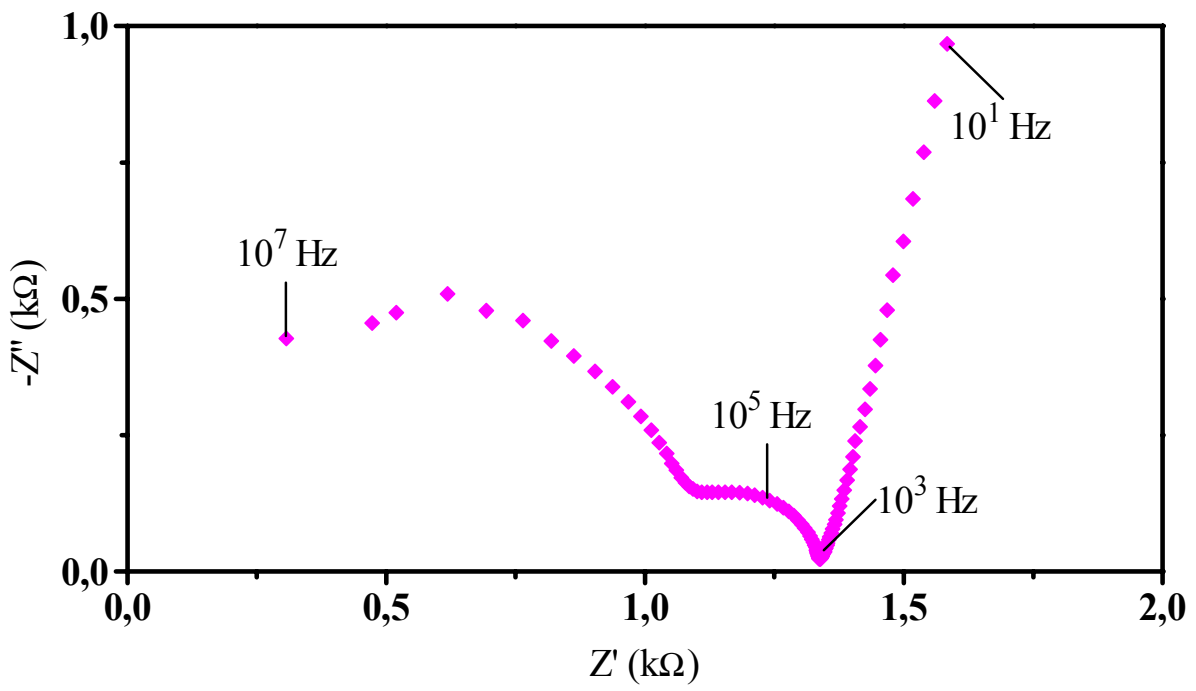

Figura 3.5.25: Diagrama de impedância, obtido a aproximadamente $400{ }^{\circ} \mathrm{C}$, da amostra de $\mathrm{ZrO}_{2}: 8 \%$ mol $\mathrm{Y}_{2} \mathrm{O}_{3}$, comercial, sinterizada a $1350{ }^{\circ} \mathrm{C}$ por $2,2 \mathrm{~h}$. 


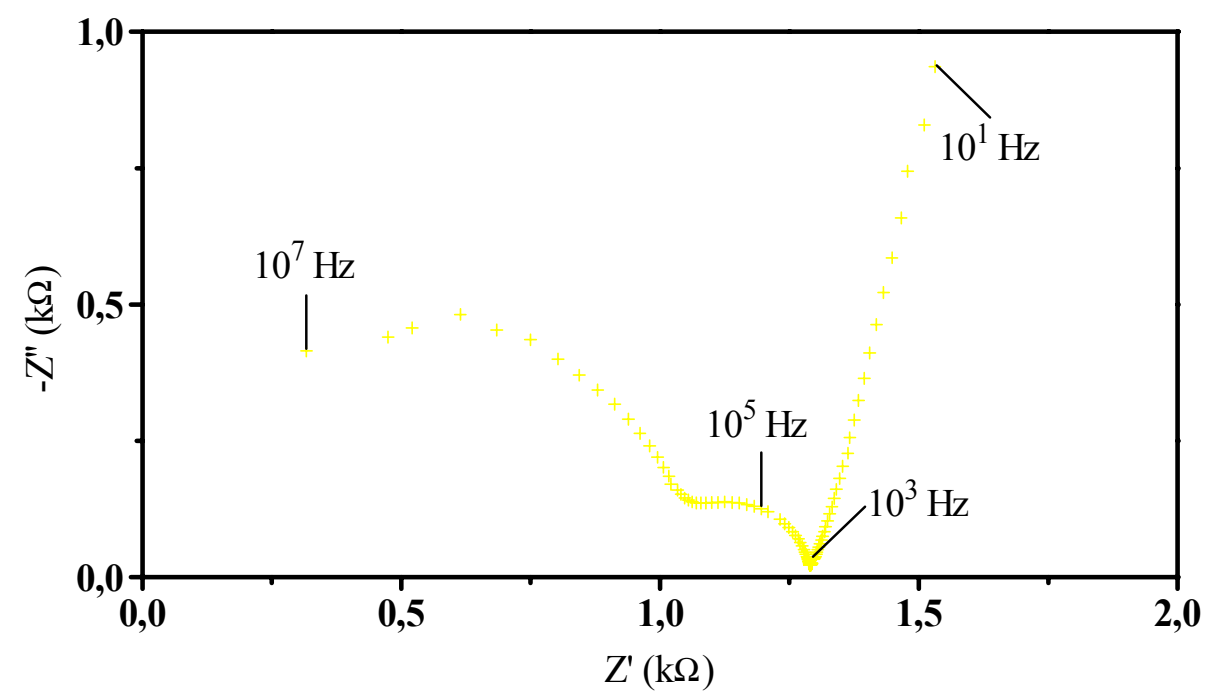

Figura 3.5.26: Diagrama de impedância, obtido a aproximadamente $400{ }^{\circ} \mathrm{C}$, da amostra de $\mathrm{ZrO}_{2}: 8 \%$ mol $\mathrm{Y}_{2} \mathrm{O}_{3}$, comercial, sinterizada a $1350{ }^{\circ} \mathrm{C}$ por $2,7 \mathrm{~h}$.

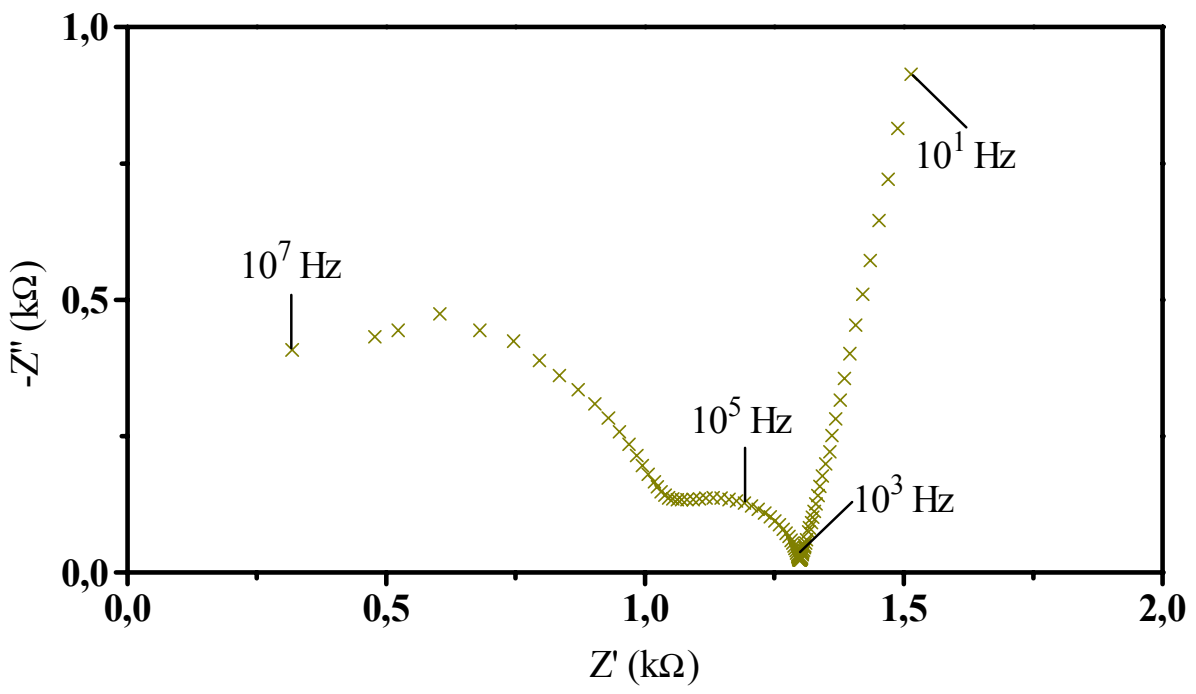

Figura 3.5.27: Diagrama de impedância, obtido a aproximadamente $400{ }^{\circ} \mathrm{C}$, da amostra de $\mathrm{ZrO}_{2}: 8 \%$ mol $\mathrm{Y}_{2} \mathrm{O}_{3}$, comercial, sinterizada a $1350{ }^{\circ} \mathrm{C}$ por $3,2 \mathrm{~h}$. 


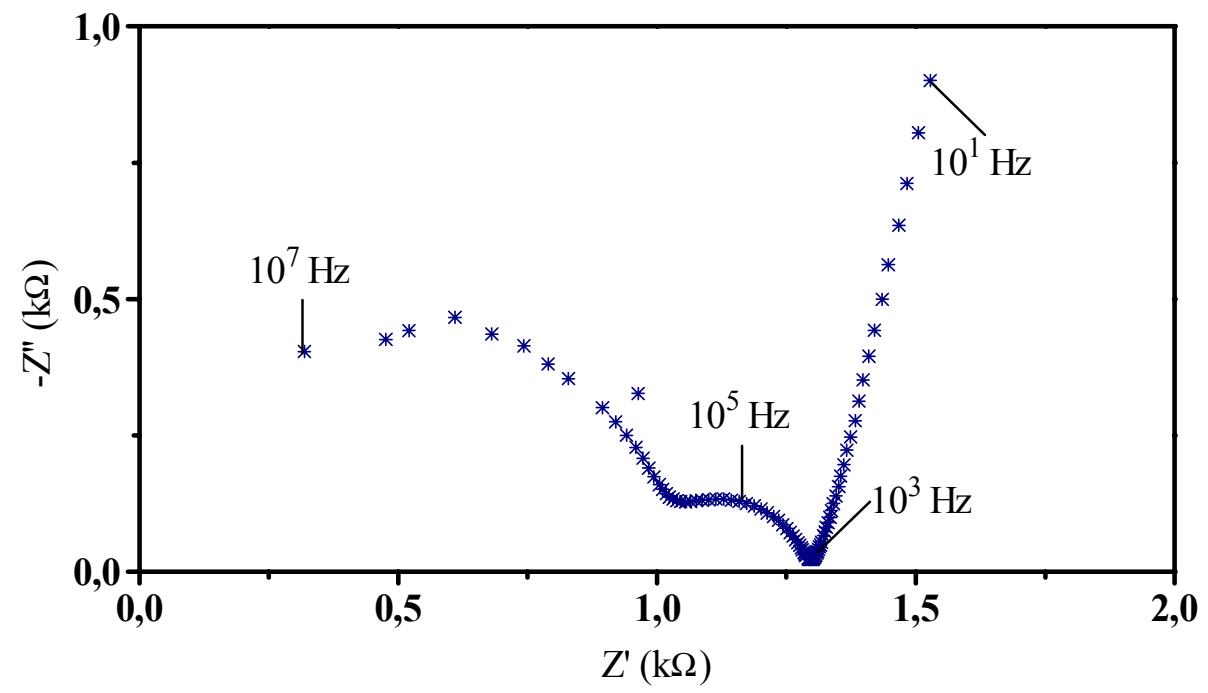

Figura 3.5.28: Diagrama de impedância, obtido a aproximadamente $400{ }^{\circ} \mathrm{C}$, da amostra de $\mathrm{ZrO}_{2}: 8 \%$ mol $\mathrm{Y}_{2} \mathrm{O}_{3}$, comercial, sinterizada a $1350{ }^{\circ} \mathrm{C}$ por $3,7 \mathrm{~h}$.

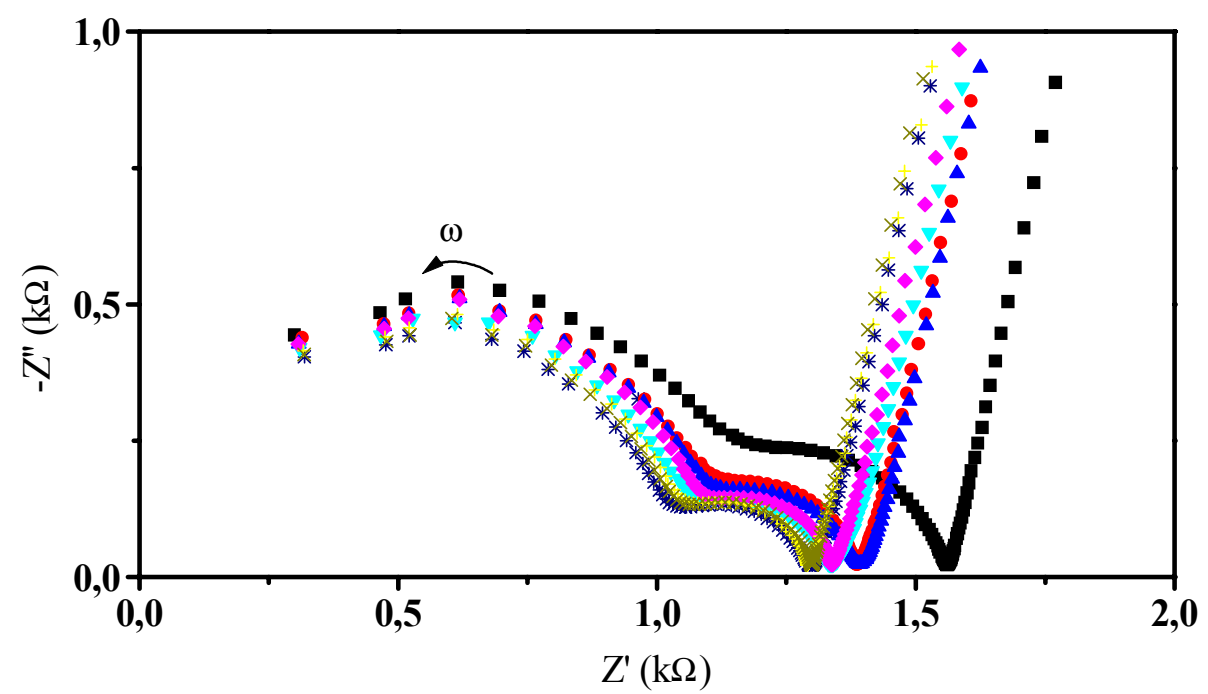

Figura 3.5.29: Sobreposição dos diagramas de impedância apresentados nas figuras 3.5.21 a 3.5.28. Os intervalos de tempo de sinterização a $1350{ }^{\circ} \mathrm{C}$ foram: $0,2 \mathrm{~h} \mathrm{( \bullet ),} \mathrm{0,6} \mathrm{h} \mathrm{( \bullet}$ ), 1,2 h (४), 1,7 h ( $\vee), 2,2 \mathrm{~h} \mathrm{( \diamond ),} \mathrm{2,7} \mathrm{h} \mathrm{(} \mathrm{)} \mathrm{,} \mathrm{3,2} \mathrm{h} \mathrm{(×)} \mathrm{3,7} \mathrm{h} \mathrm{(*).}$ 


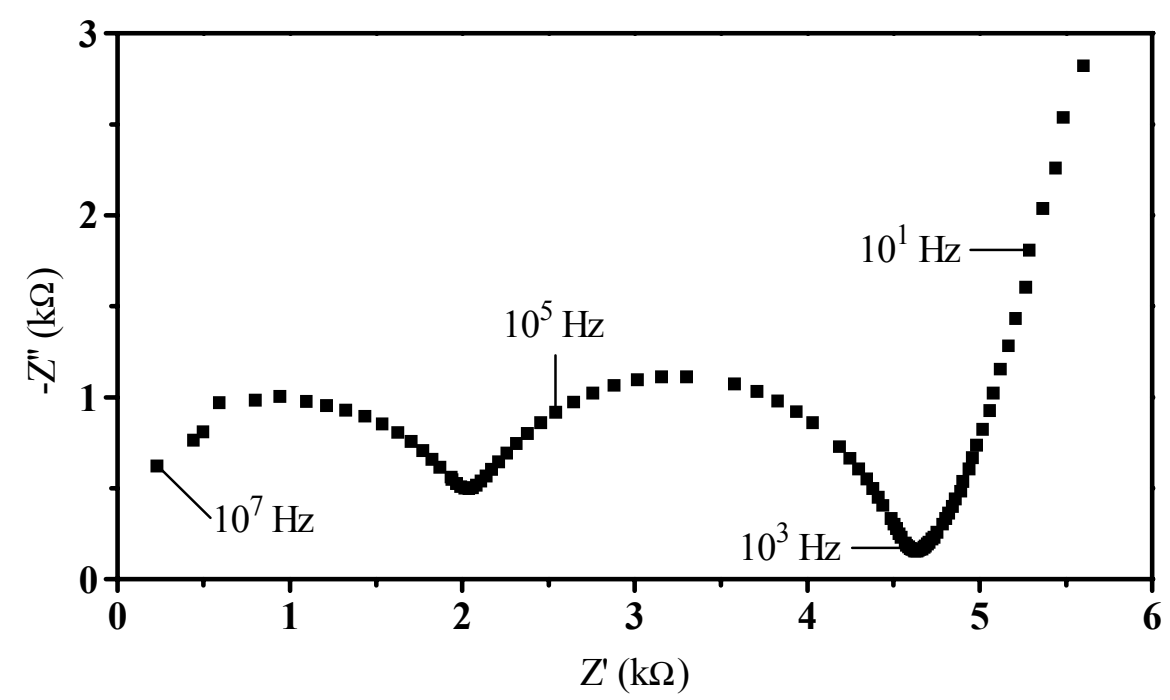

Figura 3.5.30: Diagrama de impedância, obtido a aproximadamente $400{ }^{\circ} \mathrm{C}$, da amostra de $\mathrm{ZrO}_{2}: 8 \%$ mol $\mathrm{Y}_{2} \mathrm{O}_{3}$, coprecipitada, sinterizada a $1350{ }^{\circ} \mathrm{C}$ por $0,2 \mathrm{~h}$.

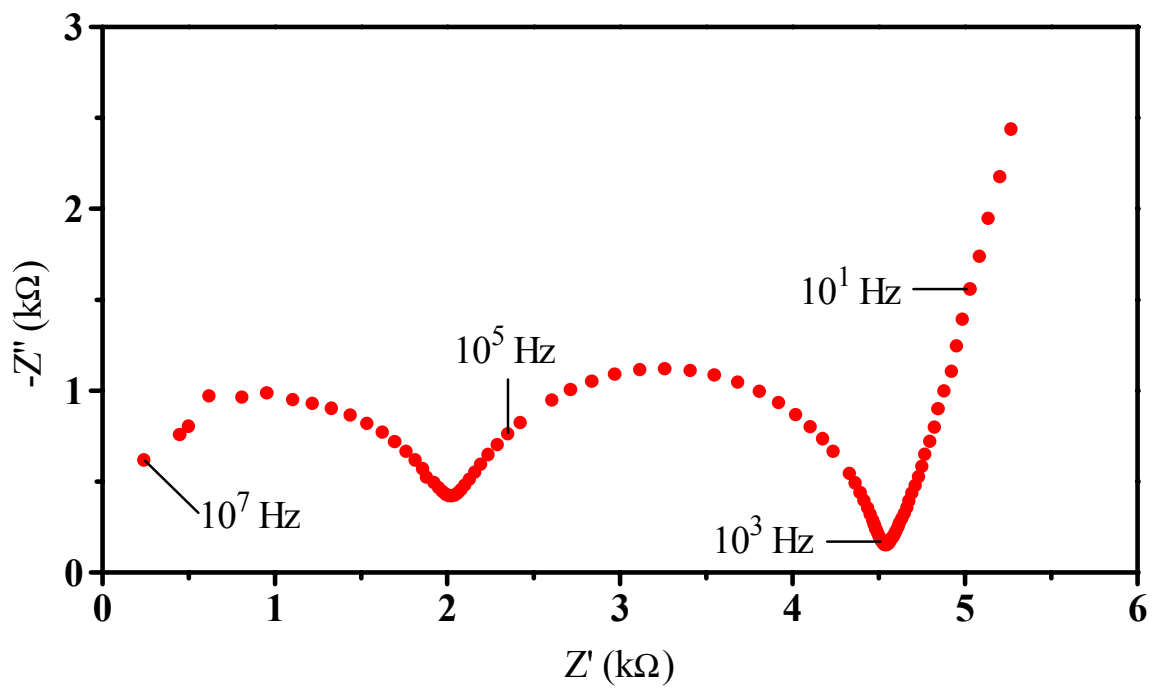

Figura 3.5.31: Diagrama de impedância, obtido a aproximadamente $400{ }^{\circ} \mathrm{C}$, da amostra de $\mathrm{ZrO}_{2}: 8 \%$ mol $\mathrm{Y}_{2} \mathrm{O}_{3}$, coprecipitada, sinterizada a $1350{ }^{\circ} \mathrm{C}$ por $0,6 \mathrm{~h}$. 


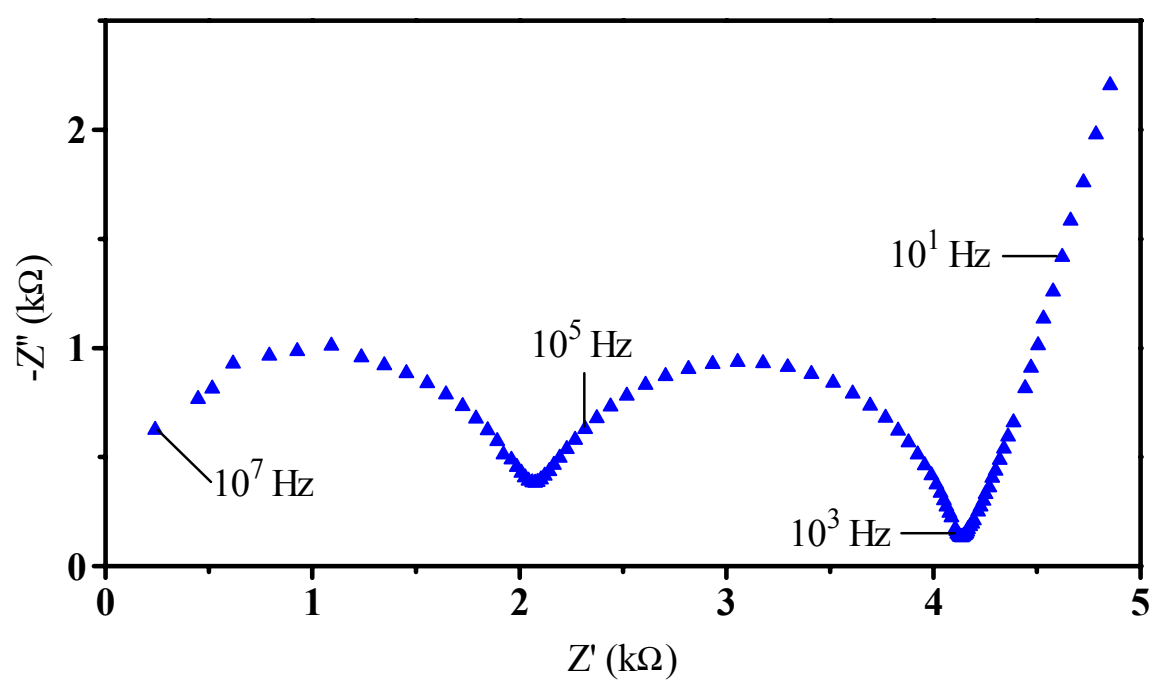

Figura 3.5.32: Diagrama de impedância, obtido a aproximadamente $400{ }^{\circ} \mathrm{C}$, da amostra de $\mathrm{ZrO}_{2}: 8 \%$ mol $\mathrm{Y}_{2} \mathrm{O}_{3}$, coprecipitada, sinterizada a $1350{ }^{\circ} \mathrm{C}$ por $1,2 \mathrm{~h}$.

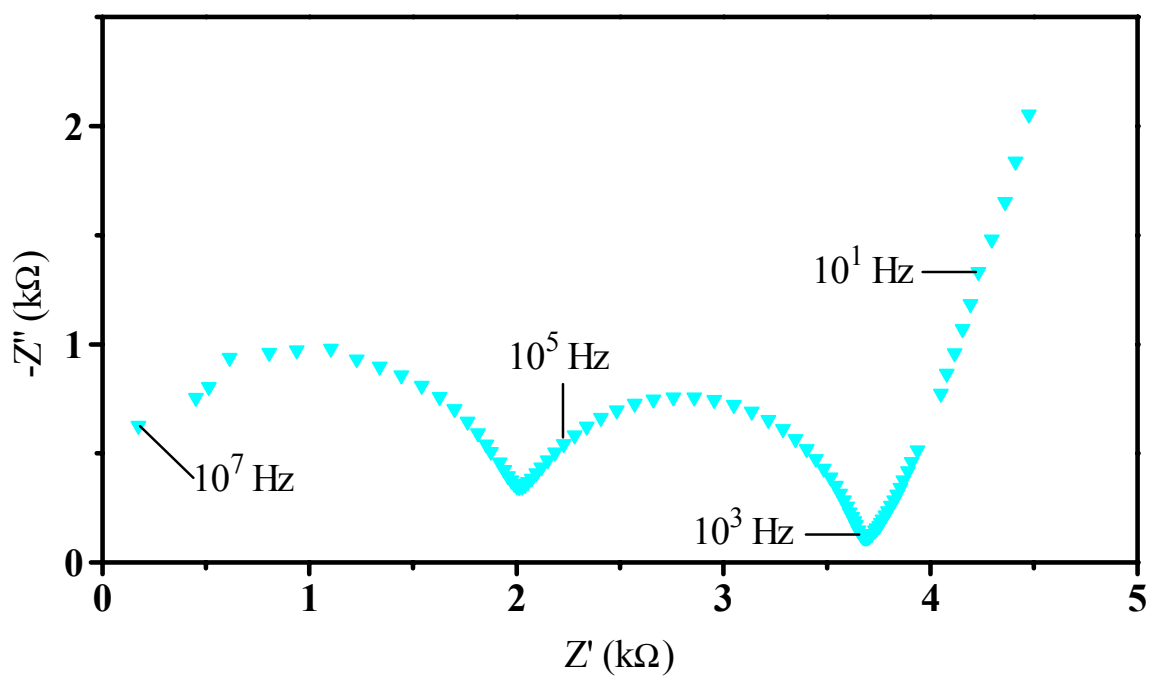

Figura 3.5.33: Diagrama de impedância, obtido a aproximadamente $400{ }^{\circ} \mathrm{C}$, da amostra de $\mathrm{ZrO}_{2}: 8 \%$ mol $\mathrm{Y}_{2} \mathrm{O}_{3}$, coprecipitada, sinterizada a $1350{ }^{\circ} \mathrm{C}$ por $1,7 \mathrm{~h}$. 


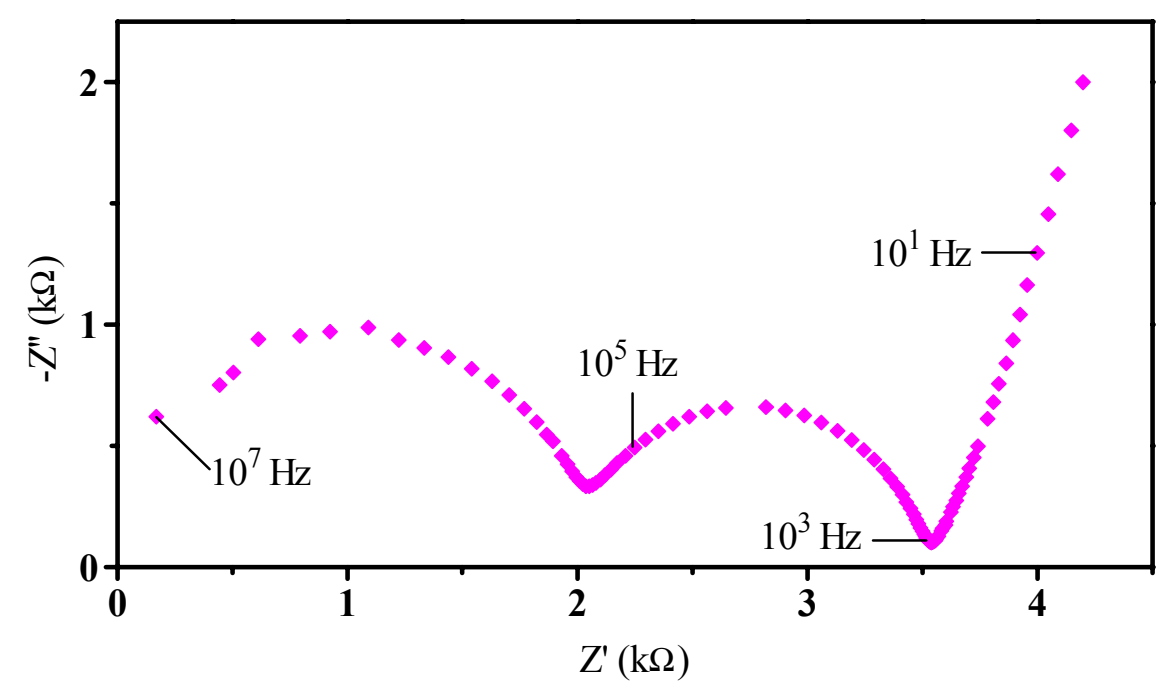

Figura 3.5.34: Diagrama de impedância, obtido a aproximadamente $400{ }^{\circ} \mathrm{C}$, da amostra de $\mathrm{ZrO}_{2}: 8 \%$ mol $\mathrm{Y}_{2} \mathrm{O}_{3}$, coprecipitada, sinterizada a $1350{ }^{\circ} \mathrm{C}$ por $2,2 \mathrm{~h}$.

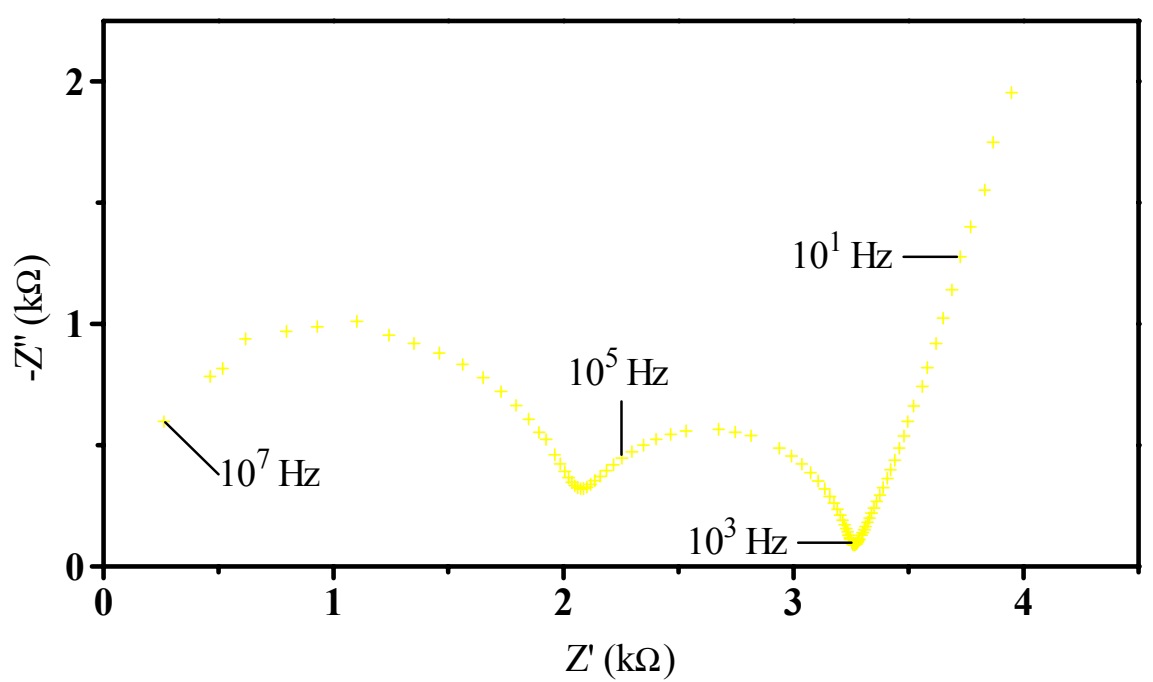

Figura 3.5.35: Diagrama de impedância, obtido a aproximadamente $400{ }^{\circ} \mathrm{C}$, da amostra de $\mathrm{ZrO}_{2}: 8 \%$ mol $\mathrm{Y}_{2} \mathrm{O}_{3}$, coprecipitada, sinterizada a $1350{ }^{\circ} \mathrm{C}$ por $2,7 \mathrm{~h}$. 


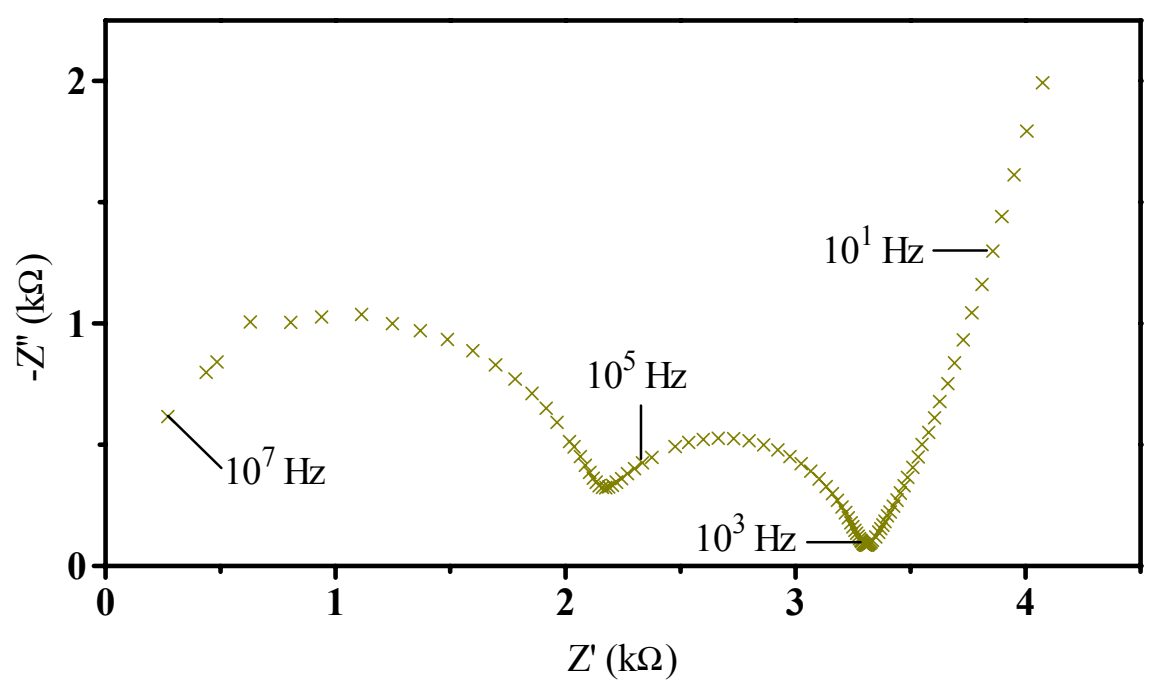

Figura 3.5.36: Diagrama de impedância, obtido a aproximadamente $400{ }^{\circ} \mathrm{C}$, da amostra de $\mathrm{ZrO}_{2}: 8 \%$ mol $\mathrm{Y}_{2} \mathrm{O}_{3}$, coprecipitada, sinterizada a $1350{ }^{\circ} \mathrm{C}$ por $3,2 \mathrm{~h}$.

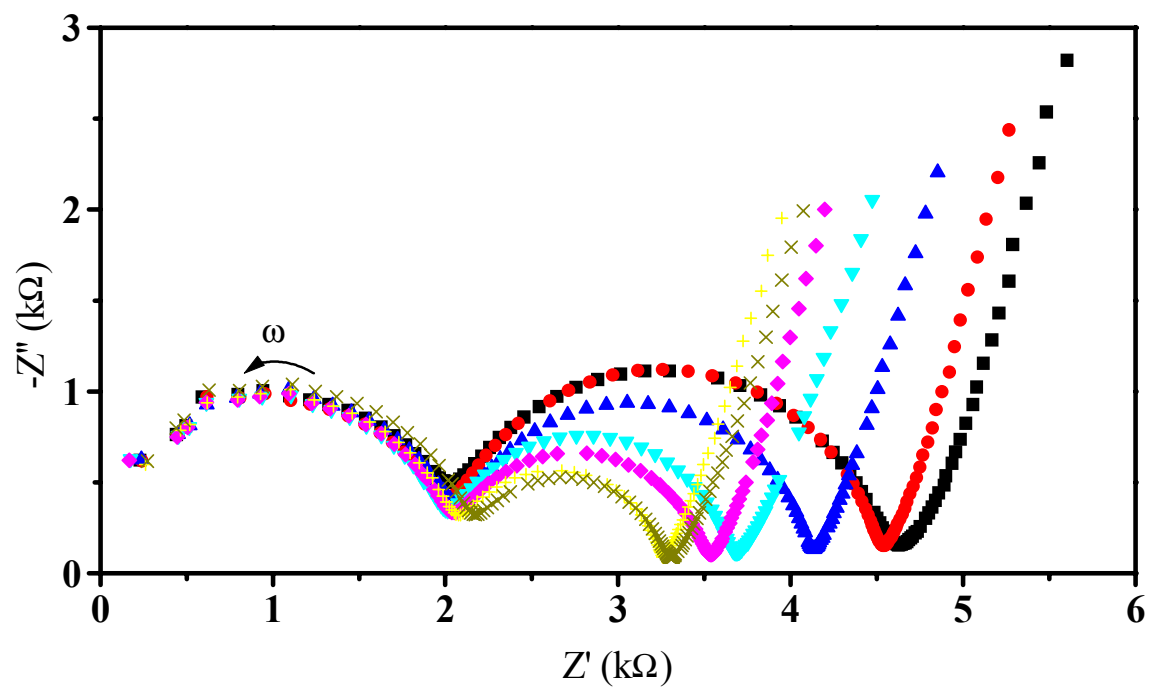

Figura 3.5.37: Sobreposição dos diagramas de impedância apresentados nas figuras 3.5.30 a 3.5.36. Os intervalos de tempo de sinterização a $1350{ }^{\circ} \mathrm{C}$ foram: $0,2 \mathrm{~h} \mathrm{( \bullet ),} \mathrm{0,6} \mathrm{h} \mathrm{( \bullet}$ ), 1,2 h (^), 1,7 h ( $), 2,2 \mathrm{~h}(\diamond), 2,7 \mathrm{~h}(+), 3,2 \mathrm{~h} \mathrm{(×).}$

Podemos notar nas figuras acima que o arco de semicírculo devido aos grãos do material não apresenta mudanças significativas em função do tempo de sinterização a 1350 
${ }^{\circ} \mathrm{C}$. Já o arco de semicírculo devido aos contornos de grão do material apresenta uma diminuição em função do tempo de sinterização na temperatura de $1350{ }^{\circ} \mathrm{C}$. Isso fica mais claro de se observar nas figuras 3.5.38 a 3.5.40 onde são mostrados a variação da resistência dos grãos e dos contornos de grão para as amostras comercial e coprecipitada com o tempo de sinterização a $1350{ }^{\circ} \mathrm{C}$. A incerteza em cada ponto experimental foi determinada pelo desvio padrão da média de, no mínimo, três medidas.

Esses resultados da dependência de $\mathrm{R}_{\mathrm{g}}$ e $\mathrm{R}_{\mathrm{cg}}$ com o tempo de sinterização mostram a possibilidade de se estudar crescimento de grão por espectroscopia de impedância. Quanto maior o tamanho médio de grão, menor a densidade de contornos de grão, e consequentemente, menor a resistência dos contornos de grão. A situação limite é a do monocristal, que por não apresentar contornos de grão, tem seu diagrama de impedância composto de um único semicírculo devido ao grão [3].

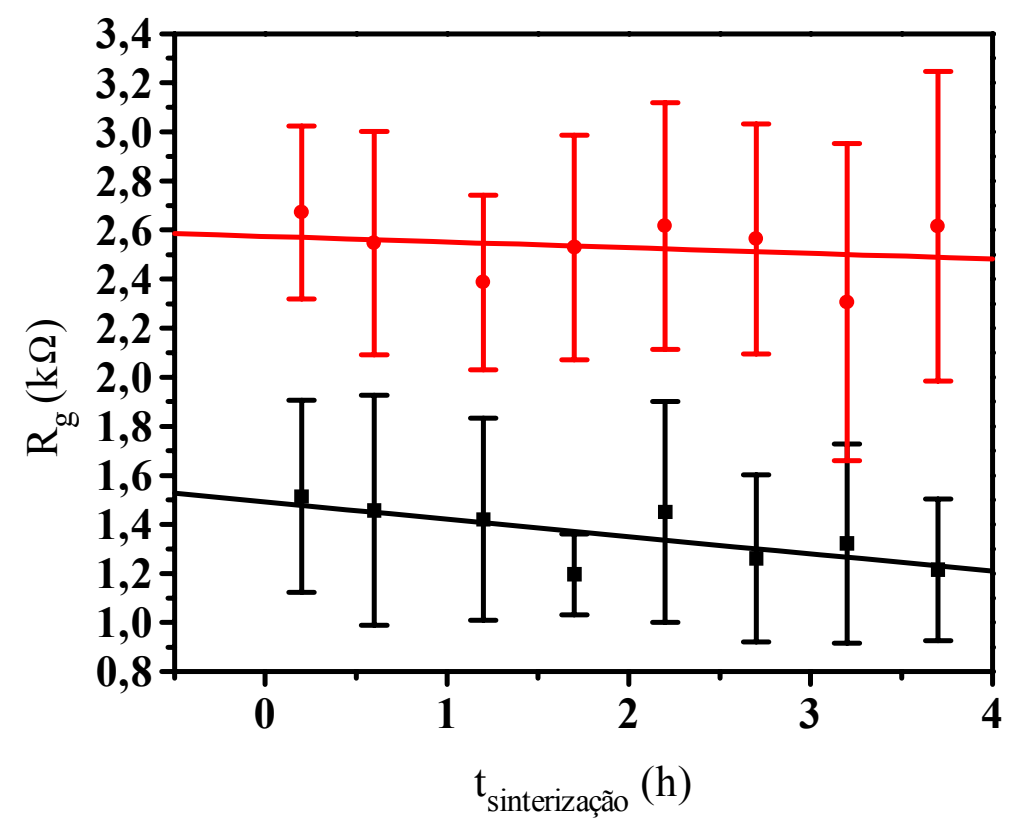

Figura 3.5.38: Variação da resistência dos grãos das amostras de $\mathrm{ZrO}_{2}: 8 \%$ mol $\mathrm{Y}_{2} \mathrm{O}_{3}$, comercial (घ) e coprecipitada (๑), com o tempo de sinterização na temperatura de $1350{ }^{\circ} \mathrm{C}$. 


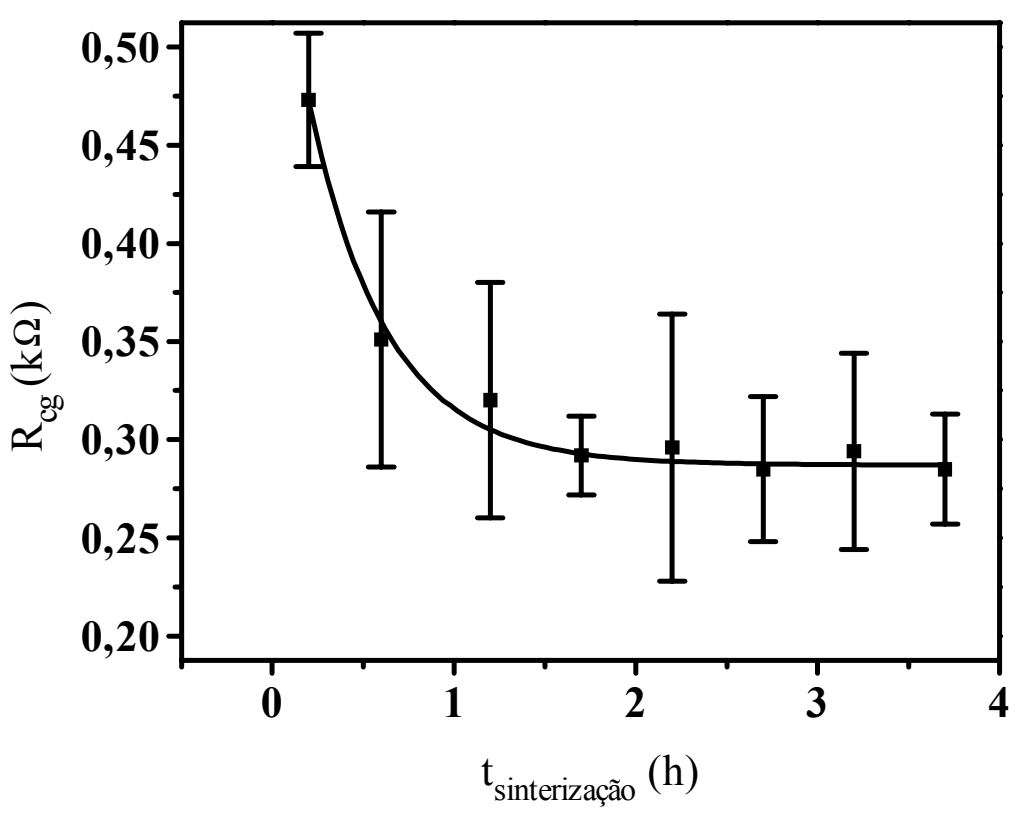

Figura 3.4.39: Variação da resistência dos contornos de grão da amostra de $\mathrm{ZrO}_{2}: 8 \%$ mol $\mathrm{Y}_{2} \mathrm{O}_{3}$, comercial, com o tempo de sinterização na temperatura de $1350{ }^{\circ} \mathrm{C}$.

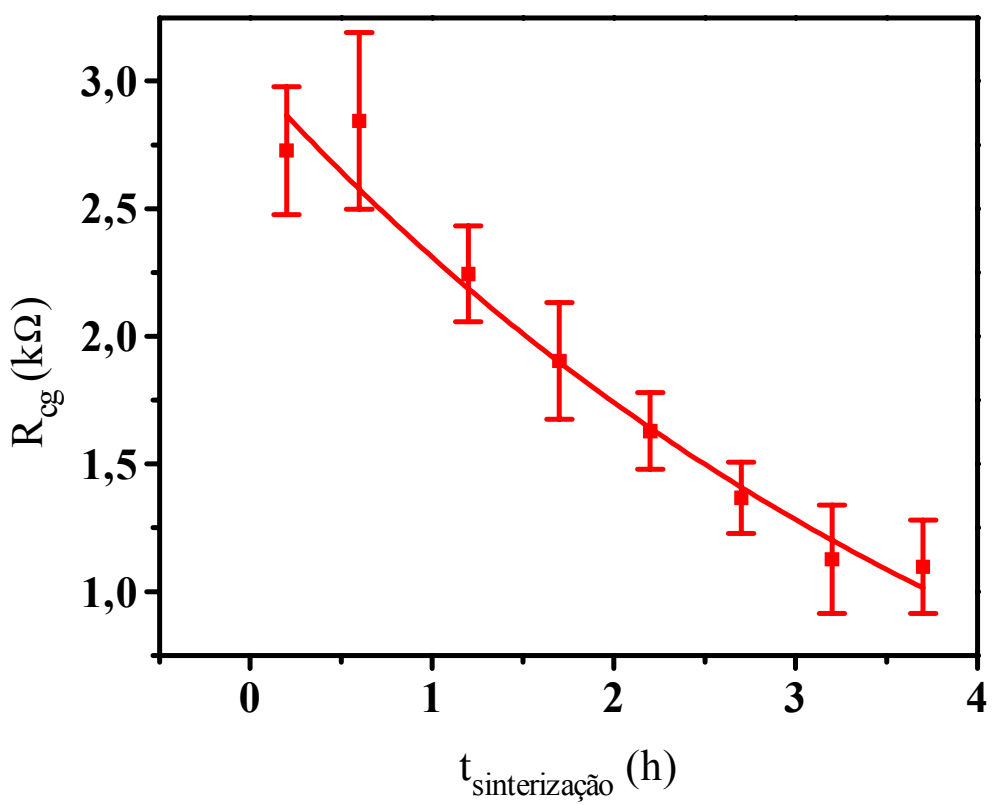

Figura 3.5.40: Variação da resistência dos contornos de grão da amostra de $\mathrm{ZrO}_{2}: 8 \%$ mol $\mathrm{Y}_{2} \mathrm{O}_{3}$, coprecipitada, com o tempo de sinterização na temperatura de $1350{ }^{\circ}$ C. 
Na figura 3.5.41 é mostrada variação do parâmetro $\alpha_{R}[29,30]$ em função do tempo de sinterização a $1350{ }^{\circ} \mathrm{C}$ para ambas as amostras.

Podemos notar que o parâmetro $\alpha_{R}$ diminui linearmente com o tempo de sinterização para a amostra coprecipitada, ficando aproximadamente constante para a amostra comercial em relação ao mesmo parâmetro determinado para a amostra coprecipitada.

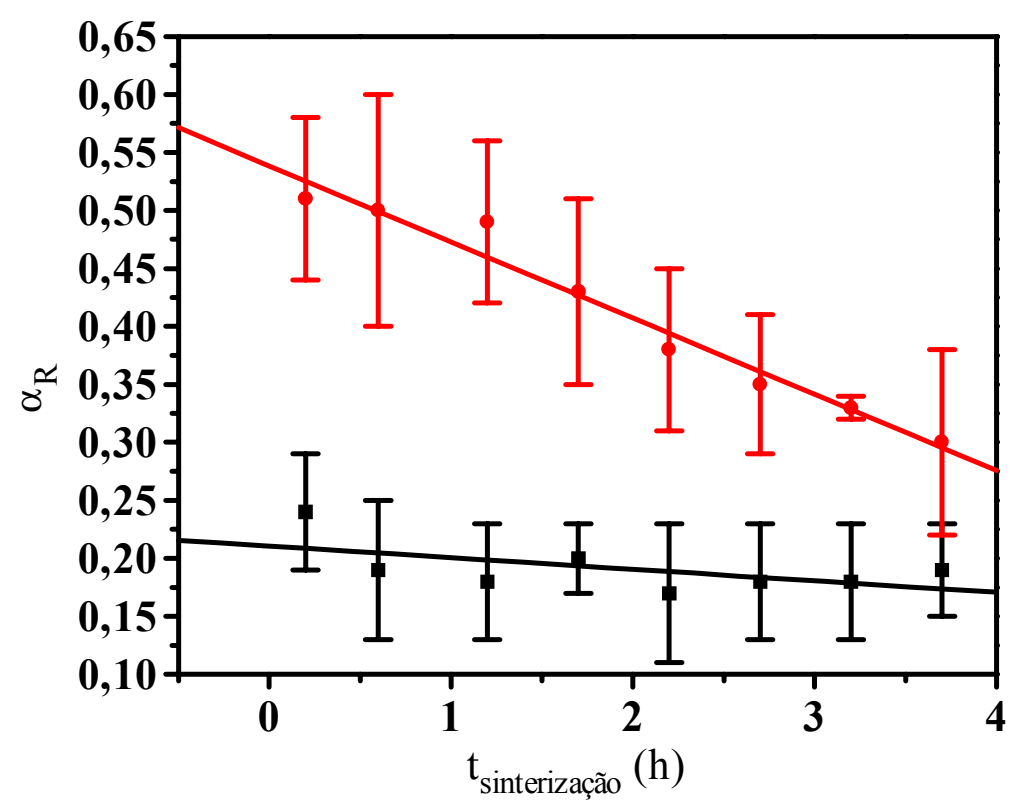

Figura 3.5.41: Variação do parâmetro $\alpha_{\mathrm{R}}$ com o tempo de sinterização a $1350{ }^{\circ} \mathrm{C}$, ) comercial e (๑) coprecipitada.

O parâmetro $\alpha_{R}$ está relacionado com o número de portadores de carga bloqueados, e assim, assumindo que os fenômenos de bloqueio dos portadores de carga se dão nos contornos de grão do material, o parâmetro $\alpha_{R}$ está associado à densidade desses bloqueios/contornos de grão. 
Como sabemos a densidade de contornos de grão está relacionada ao tamanho médio de grão do material [30]. A partir da figura 3.4 .41 podemos verificar, qualitativamente, que os mecanismos de crescimento de grão, nesse intervalo de tempo, na temperatura de $1350{ }^{\circ} \mathrm{C}$, são diferentes para as duas amostras, a pequena variação do parâmetro $\alpha_{R}$ para a amostra comercial indica um lento crescimento de grão na temperatura de $1350{ }^{\circ} \mathrm{C}$ enquanto que para a amostra coprecipitada essa temperatura é suficiente para a promoção do crescimento de grão.

Devido a pureza dos materiais de partida podemos assumir que os contornos de grão das amostras são constituídos, basicamente, de poros; dessa forma o produto $\alpha_{R} \cdot \alpha_{f}$ deve ser proporcional a porosidade do material [63]. Nas figura 3.5.42 e 3.5.43 são apresentadas as relações entre o produto $\alpha_{R} \cdot \alpha_{f}$ e o tempo de sinterização isotérmica segundo a equação [16]:

$$
\varepsilon^{3 / 2}=C+\frac{B}{t^{1 / 3}}
$$

onde $\varepsilon$ é a porosidade, $\mathrm{C}$ e B são constantes e t é o tempo de sinterização.

A equação 3.5.2 foi utilizada primeiramente no estudo da sinterização de metais durante o estágio intermediário, tendo como mecanismo de controle de sua cinética de sinterização a difusão por contorno de grão. Portanto as figuras 3.5.42 e 3.5.43 devem ser tomadas como tentativas de se utilizar os parâmetros determinados por espectroscopia de impedância no estudo da cinética de sinterização de materiais. 


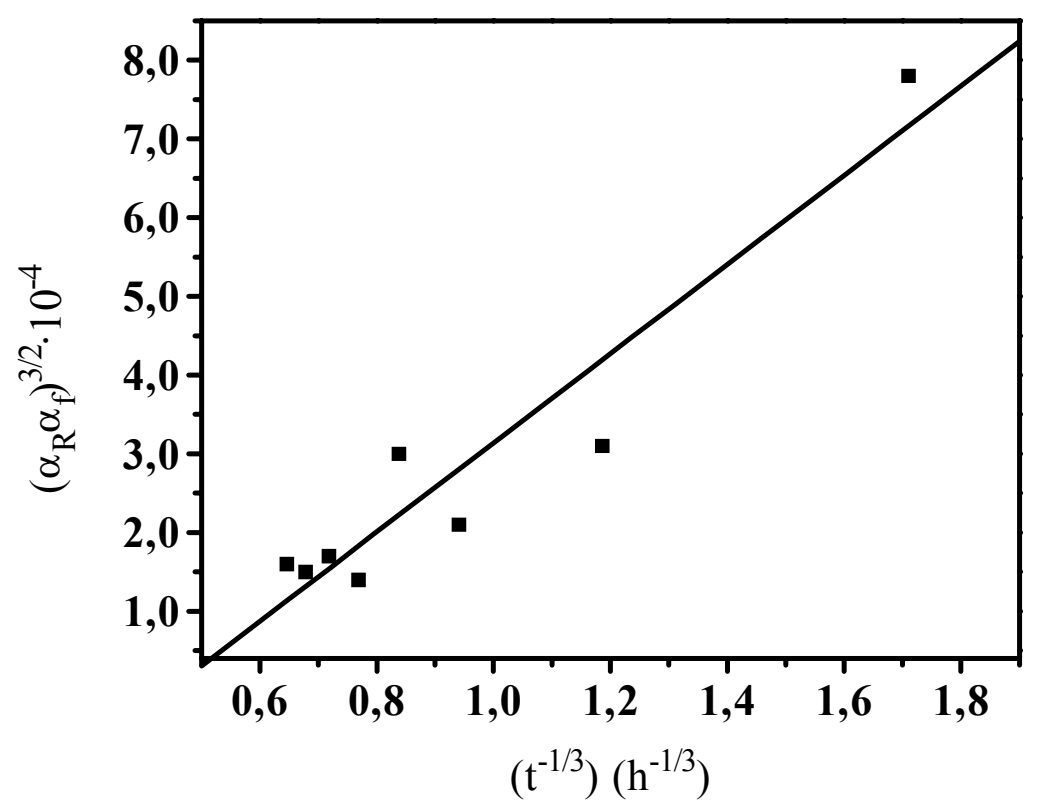

Figura 3.5.42: Dependência do produto $\alpha_{R} \cdot \alpha_{f}$ (porosidade) com o tempo de sinterização isotérmica para a amostra de $\mathrm{ZrO}_{2}: 8 \%$ mol $\mathrm{Y}_{2} \mathrm{O}_{3}$ comercial.

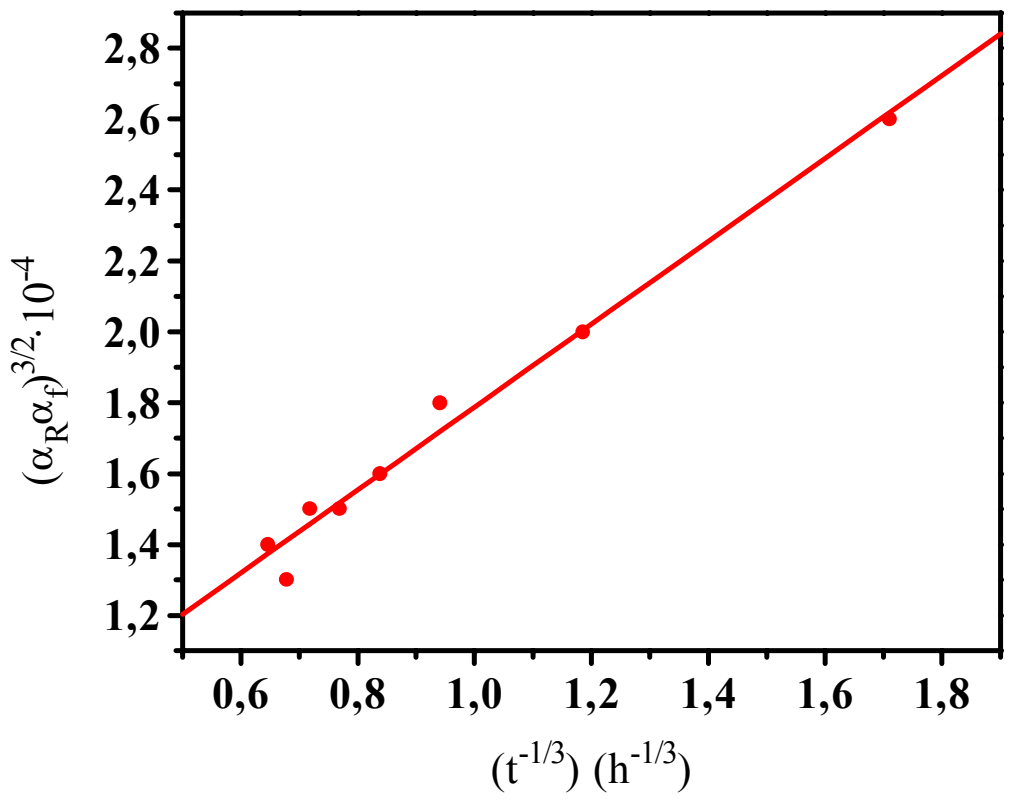

Figura 3.5.43: Dependência do produto $\alpha_{R} \cdot \alpha_{f}$ (porosidade) com o tempo de sinterização isotérmica para a amostra de $\mathrm{ZrO}_{2}: 8 \%$ mol $\mathrm{Y}_{2} \mathrm{O}_{3}$ coprecipitada. 
Análise microestrutural e por espectroscopia de impedância em cerâmicas de $\mathrm{ZrO}_{2}$ : $8 \% \mathrm{~mol}_{2} \mathrm{O}_{3}$ obtidas com pós de três diferentes origens mostraram que:

- O sinal do sensor não descartável de oxigênio, que tem na cerâmica de zircônia - ítria seu transdutor eletroquímico, varia com o tempo de operação do sensor.

- O envelhecimento térmico do eletrólito sólido preparado com o pó obtido por mistura de óxidos permitiu determinar um tratamento térmico padrão $\left(600^{\circ} \mathrm{C} / 100 \mathrm{~h}\right)$ para que a resposta desse eletrólito sólido, quando usado como transdutor eletroquímico, em sensores de oxigênio, seja constante em função do tempo de trabalho na temperatura de $600{ }^{\circ} \mathrm{C}$.

- Foi mostrada a eficiência de medidas elétricas como indicadores das mudanças ocorridas durante a sinterização de cerâmicas de $\mathrm{ZrO}_{2}: 8 \%$ mol $\mathrm{Y}_{2} \mathrm{O}_{3}$.

- Foi mostrada a possibilidade do uso de medidas de espectroscopia de impedância no estudo da sinterização de cerâmicas $\mathrm{ZrO}_{2}: 8 \% \mathrm{~mol} \mathrm{Y}_{2} \mathrm{O}_{3}$. 


\section{REFERÊNCIAS BIBLIOGRÁFICAS}

[1] E. C. Subbarao, Advances In Ceramics, volume 3, Science and Technology of Zirconia, eds.: A. H. Heuer, L. W. Hobbs, The American Ceramic Society, Columbus, Ohio (1981) 1 .

[2] D. Brockis, Ceramic Industries International (1992) 22.

[3] E. N. S. Muccillo, Tese de Doutorado, IPEN - USP, São Paulo, Brasil (1993).

[4] R. C. Garvie, High Temperature Oxides Part II, ed.: A. M. Alper, Academic Press, New York (1970) 117.

[5] R. P. Ingel, P. A. Willging, B. A. Bender, T. W. Coyle, Advances In Ceramics, volume 24 B, eds.: S. Somiya, N. Yamamoto, H. Yanagida, The American Ceramic Society, Westerville, Ohio (1988) 459.

[6] V. S. Stubican, J. R. Hellmann, Advances In Ceramics, volume 3, Science and Technology of Zirconia, eds.: A. H. Heuer, L. W. Hobbs, The American Ceramic Society, Columbus, Ohio (1981) 25.

[7] T. Sato, M. Shimada, J. Am. Ceram. Soc., 67 [10] (1984) C - 212.

[8] T. Masaki, J. Am. Ceram. Soc., 69 [7] (1986) 519.

[9] T. L. Wen, Z. Y. Lu, S. F. Li, Solid State Ionics, 28 - 30 (1988) 475.

[10] S. Lawson, P. A. Smith, J. Am. Ceram. Soc., 76 [12] (1993) 3170.

[11] S. Lawson, J. Eur. Ceram. Soc., 15 (1995) 485.

[12] M. Oishi, Y. Kitano, H. Iwanaga, T. Masaki, Materials Science Research International, 2 [3] (1996) 181.

[13] X. Guo, R. Yuan, J. Mater. Sci., 30 (1995) 923.

[14] B. C. H. Steele, J. Drennan, R. K. Slotwinski, N. Bonanos, E. P. Butler, Advances In Ceramics, volume 3, Science and Technology of Zirconia, eds.: A. H. Heuer, L. W. Hobbs, The American Ceramic Society, Columbus, Ohio (1981) 286.

[15] N. Bonanos, R. K. Slotwinski, B. C. H. Steele, E. P. Butler, J. Mater. Sci., 19 (1984) 785. 
[16]R. M. German, Powder Metallurgy Science, Metal Powder Industries Federation, Princeton, New Jersey (1984) 145.

[17] N. J Shaw, Powder Metallurgy International, 21 [3] (1989) 16.

[18] H. Su, L. Johnson, J. Am. Ceram. Soc. 79 [12] (1996) 3211.

[19] W. A. Kaysser, Ullmann's Encyclopedia of Industrial Chemistry volume A 22, VCH Publishers, Weinheim (1993) 118.

[20] A. Koller, Materials Science Monographs, volume 80, Structure and Properties of Ceramics, Elsevier, Czech Republic (1994) 114.

[21] R. J. Brook, Advances In Ceramics, volume 3, Science and Technology of Zirconia, eds.: A. H. Heuer, L. W. Hobbs, The American Ceramic Society, Columbus, Ohio (1981) 272.

[22] N. J Shaw, Powder Metallurgy International, 21 [5] (1989) 31.

[23] C. D. Sagel-Ransijn, A. J. A. Winnubst, A. J. Burggraaf, H. Verweij, J. Eur. Ceram. Soc., 17 (1997) 1133.

[24] H. H. Hausner, J. H. Dedrick, The Physics of Powder Metallurgy, ed.: W. E. Kingston, McGraw-Hill Book Company, New York (1951) 320.

[25] J. E. Bauerle, J. Phys. Chem. Solids, 30 (1969) 2657.

[26] J. R. Macdonald, W. B. Johnson, Impedance Spectroscopy - Emphasizing Solid Material and Systems, ed.: J. R. Macdonald, Wiley Interscience, New York (1987) 1. [27] J. G. Fletcher, A. R. West, J. T. S. Irvine, J. Electrochem. Soc., 142 [8] (1995) 2650. [28] M. Kleitz, J. H. Kennedy, Fast Ion Transport in Solids, eds.: P. Vashishta, J. N. Mundy, G. K. Shenoy, Elsevier, North Holland (1979) 185.

[29] L. Dessemond, R. Muccillo, M. Hénault, M. Kleitz, Appl. Phys. A, 57 (1993) 57.

[30] M. Kleitz, L. Dessemond, M. C. Steil, Solid State Ionics, 75 (1995) 107.

[31] J. S. Reed, Principles of Ceramics Processing, Wiley Interscience, New York (1995) 54.

[32] A. K. Ray, E. C. Subbarao, Solid Electrolytes and Their Applications, ed.: E. C. Subbarao, Plenum Press, New York (1980) 261.

[33] W. F. Chu, V. Leonhard, H. Erdmann, M. Ilgenstein, Sensor and Actuators B, 4 (1991) 321.

[34] H. Toraya, J. Am. Ceram. Soc., 72 [4] (1989) 662.

[35] F. T. Ciacchi, K. M. Crane, S. P. S. Badwal, Solid State Ionics, 73 (1994) 49.

[36] R. C. Garvie, P. S. Nicholson, J. Am. Ceram. Soc., 55 [3] (1972) 303. 
[37] H. Toraya, M. Yoshimura, S. Sömiya, J. Am. Ceram. Soc., 67 [6] (1984) C-119.

[38] H. Toraya, M. Yoshimura, S. Sömiya, J. Am. Ceram. Soc., 67 [9] (1984) C-183.

[39] P. A. Evans, R. Stevens, J. G. P. Binner, Br. Ceram. Trans. J., 83 (1984) 39.

[40] A. Paterson, R. Stevens, J. Mater. Res., 1 [2] (1986) 295.

[41] C. A. Leach, J. Mater. Sci. Lett., 6 (1987) 303.

[42] H. K. Schmid, J. Am. Ceram. Soc., 70 [5] (1987) 367.

[43] Y. Mori, Y. Kitano, A. Ishitani, T. Masaki, J. Am. Ceram. Soc., 71 [7] (1988) C-322.

[44] F. Sánchez-Bajo, F. L. Cumbrera, F. Guiberteau, A. Dominguez-Rodriguez, Mater. Lett., 15 (1992) 39.

[45] C. B. Choudhary, H. S. Maiti, E. C. Subbarao, Solid Electrolytes and Their

Applications, ed.: E. C. Subbarao, Plenum Press, New York (1980) 1.

[46] R. P. Ingel, D. Lewis III, J. Am. Ceram. Soc., 69 [4] (1986) 325.

[47] M. J. Verkerk, A. J. A. Winnubst, A. J. Burggraaf, J. Mater. Sci., 17 (1982) 3113.

[48] S. P. S. Badwal, Solid State Ionics, 76 (1995) 67.

[49] Y. Zhou, T. -C. Lei, J. Am. Ceram. Soc., 74 [3] (1991) 633.

[50] S. An, X. Wu, W. Wu, Q. Liu, Solid State Ionics, 57 (1992) 31.

[51] A. El Barhmi, E. J. L. Schouler, A. Hammou, M. Kleitz, Solid State Ionics, 28 - 30 (1988) 493.

[52] M. Kleitz, H. Bernard, E. Fernandez, E. Schouler, Advances In Ceramics, volume 3,

Science and Technology of Zirconia, eds.: A. H. Heuer, L. W. Hobbs, The American Ceramic Society, Columbus, Ohio (1981) 310.

[53] A. N. Vlasov, M. V. Perfiliev, Solid State Ionics, 25 (1987) 245.

[54] B. Krafthefer, P Bohrer, P. Moenkhaus, D. Zook, L. Pertl, U. Bonne, Advances In Ceramics, volume 12, Science and Technology of Zirconia II, eds.: N. Claussen, M. Rühle, A. H. Heuer, The American Ceramic Society, Columbus, Ohio (1984) 607. [55] F. K. Moghadam, D. A. Stevenson, J. Am. Ceram. Soc., 65 [4] (1982) 213.

[56]F. K. Moghadam, T. Yamashita, D. A. Stevenson, Advances In Ceramics, volume 3, Science and Technology of Zirconia, eds.: A. H. Heuer, L. W. Hobbs, The American Ceramic Society, Columbus, Ohio (1981) 364.

[57] S. P. S. Badwal, J. Drennan, J. Mater. Sci., 22 (1987) 3231.

[58] A. I. Ioffe, M. V. Inozemtsev, A. S. Lipilin, M. V. Perfilev, S. V. Karpachov, Phys. Stat. Sol. (a), 30 (1975) 87.

[59] M. J. Verkerk, B. J. Middelhuis, A. J. Burggraaf, Solid State Ionics 6 (1982) 159. 
[60] E. J. L. Schouler, M Mesbahi, G. Vitter, Solid State Ionics, 9 - 10 (1983) 989.

[61] M. Gödickemeier, B. Michel, A. Orliukas, P. Bohac, K. Sasaki, L. Gauckler, H. Heinrich, P. Schwander, G. Kostorz, H. Hofmann, O. Frei, J. Mater. Res., 9 [5] (1994) 1228.

[62] M. Aoki, Y. -M. Chiang, I. Kosacki, L. J. -R. Lee, H. Tuller, Y. Lu, J. Am. Ceram. Soc., 79 [5] (1996) 1169.

[63] M. C. Steil, F. Thevenot, M. Kleitz, J. Electrochem. Soc., 144 [1] (1997) 390. 